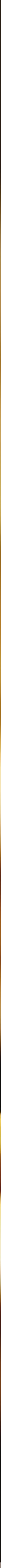

\title{
Proficiency test for pesticides in soy acid oil and soybean meal
}





\section{Proficiency test for pesticides in soy acid oil and soybean meal}

D.P.K.H. Pereboom, W.C.M. de Nijs, J.G.J. Mol

This research has been carried out by RIKILT Wageningen University \& Research, institute within the legal entity Wageningen Research Foundation funded by the Dutch Ministry of Economic Affairs, WOT programme Food Safety, theme Animal Feed.

Wageningen, July 2017

RIKILT report 2017.008 
Pereboom, D.P.K.H., W.C.M. de Nijs, J.G.J. Mol, 2017. Proficiency test for pesticides in soy acid oil and soybean meal. Wageningen, RIKILT Wageningen University \& Research, RIKILT report 2017.008. 58 pp.; 0 fig.; 8 tab.; 10 ref.

Project number: 1227248801-WOT BPL

Project title: Borging private laboratoria (WOT-02-004-004)

Coordinator proficiency tests: D.P.K.H. Pereboom

Project leader: W.C.M. de Nijs

Scientific expert: J.G.J. Mol

This report can be downloaded for free at https://doi.org/10.18174/419320 or at www.wur.eu/rikilt (under RIKILT publications).

(C) 2017 RIKILT Wageningen University \& Research, institute within the legal entity Wageningen Research Foundation. Hereinafter referred to as RIKILT.

The client is allowed to publish or distribute the full report to third parties. Without prior written permission from RIKILT it is not allowed to:

a) publish parts of this report;

b) use this report or title of this report in conducting legal procedures, for advertising, acquisition or other commercial purposes;

c) use the name of RIKILT other than as author of this report.

P.O. Box 230, 6700 AA Wageningen, The Netherlands, T +31(0)317 4802 56, E info.RIKILT@wur.nl, www.wur.eu/rikilt. RIKILT is part of Wageningen University \& Research.

This report from RIKILT has been produced with the utmost care. However, RIKILT does not accept liability for any claims based on the contents of this report.

RIKILT report 2017.008

Distribution list:

- Twenty-nine participating laboratories 


\section{Contents}

$\begin{array}{ll}\text { Summary } & 5\end{array}$

$\begin{array}{ll}\text { Introduction } & \mathbf{7}\end{array}$

2

$\begin{array}{ll}\text { Material and methods } & 8\end{array}$

$\begin{array}{lll}2.1 & \text { Scope of the PT } & 8\end{array}$

2.2 Participants $\quad 8$

2.3 Material preparation $\quad 8$

2.4 Material distribution and instructions 9

2.5 Sample identification 9

2.6 Homogeneity study 9

$\begin{array}{ll}2.7 & \text { Stability of the materials } \\ 2.8 & 10\end{array}$

$\begin{array}{ll}2.8 & \text { Interpretation of the results }\end{array}$

3.1 Calculation of the consensus value 12

3.2 Calculation of the uncertainty of the consensus value 12

3.3 Calculation of the standard deviation for proficiency assessment $\left(\sigma_{P}\right) \quad 13$

$\begin{array}{ll}3.4 & \text { Performance characteristics with regard to the accuracy } \\ \end{array}$

4.1 Participants $\quad 15$

4.2 Methods of analysis applied by participants $\quad 15$

$\begin{array}{lll}4.3 & \text { Performance participants material A } & 15\end{array}$

$\begin{array}{lll}4.3 .1 & \text { Anthraquinone } & 15\end{array}$

4.3.2 Biphenyl 16

4.3.3 Cis-chlordane 16

$\begin{array}{ll}\text { 4.3.4 Chlorpyrifos } & 17\end{array}$

$\begin{array}{ll}4.3 .5 \mathrm{p}, \mathrm{p}^{\prime}-\mathrm{DDE} & 17\end{array}$

$\begin{array}{ll}\text { 4.3.6 Cis-deltamethrin } & 17\end{array}$

4.3.7 Alpha-endosulfan $\quad 18$

4.3.8 Endosulfan sulfate 18

$\begin{array}{ll}\text { 4.3.9 Pirimiphos-methyl } & 18\end{array}$

4.4 Performance participants material B 19

4.4.1 Azoxystrobin $\quad 19$

$\begin{array}{ll}4.4 .2 \text { Boscalid } & 19\end{array}$

4.4.3 Chlorpyrifos $\quad 20$

4.4.4 Cypermethrin $\quad 20$

4.4.5 Cyproconazole $\quad 20$

4.4.6 Ortho-phenylphenol 21

4.4.7 Pirimiphos-methyl 21

4.4.8 Tebuconazole $\quad 21$

$\begin{array}{lll}4.5 & \text { False positive and false negative results } & 22\end{array}$

$5 \quad$ Discussion and conclusions $\quad 23$

$\begin{array}{ll}\text { References } & 25\end{array}$ 
$\begin{array}{lll}\text { Annex } 2 & \text { Instruction letter } & 27\end{array}$

$\begin{array}{lll}\text { Annex } 3 & \text { Statistical evaluation of homogeneity data } & 29\end{array}$

$\begin{array}{lll}\text { Annex } 4 & \text { Statistical evaluation of stability data } & 35\end{array}$

$\begin{array}{lll}\text { Annex } 5 & \text { Overview of the applied methods } & 41\end{array}$

Annex $6 \quad$ Results material A $\quad 44$

$\begin{array}{lll}\text { Annex } 7 & \text { Results material B } & 50\end{array}$

$\begin{array}{lll}\text { Annex } 8 & \text { False positive and false negative results } & 56\end{array}$

$\begin{array}{lll}\text { Annex } 9 & \text { Overview performance per laboratory } & 57\end{array}$ 


\section{Summary}

In November 2016 a proficiency test for pesticides in the feed matrices soy acid oil and soybean meal was organised by RIKILT, Wageningen University \& Research in accordance with ISO 17043. RIKILT Wageningen University \& Research is accredited for the organisation of proficiency tests in the field of contaminants, mycotoxins, plant toxins and veterinary drugs in feed and feed ingredients according to ISO/IEC 17043 (R013). However, the specific matrix-compound used in this proficiency test is not part of the accreditation. The primary goal of this proficiency test was to give participants the opportunity to evaluate or demonstrate their competence for the analysis of pesticides in the feed matrices soy acid oil and soybean meal.

Two materials were prepared and dispatched with cool packs to the participants. The consensus values of the pesticides in each material are given in Table $1(\mathrm{mg} / \mathrm{kg})$ :

Table 1 Consensus values of the pesticides in the proficiency materials.

\begin{tabular}{llll}
\multicolumn{2}{c}{ Material A: soy acid oil } & & Material B: soybean meal \\
Compound & $\begin{array}{c}\text { Consensus value } \\
\text { mg/kg }\end{array}$ & Compound & 0.379 \\
\hline Anthraquinone & 0.072 & Azoxystrobin & 0.999 \\
\hline Biphenyl & 0.144 & Boscalid & 0.039 \\
\hline Cis-chlordane & 0.030 & Chlorpyrifos & 0.070 \\
\hline Chlorpyrifos & 0.239 & Cypermethrin & 0.070 \\
\hline p,p'-DDE & 0.048 & Cyproconazole & 0.144 \\
\hline Cis-deltamethrin & 0.089 & Ortho-phenylphenol & 0.224 \\
\hline Alpha-endosulfan & 0.076 & Pirimiphos-methyl & 0.168 \\
\hline Endosulfan sulfate & 0.134 & Tebuconazole & \\
\hline Pirimiphos-methyl & 0.178 & & \\
\hline
\end{tabular}

Material A was prepared by spiking a sample of soy acid oil with a solution of pesticides to the required target concentrations, followed by homogenization. Material B was prepared by spiking a sample of slurried soybean meal followed by extensive mixing, freeze-drying and milling of the samples.

Homogeneity assessment showed that both materials were sufficiently homogeneous for proficiency testing. The stability test demonstrated no statistically significant loss of the pesticides in soybean meal during the timescale of the proficiency test. For all the pesticides in soy acid oil, there was an apparent increase in concentration of the samples stored in the refrigerator, except for cis-chlordane. This increase was not accounted for in the calculation of the z-scores. The stability test showed a consequential loss for cis-chlordane in soy acid oil during the storage in the refrigerator. This instability was taken into account in the calculation of the z-scores. The apparent increase and decrease are not likely to be caused by instability given the fact that a similar trend was observed for multiple pesticides, and because of the known persistence of most pesticides. This was further supported by the robust standard deviations obtained from the data of the participant, which was generally good.

Thirty-one participants subscribed for the participation in this proficiency test, of which 29 reported results. One participant submitted the results 13 days after the closing date for reporting, but the results were still taken into account. Two participants were unable to report results. 
For calculating of the accuracy z-scores in this test a target standard deviation of $25 \%$ was taken as an acceptable deviation for reproducibility conditions. However, the quantification of alpha-endosulfan in material A resulted in a high uncertainty of the consensus value and, therefore, the results of this pesticide were not statistically evaluated.

The results of the proficiency test on pesticides in soy acid oil and soybean meal are summarized in Table 2. Seven participants showed optimal performance by detecting the pesticides with a correct quantification/qualification within the participants' scope and the absence of false positive and false negative results. Ten participants did not analyse the pesticides in material A, of which one laboratory indicated that soy acid oils are not in their scope. Five participants did not report results for the pesticides in material $B$ due to the absence of the compounds from their scope.

For material A 38 false negative results were reported for 8 of the 9 pesticides and 2 false positive results and for material B 4 false negative results were reported for 4 of the 8 pesticides by 1 participant each and 2 participants reported a false positive result.

Table 2 Summarized performance of laboratories reporting results in the proficiency test on pesticides in the feed matrices soy acid oil and soybean meal.

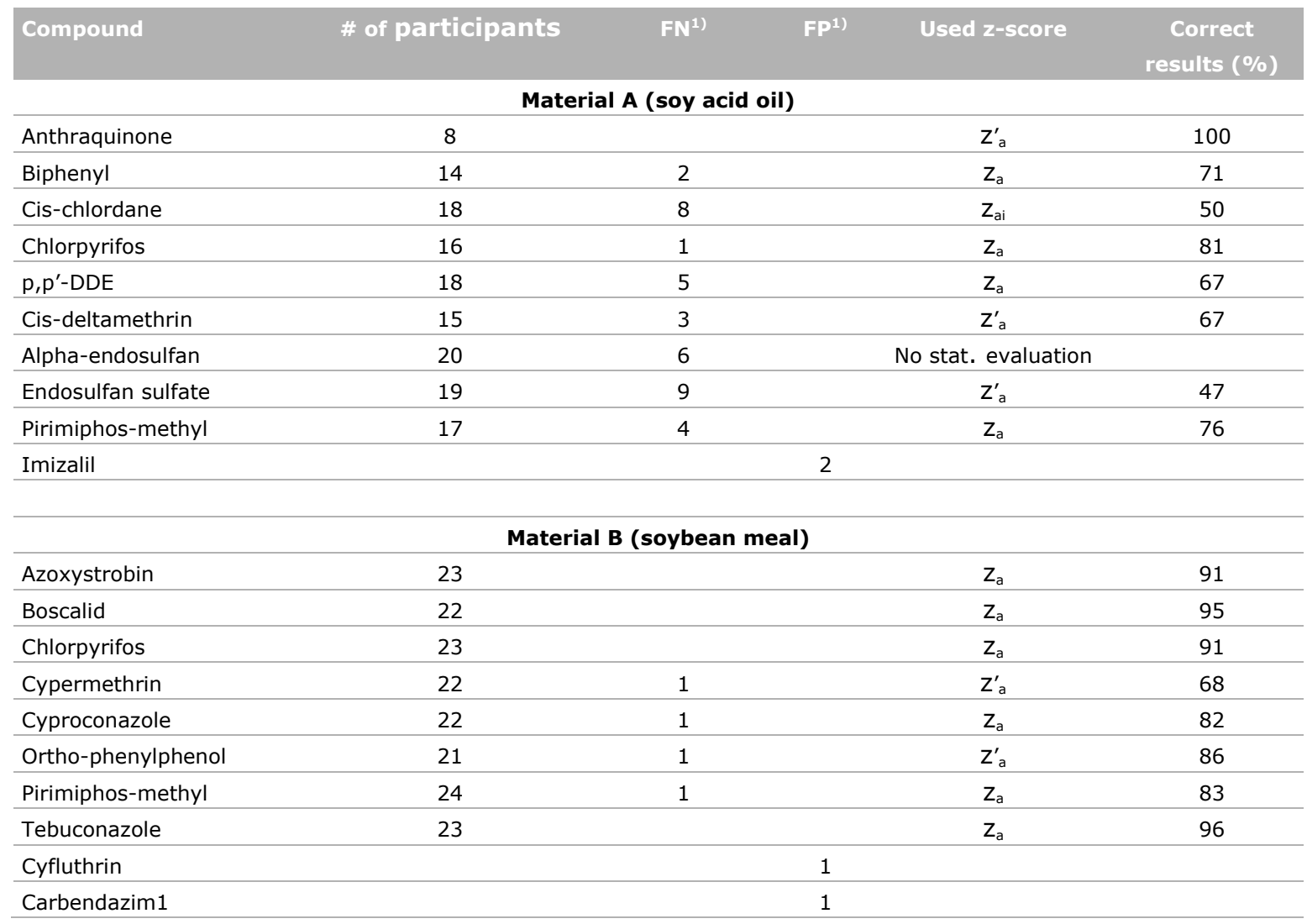

1) $\mathrm{FN}=$ false negatives; $F P=$ false positives.

Based on the results of this test it can be concluded that the variation in results for soy acid oil is larger than the variation in the results of soybean meal and that there is a need for improvement of the quantification of pesticides in soy acid oil. The larger variation might be related to the nature of the material. Soy acid oil consists of fat and fatty acids which makes this matrix challenging for pesticide residue analysis. 


\section{Introduction}

Proficiency testing is conducted to provide participants with a powerful tool to evaluate and demonstrate the reliability of the data that are produced by the laboratory. Proficiency testing is an important requirement of the EU Additional Measures Directive 93/99/EEC [1] and is demanded by ISO/IEC 17025:2005 [2].

The preparation of the materials, including the homogeneity and stability testing of the materials, and the evaluation of the quantitative results were carried out under accreditation according to ISO/IEC 17043:2010 [3] accreditation by the Dutch Accreditation Board (R013). However, the specific matrixcompound used in this proficiency test is not part of the accreditation.

There is no harmonised legislation in the EU for pesticides in the matrices soy acid oil and soybean meal. However, maximum levels (ML) for pesticides in soy are regulated in Regulation (EC) No 396/2005 [10] and amendments thereof.

The aim of this proficiency test was to give participants the opportunity to evaluate or demonstrate their competence for the analysis of pesticides in the feed matrices soy acid oil and soybean meal. 


\section{Material and methods}

\subsection{Scope of the PT}

This proficiency test focused on the pesticides anthraquinone, biphenyl, cis-chlordane, chlorpyrifos, $\mathrm{p}, \mathrm{p}^{\prime}$-DDE, cis-deltamethrin, alpha-endosulfan, endosulfan-sulfate and pirimiphos-methyl in soy acid oil and azoxystrobin, boscalid, chlorpyrifos, cypermethrin, cyproconazole, ortho-phenylphenol, pirimiphos-methyl and tebuconazole in soybean meal. The target concentrations for this test are presented in Table 4. Two matrices were under investigation. Soy acid oil is a vegetable oil extracted from the seeds of soybeans. The second matrix was soybean meal, which is a by-product released during the extraction of soybean oil.

\subsection{Participants}

Thirty-one participants registered for the participation in the proficiency test and 29 participants reported their results. All of these participants are situated in Europe. Two participants were unable to report results. In case the results were delivered after the deadline, the results were evaluated but no optimal performance was granted. Each participant was asked a priori, to indicate which compounds were included in the scope of their method. The participants were asked to report the results through a web application designed for proficiency tests.

\subsection{Material preparation}

Two spiked materials, material A and material B, were prepared for the proficiency test. Material A was prepared by adding a solution of a pesticide mix in ethyl acetate to 1700 grams of soy acid oil aiming at the levels presented in Table 3 . The oil was heated to $37^{\circ} \mathrm{C}$ and shaken during the entire process to allow better distribution of the pesticides. For material B, 2 kilograms of soybean meal was first fortified by adding a solution of pesticide mix in methanol aiming at the levels as presented in Table 3. The soybean meal was mixed with six litres of water and homogenized using a concrete mixer according to in-house standard operating procedures [4]. The fortified slurry was immediately freezedried, homogenized and stored in the refrigerator until use.

Table 3 Target concentrations of pesticides in the proficiency materials.

\begin{tabular}{|c|c|c|c|}
\hline \multicolumn{2}{|r|}{ Material A } & \multicolumn{2}{|r|}{ Material B } \\
\hline Compound & Target concentration ( $\mathrm{mg} / \mathrm{kg}$ ) & Compound & Target concentration ( $\mathrm{mg} / \mathrm{kg})$ \\
\hline anthraquinone & 0.10 & azoxystrobin & 0.35 \\
\hline cis-chlordane & 0.05 & chlorpyrifos & 0.05 \\
\hline chlorpyrifos & 0.25 & cypermethrin & 0.1 \\
\hline cis-deltamethrin & 0.10 & ortho-phenylphenol & 0.15 \\
\hline alpha-Endosulfan & 0.10 & pirimiphos-methyl & 0.25 \\
\hline endosulfan-sulfate & 0.15 & tebuconazole & 0.15 \\
\hline pirimiphos-methyl & 0.12 & & \\
\hline
\end{tabular}




\subsection{Material distribution and instructions}

Each of the participating participants received a randomly assigned laboratory code, generated by the web application. The sample sets with the corresponding number, consisting of two coded samples (Annex 1 ) were sent to the participating participants on January $16^{\text {th }} 2017$. The sample sets were packed in a insulation box with cool packs and were dispatched to the participants immediately by courier. The samples were accompanied by a letter describing the requested analysis (Annex 2) and an acknowledgement of receipt form. By e-mail the participants received instructions on how to use the web application to report the results.

The participants were asked to store the samples in the refrigerator and to analyse the samples according to their routine method. A single analysis result for the pesticides in each sample was requested. The deadline for submitting the quantitative results was March $10^{\text {th }} 2017$, allowing the participants eight weeks for the analysis.

Results should be reported for pesticides as $\mathrm{mg} / \mathrm{kg}$ product. Participants were asked to provide information on their analytical method (extraction solvent, clean-up procedure, internal standards used, detection technique, limit of detection, limit of quantification).

\subsection{Sample identification}

For material A, 25 grams of soy acid oil was weighed into airtight closed polypropylene centrifuge tubes of $50 \mathrm{ml}$. After freeze-drying and homogenization, material B was divided into sub-portions of 30 gram and stored in polypropylene, airtight closed containers. After preparation of materials $A$ and $B$ the tubes and containers were stored in the refrigerator until use.

The samples for the participants were randomly selected and coded using a web application designed for proficiency tests. The code used was Pesticides/2017/feed/000, in which the three digit number at the end of the code was automatically generated by the RIKILT Laboratory Quality Services web application. One sample set was prepared for each laboratory consisting of one random selected sample of each material $A$ and $B$. The codes of the samples for each sample set are presented in Annex 1 . For homogeneity and stability testing, 44 randomly selected tubes of material $A$ and 44 containers of material $B$ were assigned.

\subsection{Homogeneity study}

For testing the homogeneity of material A ten containers of material A were analysed in duplicate for the pesticides chlorpyrifos, cis-deltamethrin and pirimiphos-methyl. The homogeneity of the other compounds in material A were not tested, since the homogeneity test of chlorpyrifos, cis-deltamethrin and pirimiphos-methyl was considered adequate to prove sufficient homogeneity of the material since the pesticides added were dissolved in one solution before spiking the matrix, and because the matrix was a liquid during homogenisation. Also ten containers of material B were analysed in duplicate for all the spiked pesticides to determine the homogeneity of the material.

The homogeneity of the materials was tested according to The International Harmonized Protocol for Proficiency Testing of Analytical Laboratories [7] and ISO 13528:2015 [5]. For homogeneity a target standard deviation for proficiency assessment $\left(\sigma_{P}\right)$ of $25 \%$ was used as a fit-for-purpose standard deviation in the feed matrices soy acid oil and soybean meal which is in line with the target RSD used in proficiency tests on pesticides as organised by the EURL. With this procedure the between-sample standard deviation $\left(s_{s}\right)$ and the within-sample standard deviation $\left(s_{w}\right)$ were compared with the standard deviation for proficiency assessment. The method applied for homogeneity testing is considered suitable if $\mathrm{s}_{\mathrm{w}}<0.5^{*} \sigma_{\mathrm{p}}$ and a material is considered adequately homogeneous if $\mathrm{s}_{\mathrm{s}}<0.3^{*} \sigma_{\mathrm{p}}$. The results of the homogeneity study, the grand mean with the corresponding RSD are presented in Table 4 and the statistical evaluation of material A and material $B$ are presented in Annex 3. 
The pesticides measured in Material A for the homogeneity study fulfilled the criteria. Concentrations in this specific run were determined against standards in solvent, as opposed to standard in the matrix soy acid oil as used for all other measurements. This resulted in lower concentrations of chlorpyrifos ( 7 times) and cis-deltamethrin ( 5 times) than anticipated due to absence of matrix effects. For pirimiphos-methyl the concentration was comparable with the target concentration.

Cypermethrin in material B was the only analyte for which the criteria did not comply. This originated from a high variation in the ten results in duplicate, causing $s_{s}(0.007 \mathrm{mg} / \mathrm{kg})$ exceeding the critical value $0.3 \sigma_{\mathrm{p}}(0.003 \mathrm{mg} / \mathrm{kg})$ and $\mathrm{s}_{\mathrm{w}}(0.007 \mathrm{mg} / \mathrm{kg})$ exceeding $0.5 \sigma_{\mathrm{p}}(0.004 \mathrm{mg} / \mathrm{kg})$. During the measurements of cypermethrin a poor sensitivity of the LC-MS/MS equipment was observed. Despite the deviation of the pesticide cypermethrin, the material B was considered to be homogeneous, since the other seven pesticides fulfilled the homogeneity requirements and were spiked in the same solution.

The pesticides in material A and material B demonstrated to be sufficiently homogeneous for use in the proficiency test.

Table 4 Concentration of pesticides in material A and material B obtained during homogeneity testing.

\begin{tabular}{|c|c|c|c|c|c|}
\hline \multirow[t]{3}{*}{ Material code } & \multicolumn{2}{|c|}{ Material A } & \multicolumn{3}{|c|}{ Material B } \\
\hline & Conc. & RSD & & Conc. & RSD \\
\hline & mg/kg & $\%$ & & $\mathrm{mg} / \mathbf{k g}$ & $\%$ \\
\hline cis-deltamethrin & 0.019 & 5.4 & boscalid & 0.969 & 5.1 \\
\hline \multirow[t]{5}{*}{ pirimiphos-methyl } & 0.101 & 1.8 & chlorpyrifos & 0.042 & 4.9 \\
\hline & & & cyproconazole & 0.068 & 3.0 \\
\hline & & & ortho-phenylphenol & 0.128 & 10.8 \\
\hline & & & pirimipfos-methyl & 0.235 & 5.0 \\
\hline & & & tebuconazole & 0.157 & 3.1 \\
\hline
\end{tabular}

\subsection{Stability of the materials}

On January $18^{\text {th }} 2016$, the day the materials were distributed to the participants, three randomly selected samples of material A and six randomly selected samples of material B were stored at $<-18^{\circ} \mathrm{C}$. It is assumed that the pesticides are stable at these storage conditions. Also, three samples of material $A$ and six samples of material $B$ were stored in the refrigerator.

On March $13^{\text {th }} 2017,56$ days after distribution of the samples, three samples of materials $A$ and six samples of material $B$ that were stored at $<-18^{\circ} \mathrm{C}$ and in the refrigerator were analysed for pesticides. For each set of test samples, the average of the results and the standard deviation were calculated.

First it is determined whether a consequential instability of the analytes occur [5, 7]. A consequential instability is observed when the average value of an analyte in the samples stored in the refrigerator is more than $0.3 \sigma_{\mathrm{p}}$ below the average value of the analyte in the samples stored at $<-18^{\circ} \mathrm{C}$. If so, the instability has a significant influence on the calculated z-scores. A possible statistically significant instability is determined using a Students t-test [5].

For anthraquinone, biphenyl, chlorpyrifos, p, p'-DDE, cis-deltamethrin, alpha-endosulfan, endosulfansulfate and pirimiphos-methyl in material $A$ there was a consequential difference between the samples stored in the refrigerator and the samples stored at $<-18^{\circ} \mathrm{C}$. The average concentration in the refrigerator was higher than the average concentration of the samples stored at $<-18^{\circ} \mathrm{C}$. The concentration showed an increase of resp. 20,53,17, 20,50, 9, 20 and $12 \%$. This increase in 
concentration was not incorporated in the calculation of the z-scores. The results of the stability of material $A$ is presented in Annex 4.

For cis-chlordane in material $A$ there was also a consequential difference between the samples stored in the refrigerator and the samples stored at $<-18^{\circ} \mathrm{C}$. The average concentration in the refrigerator was lower than the average concentration of the samples stored at $<-18^{\circ} \mathrm{C}$. The concentration showed a decrease of $14 \%$.

The apparent increase and decrease are not likely to be caused by instability given the fact that a similar trend was observed for multiple pesticides, and because of the known persistence of most pesticides.

For the pesticides in materials $B$, no consequential nor statistical significant difference were observed among the samples stored at $<-18^{\circ} \mathrm{C}$ and the samples stored in the refrigerator. The compounds in the materials are, therefore, considered stable for the duration of the study. The results of the stability of material $B$ is presented in Annex 4.

\subsection{Interpretation of the results}

A result was assigned as false negative result if a compound was not detected, taken into account the reported scope of the participant, the consensus value and the reported LOQ of the participant.

For example: the consensus value of compound $A$ is $0.07 \mathrm{mg} / \mathrm{kg}$ and a participants' $L O Q=$ $0.02 \mathrm{mg} / \mathrm{kg}$. Taken into account the $25 \%$ standard deviation in this test, the $-2 \mathrm{z}$ threshold would be at $0.035 \mathrm{mg} / \mathrm{kg}(0.07-(2 * 25 \%$ of 0.07$))$. Since the LOQ of this participant is lower than the $-2 z$ value this participant should be able to detect the presence. If the $L O Q$ would have been $0.04 \mathrm{mg} / \mathrm{kg}$ no false negative result would be assigned.

Also, when no LOQ values were reported and the compound was reported as not detected (nd), or the compound was not reported but was within the participants' scope, a false negative (FN) result was assigned.

For false positive results it was decided to apply a cut-off level of $0.04 \mathrm{mg} / \mathrm{kg}$ for the materials and concentrations below $0.04 \mathrm{mg} / \mathrm{kg}$ were not assigned as false positive results. 


\section{Statistical evaluation}

The statistical evaluation was carried out according to the International Harmonized Protocol for the Proficiency Testing of Analytical Laboratories [7], elaborated by ISO, IUPAC and AOAC and ISO 13528:2015 [5] in combination with the insights published by the Analytical Methods Committee [8, 9] regarding robust statistics.

For the evaluation of the quantitative results, the consensus value, the uncertainty of the consensus value, the standard deviation for proficiency assessment and z-scores were calculated.

\subsection{Calculation of the consensus value}

The consensus value $(X)$ was determined using robust statistics $[5,8,9]$. The advantage of robust statistics is that all values are taken into account: outlying observations are retained, but given less weight. Furthermore, it is not expected to receive normally distributed data in a proficiency test. When using robust statistics, the data do not have to be normally distributed in contrast to conventional outlier elimination methods.

The robust mean of the reported results of all participants, calculated from an iterative process that starts at the median of the reported results using a cut-off value depending on the number of results, was used as the consensus value $[5,8]$.

\subsection{Calculation of the uncertainty of the consensus value}

The uncertainty of the consensus value is calculated to determine the influence of this uncertainty on the evaluation of the participants. A high uncertainty of the consensus value will lead to a high uncertainty of the calculated participants $z_{a}$-scores. If the uncertainty of the consensus value and thus the uncertainty of the $z_{a}$-score is high, the evaluation could indicate unsatisfactory method performance without any cause within the laboratory. In other words, illegitimate conclusions could be drawn regarding the performance of the participating participants from the calculated $z_{a}$-scores if the uncertainty of the consensus value is not taken into account.

The uncertainty of the consensus value (the robust mean) is calculated from the estimation of the standard deviation of the consensus value and the number of values used for the calculation of the consensus value [5]:

$\mathrm{u}=1.25 * \frac{\hat{\sigma}}{\sqrt{\mathrm{n}}}$

where:

$\mathrm{u}=$ Uncertainty of the consensus value;

$\mathrm{n}=$ Number of values used to calculate the consensus value;

$\hat{\sigma}=$ The estimate of the standard deviation of the consensus value resulting from robust statistics.

According to ISO $13528: 2015$ [5] the uncertainty of the consensus value (u) is negligible and therefore does not have to be included in the statistical evaluation if:

$u \leq 0.3 \sigma_{\mathrm{P}}$ 
where:

$\mathrm{u}=$ The uncertainty of the consensus value;

$\sigma_{\mathrm{P}}=$ Standard deviation for proficiency assessment (§3.3).

In case the uncertainty of the consensus value does not comply with this criterion, the uncertainty of the consensus value should be taken into account when evaluating the performance of the participants regarding the accuracy ( $\S 3.4)$. In case the uncertainty is $>0.7 \sigma_{\mathrm{p}}$ the calculated $z$-scores should not be used for evaluation of participants performance and are presented for information only.

\subsection{Calculation of the standard deviation for proficiency assessment $\left(\sigma_{P}\right)$}

A target standard deviation for proficiency assessment $\left(\sigma_{\mathrm{P}}\right)$ of $25 \%$ was used as a fit-for-purpose standard deviation which is in line with the target RSD used in proficiency tests on pesticides as organised by the EURL.

$\sigma_{\mathrm{P}}=0.25 \mathrm{C}$

where:

$\sigma_{\mathrm{P}}=$ Expected standard deviation in proficiency tests for animal feed;

$c=$ Concentration of the analyte $(\mathrm{mg} / \mathrm{kg})$.

\subsection{Performance characteristics with regard to the accuracy}

For illustrating the performance of the participating participants with regard to the accuracy a $z_{a}$-score is calculated. For the evaluation of the performance of the participants, ISO 13528:2015 [5] is applied. According to these guidelines $\mathrm{z}_{\mathrm{a}}$-scores are classified as presented in Table 5 .

Table 5 Classification of $z_{a}$-scores.

\begin{tabular}{cc}
\hline$\left|z_{a}\right| \leq 2$ & Satisfactory \\
\hline $2<\left|z_{a}\right|<3$ & Questionable \\
\hline$\left|z_{a}\right| \geq 3$ & Unsatisfactory
\end{tabular}

If the calculated uncertainty of the consensus value complies with the criterion mentioned in $\S 3.2$, the uncertainty is negligible. In this case the accuracy z-score is calculated from:

$\mathrm{z}_{\mathrm{a}}=\frac{\bar{X}-\mathrm{X}}{\sigma_{\mathrm{P}}}$

where:

$z_{a}=$ Accuracy z-score;

$\bar{x}=$ The average result of the laboratory;

$\mathrm{X}=$ Consensus value;

$\sigma_{\mathrm{P}}=$ Standard deviation for proficiency assessment. 
However, if the uncertainty of the consensus value does not comply with the criterion mentioned in $\S 3.2$, it could influence the evaluation of the participants. Although, according to ISO 13528 in this case no z-scores can be calculated, we feel that evaluation of the participating participants is of main importance justifying the participating participants' effort. Therefore in this case, the uncertainty is taken into account by calculating the accuracy z-score [5]:

$z^{\prime}{ }_{a}=\frac{x-X}{\sqrt{\sigma_{p}^{2}+u^{2}}}$

Equation II

where:

$\mathrm{z}^{\prime}{ }_{\mathrm{a}}=$ Accuracy $\mathrm{z}$-score taking into account the uncertainty of the consensus value;

$\bar{x}=$ The average result of the laboratory;

$\mathrm{X}=$ Consensus value;

$\sigma_{\mathrm{P}}=$ Standard deviation for proficiency assessment;

$\mathrm{u}=$ Uncertainty of the consensus value.

A consequential instability of the proficiency materials can influence the evaluation of the laboratory performance. Therefore, in that case the consequential instability is taken into account when calculating z-scores. Because instability only regards one side of the confidence interval (a decrease of the concentration) this correction only applies to the lower $2 \mathrm{~s}$ limit and results in an asymmetrical confidence interval.

In the case of a consequential instability the accuracy z-score for the participants that reported an amount below the consensus value is corrected for this instability by:

$z_{\mathrm{ai}}=\frac{\mathrm{X}-\mathrm{X}}{\sqrt{\sigma_{\mathrm{p}}^{2}+\Delta^{2}}}$

Equation III

where:

$\mathrm{z}_{\overline{\mathrm{ai}}}=$ Accuracy $z$-score taking into account the instability of the consensus value;

$\bar{x}=$ The average result of the laboratory;

$\mathrm{X}=$ Consensus value;

$\sigma_{\mathrm{P}}=$ Standard deviation for proficiency assessment;

$\Delta=$ Difference between average concentration of compound stored at $<-18{ }^{\circ} \mathrm{C},<4^{\circ} \mathrm{C}$ and average concentration at room temperature.

In some cases the uncertainty of the consensus value does not comply with the criterion in $\S 3.2$ and a consequential instability is observed. In this case the $\mathrm{z}_{\mathrm{a}}{ }_{\mathrm{a}}$-score for the participants that reported an amount below the consensus value is corrected for this instability by:

$z^{\prime}{ }_{a i}=\frac{X-X}{\sqrt{\sigma_{p}^{2}+\Delta^{2}+u^{2}}}$

Equation IV

where:

$z^{\prime}{ }_{a i}=$ Accuracy z-score taking into account the uncertainty and instability of the consensus value;

$\bar{x}=$ The average result of the laboratory;

$\mathrm{X}=$ Consensus value;

$\sigma_{\mathrm{P}} \quad=$ Standard deviation for proficiency assessment;

$\Delta=$ Difference between average concentration of compound stored at $<-18{ }^{\circ} \mathrm{C},<4{ }^{\circ} \mathrm{C}$ and average concentration at room temperature;

$\mathrm{u}=$ Uncertainty of the consensus value. 


\section{$4 \quad$ Methods and Results}

\subsection{Participants}

Thirty-one participants registered for the proficiency test. All samples were received in good order and twenty-eight participants submitted the results in time, one participant reported too late and two participants were unable to report results. Participant PT498 was the only laboratory which indicated not to perform oil analysis. The performance of individual participants is summarized in Annex 9. Laboratory PT484 reported an unsatisfactory result ( $\mathrm{z}_{\mathrm{a}}{ }_{\mathrm{a}}$-score 47.95) for cis-deltamethrin in material $A$ and laboratory PT500 reported an unsatisfactory result ( $z_{a}$-score 11.36 ) for cyproconazole in material B. Possibly a reporting error was made respectively for cis-deltamethrin (reporting $1.25 \mathrm{mg} / \mathrm{kg}$ instead of $0.125 \mathrm{mg} / \mathrm{kg}$ and cyproconazole (reporting $0.27 \mathrm{mg} / \mathrm{kg}$ instead of $0.027 \mathrm{mg} / \mathrm{kg}$ ).

\subsection{Methods of analysis applied by participants}

An overview of the information provided by the participants regarding the methods applied in this proficiency test is presented in Annex 5. The samples were analysed using various extraction methods, purification steps and detection techniques.

Reported limits of detection (LODs) and limits of quantification (LOQs) for the pesticides are presented in Table 6.

Table 6 Overview of reported $L O D$ and $L O Q$ reported by the participants.

\begin{tabular}{lccccc}
\multicolumn{7}{c}{ Material A } & \multicolumn{2}{c}{ Material B } & Lo \\
\multicolumn{1}{c}{ Compound } & LOD $(\mathrm{mg} / \mathrm{kg})$ & LOQ $(\mathrm{mg} / \mathrm{kg})$ & Compound & LOD $(\mathrm{mg} / \mathrm{kg})$ & LOQ $(\mathrm{mg} / \mathrm{kg})$ \\
\hline Anthraquinone & $0.0018-0.01$ & $0.01-0.05$ & Azoxystrobin & $0.0007-0.01$ & $0.00737-0.05$ \\
\hline Biphenyl & $0.003-0.01$ & $0.01-0.02$ & Boscalid & $0.0009-0.01$ & $0.00661-0.05$ \\
\hline Cis-chlordane & $0.0001-0.01$ & $0.005-0.05$ & Chlorpyrifos & $0.0009-0.01$ & $0.004-0.02$ \\
\hline Chlorpyrifos & $0.0009-0.01$ & $0.004-0.02$ & Cypermethrin & $0.0015-0.01$ & $0.005-0.02$ \\
\hline p,p'-DDE & $0.0001-0.01$ & $0.00427-0.02$ & Cyproconazole & $0.00193-0.03$ & $0.0064-0.03$ \\
\hline Deltamethrin & $0.0025-0.01$ & $0.00834-0.02$ & Phenylphenol, ortho & $0.003-0.02$ & $0.01-0.02$ \\
\hline Alpha-endosulfan & $0.0001-0.01$ & $0.00457-0.05$ & Pirimiphos-methyl & $0.0007-0.01$ & $0.004-0.05$ \\
\hline Endosulfan sulfate & $0.0001-0.01$ & $0.005-0.05$ & Tebuconazole & $0.0019-0.01$ & $0.0063-0.05$ \\
\hline Pirimiphos-methyl & $0.0007-0.01$ & $0.004-0.05$ & & & \\
\hline
\end{tabular}

\subsection{Performance participants material A}

Participants PT481, PT483, PT 485, PT487, PT489, PT490, PT498, PT499, PT506 and PT509 did not analyse material A. Participants PT484 and PT501 reported results above the cut-off level of $0.04 \mathrm{mg} / \mathrm{kg}$, by reporting the presence of imazalil at $0.149 \mathrm{mg} / \mathrm{kg}$ and $0.184 \mathrm{mg} / \mathrm{kg}$, which are considered false positive results. Results for material A are presented in Annex 6.

\subsubsection{Anthraquinone}

Eight participants reported quantitative results for anthraquinone. Twenty participants did not analyse anthraquinone of which 16 reported anthraquinone as not tested (although some of these participants reported the matrix-pesticide combination in their scope) and 4 participants (PT484, PT485, PT489, PT505) did not report quantitative results for anthraquinone due to the absence of the compound in their scope. 
The lowest concentration reported was $0.04 \mathrm{mg} / \mathrm{kg}$ and the highest was $0.104 \mathrm{mg} / \mathrm{kg}$. The consensus value was $0.072 \mathrm{mg} / \mathrm{kg}$ with a robust standard deviation of $0.017 \mathrm{mg} / \mathrm{kg}$ (resulting in an $\mathrm{RSD}_{\mathrm{R}}$ of $24 \%$ ) expressing the reproducibility within this proficiency test. The robust standard deviation of $0.017 \mathrm{mg} / \mathrm{kg}$ is comparable to the target standard deviation $\sigma_{\mathrm{p}}$ of $0.018 \mathrm{mg} / \mathrm{kg}$ ( $25 \%$ of the consensus value) suggested in $\S 3.3$ for feed material.

The uncertainty of the consensus value was $0.008 \mathrm{mg} / \mathrm{kg}$. Since this value exceeds $0.3 \sigma_{\mathrm{p}}$ $(0.005 \mathrm{mg} / \mathrm{kg}, \S 3.2)$, the uncertainty is taken into account in the evaluation, and therefore $\mathrm{z}_{\mathrm{a}}{ }_{\mathrm{a}}$-scores using equation II, were calculated. With respect to the accuracy all results were satisfactory.

\subsubsection{Biphenyl}

Twelve participants reported quantitative results for biphenyl in material A. Participants PT484 and PT489 did not report quantitative results for biphenyl, even though they included biphenyl in their scope and therefore a FN result was assigned. Fourteen participants did not analyse biphenyl of which 12 reported biphenyl as not tested (although some of these participants reported the matrix pesticide combination in their scope) and 2 participants (PT485, PT505) did not report quantitative results for biphenyl due to the absence of the compound in their scope.

The lowest concentration reported was $0.06 \mathrm{mg} / \mathrm{kg}$ and the highest was $0.325 \mathrm{mg} / \mathrm{kg}$. The consensus value was $0.144 \mathrm{mg} / \mathrm{kg}$ with a robust standard deviation of $0.019 \mathrm{mg} / \mathrm{kg}$ (resulting in an $\mathrm{RSD}_{\mathrm{R}}$ of $13.5 \%$ ) expressing the reproducibility within this proficiency test. The robust standard deviation of $0.019 \mathrm{mg} / \mathrm{kg}$ is almost 2 times lower than the target standard deviation $\sigma_{\mathrm{P}}$ of $0.036 \mathrm{mg} / \mathrm{kg}$.

The uncertainty of the consensus value was $0.007 \mathrm{mg} / \mathrm{kg}$. Since this value does not exceed $0.3 \sigma_{\mathrm{P}}$ $(0.011 \mathrm{mg} / \mathrm{kg}, \S 3.2)$, the uncertainty is not taken into account in the evaluation, and therefore $\mathrm{z}_{\mathrm{a}}$-scores using equation I (§3.4), were calculated. With respect to the accuracy, laboratory PT508 reported a questionable result and laboratory PT491 produced an unsatisfactory result.

\subsubsection{Cis-chlordane}

Nine participants reported quantitative results for cis-chlordane in material A. Participants PT485 and PT489 did not report quantitative results for cis-chlordane, even though they included cis-chlordane in their scope and therefore a FN result was assigned. PT494, PT501, PT503, PT504, PT508 and PT511 failed to detect the presence of cis-chlordane and reported also a false negative result. PT491 did not report a quantitative result due to the absence of this compound in their scope. The laboratory reported not detected instead of not tested. Laboratory PT505 reported a correct qualitative result $(<0.050 \mathrm{mg} / \mathrm{kg}$ ) because the consensus value was $0.030 \mathrm{mg} / \mathrm{kg}$ and this value was higher than the $-2 z$ value of $0.015 \mathrm{mg} / \mathrm{kg}$. Nine participants did not analyse cis-chlordane of which 8 reported cischlordane as not tested (although some of these participants reported the matrix - pesticide combination in their scope) and PT484 did not report an quantitative result due to the absence of the compound in their scope.

The lowest concentration reported was $0.024 \mathrm{mg} / \mathrm{kg}$ and the highest was $0.053 \mathrm{mg} / \mathrm{kg}$. The consensus value was $0.030 \mathrm{mg} / \mathrm{kg}$ with a robust standard deviation of $0.003 \mathrm{mg} / \mathrm{kg}$ (resulting in an $\mathrm{RSD}_{\mathrm{R}}$ of $11.5 \%$ ) expressing the reproducibility within this proficiency test. The robust standard deviation of $0.003 \mathrm{mg} / \mathrm{kg}$ is almost 2 times lower than the target standard deviation $\sigma_{\mathrm{p}}$ of $0.007 \mathrm{mg} / \mathrm{kg}$.

The uncertainty of the consensus value was $0.001 \mathrm{mg} / \mathrm{kg}$. Since this value does not exceed $0.3 \sigma_{\mathrm{P}}$ $(0.002 \mathrm{mg} / \mathrm{kg}, \S 3.2)$, the uncertainty is not taken into account in the evaluation.

A consequential instability during storage in the refrigerator was observed (14\% decrease) and thus the instability was taken into account by calculating $\mathrm{Z}_{\mathrm{ai}}$-score $(\$ 3.2$, equation III) for labs that reported a value below the consensus value. With respect to the accuracy one result was unsatisfactory

(PT493). When no instability was observed this result would remain the same. 


\subsubsection{Chlorpyrifos}

Fifteen participants reported quantitative results for chlorpyrifos in material A. Participant PT489 did not report a quantitative result for chlorpyrifos, even though they included chlorpyrifos in their scope and therefore a FN result was assigned. Twelve participants did not analyse chlorpyrifos of which 10 reported chlorpyrifos as not tested (although some of these participants reported the matrix pesticide combination in their scope) and 2 participants (PT485 and PT505) did not report quantitative results due to the absence of the compound in their scope.

The lowest concentration reported was $0.035 \mathrm{mg} / \mathrm{kg}$ and the highest was $0.431 \mathrm{mg} / \mathrm{kg}$. The consensus value was $0.239 \mathrm{mg} / \mathrm{kg}$ with a robust standard deviation of $0.030 \mathrm{mg} / \mathrm{kg}$ (resulting in an $\mathrm{RSD}_{\mathrm{R}}$ of $12.4 \%$ ) expressing the reproducibility within this proficiency test. The robust standard deviation of $0.030 \mathrm{mg} / \mathrm{kg}$ is 2 times lower than the target standard deviation $\sigma_{\mathrm{P}}$ of $0.060 \mathrm{mg} / \mathrm{kg}$.

The uncertainty of the consensus value was $0.010 \mathrm{mg} / \mathrm{kg}$. Since this value does not exceed $0.3 \sigma_{\mathrm{p}}$ $(0.018 \mathrm{mg} / \mathrm{kg}, \S 3.2)$, the uncertainty is not taken into account in the evaluation, and therefore $\mathrm{z}_{\mathrm{a}}$-scores using equation I (§3.4), were calculated. With respect to the accuracy, laboratory PT484 and laboratory PT493 produced an unsatisfactory result.

\subsection{5 $p, p^{\prime}-D D E$}

Twelve participants reported quantitative results for $\mathrm{p}, \mathrm{p}^{\prime}$-DDE in material A. Laboratory PT505 reported a correct qualitative result $(<0.050 \mathrm{mg} / \mathrm{kg})$ because the consensus value was $0.048 \mathrm{mg} / \mathrm{kg}$ and this value was higher than the $-2 z$ value of $0.024 \mathrm{mg} / \mathrm{kg}$. Participants PT485 and PT489 did not report a quantitative result for $p, p^{\prime}-D D E$, even though they included $p, p^{\prime}-D D E$ in their scope and therefore a FN result was assigned. Participants PT494, PT501 and PT508 failed to detect the presence of $p, p^{\prime}-D D E$ and reported also a false negative result. PT491 did not report a quantitative result due to the absence of this compound in their scope. The laboratory reported not detected instead of not tested. Nine participants did not analyse $p, p^{\prime}-D D E$ of which 8 reported $p, p^{\prime}-D D E$ as not tested (although some of these participants reported the matrix - pesticide combination in their scope) and PT484 did not report a quantitative result due to the absence of the compound in their scope.

The lowest concentration reported was $0.011 \mathrm{mg} / \mathrm{kg}$ and the highest was $0.060 \mathrm{mg} / \mathrm{kg}$. The consensus value was $0.048 \mathrm{mg} / \mathrm{kg}$ with a robust standard deviation of $0.010 \mathrm{mg} / \mathrm{kg}$ (resulting in an $\mathrm{RSD}_{\mathrm{R}}$ of $20.4 \%$ ) expressing the reproducibility within this proficiency test. The robust standard deviation of $0.010 \mathrm{mg} / \mathrm{kg}$ is comparable to the target standard deviation $\sigma_{\mathrm{p}}$ of $0.012 \mathrm{mg} / \mathrm{kg}$.

The uncertainty of the consensus value was $0.0036 \mathrm{mg} / \mathrm{kg}$. Since this value does not exceed $0.3 \sigma_{\mathrm{p}}$ $(0.004 \mathrm{mg} / \mathrm{kg}, \S 3.2)$, the uncertainty is not taken into account in the evaluation, and therefore $\mathrm{z}_{\mathrm{a}}$-scores using equation I (§3.4), were calculated. With respect to the accuracy, laboratory PT500 reported an unsatisfactory result.

\subsubsection{Cis-deltamethrin}

Twelve participants reported quantitative results for cis-deltamethrin in material A. Participant PT489 did not report a quantitative result for deltamethrin, even though they included cis-deltamethrin in their scope and therefore a FN result was assigned. Participants PT501 and PT504 failed to detect the presence of cis-deltamethrin and reported a false negative result. Thirteen participants did not analyse cis-deltamethrin of which 11 reported cis-deltamethrin as not tested (although some of these participants reported the matrix - pesticide combination in their scope) and 2 participants (PT485 and PT505) did not report quantitative results due to the absence of the compound in their scope.

The lowest concentration reported was $0.022 \mathrm{mg} / \mathrm{kg}$ and the highest was $1.25 \mathrm{mg} / \mathrm{kg}$. The consensus value was $0.089 \mathrm{mg} / \mathrm{kg}$ with a robust standard deviation of $0.026 \mathrm{mg} / \mathrm{kg}$ (resulting in an $\mathrm{RSD}_{\mathrm{R}}$ of $29.3 \%$ ) expressing the reproducibility within this proficiency test. The robust standard deviation of $0.026 \mathrm{mg} / \mathrm{kg}$ is 1.2 times higher than the target standard deviation $\sigma_{\mathrm{P}}$ of $0.022 \mathrm{mg} / \mathrm{kg}$. 
The uncertainty of the consensus value was $0.009 \mathrm{mg} / \mathrm{kg}$. Since this value exceeds $0.3 \sigma_{\mathrm{p}}$

$(0.007 \mathrm{mg} / \mathrm{kg}, \S 3.2)$, the uncertainty is taken into account in the evaluation, and therefore $\mathrm{z}^{\prime}{ }_{\mathrm{a}}$-scores using equation II (§3.4), were calculated. With respect to the accuracy, laboratory PT484 and PT500 reported an unsatisfactory result.

\subsubsection{Alpha-endosulfan}

Thirteen participants reported quantitative results for alpha-endosulfan in material A. Participants PT484, PT485 and PT489 did not report a quantitative result for alpha-endosulfan, even though they included alpha-endosulfan in their scope and therefore a FN result was assigned. Participants PT494, PT501 and PT504 failed to detect the presence of alpha-endosulfan and reported also a false negative result. Participant PT486 reported a correct qualitative result (nd) because the consensus value was $0.076 \mathrm{mg} / \mathrm{kg}$ and the reported LOQ $0.05 \mathrm{mg} / \mathrm{kg}$ was higher than the $-2 \mathrm{z}$ value of $0.028 \mathrm{mg} / \mathrm{kg}$. Eight participants reported alpha-endosulfan as not tested (although some of these participants reported the matrix - pesticide combination in their scope).

The lowest concentration reported was $0.02 \mathrm{mg} / \mathrm{kg}$ and the highest was $0.123 \mathrm{mg} / \mathrm{kg}$. The consensus value was $0.076 \mathrm{mg} / \mathrm{kg}$ with a robust standard deviation of $0.041 \mathrm{mg} / \mathrm{kg}$ (resulting in an $\mathrm{RSD}_{\mathrm{R}}$ of $54.6 \%$ ) expressing the reproducibility within this proficiency test. The robust standard deviation of $0.041 \mathrm{mg} / \mathrm{kg}$ is 2 times higher than the target standard deviation $\sigma_{\mathrm{p}}$ of $0.019 \mathrm{mg} / \mathrm{kg}$.

The uncertainty of the consensus value was $0.014 \mathrm{mg} / \mathrm{kg}$. Since this value exceeds $0.7 \sigma_{\mathrm{P}}$ $(0.013 \mathrm{mg} / \mathrm{kg}, \S 3.2)$, no statistical evaluation is appropriate.

\subsubsection{Endosulfan sulfate}

Ten participants reported quantitative results for endosulfan sulfate in material A. Participants PT484, PT485, PT489 and PT510 did not report a quantitative result for endosulfan sulfate, even though they included endosulfan-sulfate in their scope and therefore a FN result was assigned. Participants PT479, PT480, PT486, PT488 and PT501 failed to detect the presence of endosulfan sulfate and reported also a false negative result. PT491 did not report a quantitative result due to the absence of this compound in their scope. The participant reported not detected instead of not tested. Eight participants did not analysed endosulfan-sulfate of which 7 participants reported endosulfan sulfate as not tested (although some of these participants reported the matrix - pesticide combination in their scope) and participant PT505 did not report an quantitative result due to the absence of the compound in their scope.

The lowest concentration reported was $0.101 \mathrm{mg} / \mathrm{kg}$ and the highest was $0.264 \mathrm{mg} / \mathrm{kg}$. The consensus value was $0.134 \mathrm{mg} / \mathrm{kg}$ with a robust standard deviation of $0.028 \mathrm{mg} / \mathrm{kg}$ (resulting in an RSD of $21.1 \%$ ) expressing the reproducibility within this proficiency test. The robust standard deviation of $0.028 \mathrm{mg} / \mathrm{kg}$ is 1.2 times lower than the target standard deviation $\sigma_{\mathrm{P}}$ of $0.034 \mathrm{mg} / \mathrm{kg}$.

The uncertainty of the consensus value was $0.011 \mathrm{mg} / \mathrm{kg}$. Since this value exceeds $0.3 \sigma_{\mathrm{p}}$ $(0.010 \mathrm{mg} / \mathrm{kg}, \S 3.2)$, the uncertainty is taken into account in the evaluation, and therefore $z^{\prime}{ }^{\prime}$-scores using equation II (§3.4), were calculated. With respect to the accuracy, laboratory PT511 reported an unsatisfactory result.

\subsubsection{Pirimiphos-methyl}

Thirteen participants reported quantitative results for pirimiphos-methyl in material A. Participants PT484 and PT489 did not report a quantitative result for pirimiphos-methyl, even though they included alpha-endosulfan in their scope and therefore a FN result was assigned. Participants PT479 and PT486 failed to detect the presence of pirimiphos-methyl and reported also a false negative result. Eleven participants did not analyse pirimiphos of which 9 participants reported pirimiphos-methyl as not tested (although some of these participants reported the matrix - pesticide combination in their scope) and 2 participants (PT485 and 505) did not report quantitative results due to the absence of the compound in their scope. 
The lowest concentration reported was $0.108 \mathrm{mg} / \mathrm{kg}$ and the highest was $0.226 \mathrm{mg} / \mathrm{kg}$. The consensus value was $0.178 \mathrm{mg} / \mathrm{kg}$ with a robust standard deviation of $0.038 \mathrm{mg} / \mathrm{kg}$ (resulting in an $\mathrm{RSD}_{\mathrm{R}}$ of $21 \%$ ) expressing the reproducibility within this proficiency test. The robust standard deviation of $0.038 \mathrm{mg} / \mathrm{kg}$ is 1.2 times lower than the target standard deviation $\sigma_{\mathrm{p}}$ of $0.045 \mathrm{mg} / \mathrm{kg}$.

The uncertainty of the consensus value was $0.013 \mathrm{mg} / \mathrm{kg}$. Since this value does not exceed $0.3 \sigma_{p}$ $(0.0134 \mathrm{mg} / \mathrm{kg}, \S 3.2)$, the uncertainty is not taken into account in the evaluation, and therefore $\mathrm{z}_{\mathrm{a}}$-scores using equation I (§3.4), were calculated. With respect to the accuracy all quantitative results were satisfactory.

\subsection{Performance participants material B}

Laboratory PT485, PT490, PT492, PT497 and PT505 did not report quantitative results for the pesticides due to the absence of the added pesticides from their scope. Two FP results were reported in material B. Laboratory PT481 reported the presence of cyfluthrin as $0.0839 \mathrm{mg} / \mathrm{kg}$ and laboratory PT500 reported the presence of carbendazim as $0.087 \mathrm{mg} / \mathrm{kg}$. Results for material B are presented in Annex 7.

\subsubsection{Azoxystrobin}

Twenty-three participants reported quantitative results for azoxystrobin in material B. Seven participants did not analyse azoxystrobin of which 6 participants reported azoxystrobin as not tested (although some of these participants reported the matrix - pesticide combination in their scope) and laboratory PT505 did not report an quantitative result due to the absence of the compound in their scope.

The lowest concentration reported was $0.026 \mathrm{mg} / \mathrm{kg}$ and the highest was $0.489 \mathrm{mg} / \mathrm{kg}$. The consensus value was $0.379 \mathrm{mg} / \mathrm{kg}$ with a robust standard deviation of $0.065 \mathrm{mg} / \mathrm{kg}$ (resulting in an $\mathrm{RSD}_{\mathrm{R}}$ of $17.1 \%$ ) expressing the reproducibility within this proficiency test. The robust standard deviation of $0.065 \mathrm{mg} / \mathrm{kg}$ is 1.5 times lower than the target standard deviation $\sigma_{\mathrm{p}}$ of $0.095 \mathrm{mg} / \mathrm{kg}$.

The uncertainty of the consensus value was $0.017 \mathrm{mg} / \mathrm{kg}$. Since this value does not exceed $0.3 \sigma_{\mathrm{P}}$ $(0.028 \mathrm{mg} / \mathrm{kg}, \S 3.2)$, the uncertainty is not taken into account in the evaluation.

No consequential instability was observed for azoxystrobin during the storage period of 56 days. Therefore, $\mathrm{z}_{\mathrm{a}}$-scores using equation I (\$3.4), were calculated. With respect to the accuracy, laboratory PT487 reported a questionable result and laboratory PT508 an unsatisfactory result.

\subsubsection{Boscalid}

Twenty-two participants reported quantitative results for boscalid in material B. Seven participants did not analyse boscalid of which 6 participants reported boscalid as not tested (although some of these participants reported the matrix - pesticide combination in their scope) and participant PT505 did not report quantitative results for boscalid due to the absence of the compound in their scope.

The lowest concentration reported was $0.136 \mathrm{mg} / \mathrm{kg}$ and the highest was $1.38 \mathrm{mg} / \mathrm{kg}$. The consensus value was $0.999 \mathrm{mg} / \mathrm{kg}$ with a robust standard deviation of $0.262 \mathrm{mg} / \mathrm{kg}$ (resulting in an $\mathrm{RSD}_{\mathrm{R}}$ of $26.2 \%$ ) expressing the reproducibility within this proficiency test. The robust standard deviation of $0.262 \mathrm{mg} / \mathrm{kg}$ is comparable to the target standard deviation $\sigma_{\mathrm{p}}$ of $0.250 \mathrm{mg} / \mathrm{kg}$.

The uncertainty of the consensus value was $0.070 \mathrm{mg} / \mathrm{kg}$. Since this value does not exceed $0.3 \sigma_{\mathrm{p}}$ $(0.075 \mathrm{mg} / \mathrm{kg}, \S 3.2)$, the uncertainty is not taken into account in the evaluation.

No consequential instability was observed for boscalid during the storage period of 56 days. Therefore, $\mathrm{z}_{\mathrm{a}}$-scores using equation I (\$3.4), were calculated. With respect to the accuracy, laboratory PT508 reported an unsatisfactory result. 


\subsubsection{Chlorpyrifos}

Twenty-two participants reported quantitative results for chlorpyriphos in material B. Laboratory PT506 reported a correct qualitative result (nd) because the consensus value was $0.039 \mathrm{mg} / \mathrm{kg}$ and their LOQ of $0.02 \mathrm{mg} / \mathrm{kg}$ was the same as the $-2 z$ line of $0.020 \mathrm{mg} / \mathrm{kg}$. Six participants did not analyse chlorpyrifos of which 5 participants reported chlorpyrifos as not tested (although some of these participants reported the matrix - pesticide combination in their scope) and participant PT505 did not report quantitative results due to the absence of the compound in their scope.

The lowest concentration reported was $0.012 \mathrm{mg} / \mathrm{kg}$ and the highest was $0.054 \mathrm{mg} / \mathrm{kg}$. The consensus value was $0.039 \mathrm{mg} / \mathrm{kg}$ with a robust standard deviation of $0.010 \mathrm{mg} / \mathrm{kg}$ (resulting in an $\mathrm{RSD}_{\mathrm{R}}$ of $26.4 \%$ ) expressing the reproducibility within this proficiency test. The robust standard deviation of $0.010 \mathrm{mg} / \mathrm{kg}$ is the same as the target standard deviation $\sigma_{p}$ of $0.01 \mathrm{mg} / \mathrm{kg}$.

The uncertainty of the consensus value was $0.0028 \mathrm{mg} / \mathrm{kg}$. Since this value does not exceed $0.3 \sigma_{\mathrm{p}}$ $(0.0029 \mathrm{mg} / \mathrm{kg}, \S 3.2)$, the uncertainty is not taken into account in the evaluation.

No consequential instability was observed for chlorpyriphos during the storage period of 56 days. Therefore, $\mathrm{z}_{\mathrm{a}}$-scores using equation I (§3.4), were calculated. With respect to the accuracy, laboratory PT504 and PT508 reported a questionable result.

\subsubsection{Cypermethrin}

Twenty-one participants reported quantitative results for cypermethrin in material B. Laboratory PT498 failed to detect the presence of cypermethrin and reported a FN result. Seven participants did not analyse cypermethrin of which 6 participants reported cypermethrin as not tested (although some of these participants reported the matrix - pesticide combination in their scope) and participant PT505 did not report quantitative results due to the absence of the compound in their scope.

The lowest concentration reported was $0.012 \mathrm{mg} / \mathrm{kg}$ and the highest was $0.135 \mathrm{mg} / \mathrm{kg}$. The consensus value was $0.070 \mathrm{mg} / \mathrm{kg}$ with a robust standard deviation of $0.030 \mathrm{mg} / \mathrm{kg}$ (resulting in an $\mathrm{RSD}_{\mathrm{R}}$ of $42.6 \%$ ) expressing the reproducibility within this proficiency test. The robust standard deviation of $0.030 \mathrm{mg} / \mathrm{kg}$ is almost 2 times higher than the target standard deviation $\sigma_{\mathrm{p}}$ of $0.017 \mathrm{mg} / \mathrm{kg}$.

The uncertainty of the consensus value was $0.008 \mathrm{mg} / \mathrm{kg}$. Since this value exceeds $0.3 \sigma_{\mathrm{P}}$ $(0.005 \mathrm{mg} / \mathrm{kg}, \S 3.2)$, the uncertainty is taken into account in the evaluation.

No consequential instability was observed for cypermethrin during the storage period of 56 days. Therefore, $z^{\prime}{ }_{a}$-scores using equation VI $(\S 3.4)$, were calculated. With respect to the accuracy, three results were questionable (PT 481, PT484, PT487) and three results were unsatisfactory (PT491, PT493, PT508).

\subsubsection{Cyproconazole}

Twenty-one participants reported quantitative results for cyproconaole in material B. Laboratory PT508 failed to detect the presence of cyproconazole and reported a FN result. Seven participants did not analyse cyproconazole of which 6 participants reported cyproconazole as not tested (although some of these participants reported the matrix - pesticide combination in their scope) and participant PT505 did not report quantitative results due to the absence of the compound in their scope.

The lowest concentration reported was $0.022 \mathrm{mg} / \mathrm{kg}$ and the highest was $0.27 \mathrm{mg} / \mathrm{kg}$. The consensus value was $0.070 \mathrm{mg} / \mathrm{kg}$ with a robust standard deviation of $0.013 \mathrm{mg} / \mathrm{kg}$ (resulting in an $\mathrm{RSD}_{\mathrm{R}}$ of $18.5 \%$ ) expressing the reproducibility within this proficiency test. The robust standard deviation of $0.013 \mathrm{mg} / \mathrm{kg}$ is comparable to the target standard deviation $\sigma_{\mathrm{p}}$ of $0.018 \mathrm{mg} / \mathrm{kg}$.

The uncertainty of the consensus value was $0.004 \mathrm{mg} / \mathrm{kg}$. Since this value does not exceed $0.3 \sigma_{\mathrm{p}}$ $(0.005 \mathrm{mg} / \mathrm{kg}, \S 3.2)$, the uncertainty is not taken into account in the evaluation. 
No consequential instability was observed for cyproconazole during the storage period of 56 days. Therefore, $\mathrm{z}_{\mathrm{a}}$-scores using equation I (§3.4), were calculated. With respect to the accuracy, laboratory PT487 and PT506 reported a questionable result and laboratory PT500 reported an unsatisfactory result.

\subsubsection{Ortho-phenylphenol}

Twenty participants reported quantitative results for ortho-phenylphenol in material B. Laboratory PT504 failed to detect the presence of ortho-phenylphenol and reported a FN result. Seven participants reported ortho-phenylphenol as not tested and participant PT505 did not report an quantitative result due to the absence of the compound in their scope.

The lowest concentration reported was $0.017 \mathrm{mg} / \mathrm{kg}$ and the highest was $0.255 \mathrm{mg} / \mathrm{kg}$. The consensus value was $0.144 \mathrm{mg} / \mathrm{kg}$ with a robust standard deviation of $0.043 \mathrm{mg} / \mathrm{kg}$ (resulting in an $\mathrm{RSD}_{\mathrm{R}}$ of $29.8 \%$ ) expressing the reproducibility within this proficiency test. The robust standard deviation of $0.043 \mathrm{mg} / \mathrm{kg}$ is 1.2 times higher than the target standard deviation $\sigma_{\mathrm{P}}$ of $0.036 \mathrm{mg} / \mathrm{kg}$.

The uncertainty of the consensus value was $0.012 \mathrm{mg} / \mathrm{kg}$. Since this value exceeds $0.3 \sigma_{\mathrm{p}}$ $(0.011 \mathrm{mg} / \mathrm{kg}, \S 3.2)$, the uncertainty is taken into account in the evaluation.

No consequential instability was observed for ortho-phenylphenol during the storage period of 56 days. Therefore, $\mathrm{z}_{\mathrm{a}}^{\prime}$-scores using equation II (§3.4), were calculated. With respect to the accuracy one result was questionable (PT484) and one result was unsatisfactory (PT508).

\subsubsection{Pirimiphos-methyl}

Twenty-three participants reported quantitative results for pirimiphos-methyl in material B. Participant PT484 did not report a quantitative result for pirimiphos-methyl, but this compound was within the participants' scope, therefore a FN result was assigned. Four participants reported pirimiphos-methyl as not tested (although some of these participants reported the matrix - pesticide combination in their scope) and participant PT505 did not report an quantitative result due to the absence of the compound in their scope.

The lowest concentration reported was $0.047 \mathrm{mg} / \mathrm{kg}$ and the highest was $0.349 \mathrm{mg} / \mathrm{kg}$. The consensus value was $0.224 \mathrm{mg} / \mathrm{kg}$ with a robust standard deviation of $0.061 \mathrm{mg} / \mathrm{kg}$ (resulting in an $\mathrm{RSD}_{R}$ of $27 \%$ ) expressing the reproducibility within this proficiency test. The robust standard deviation of $0.061 \mathrm{mg} / \mathrm{kg}$ is comparable to the target standard deviation $\sigma_{\mathrm{P}}$ of $0.056 \mathrm{mg} / \mathrm{kg}$.

The uncertainty of the consensus value was $0.016 \mathrm{mg} / \mathrm{kg}$. Since this value does not exceed $0.3 \sigma_{\mathrm{P}}$ $(0.017 \mathrm{mg} / \mathrm{kg}, \S 3.2)$, the uncertainty is not taken into account in the evaluation.

No consequential instability was observed for pirimiphos-methyl during the storage period of 56 days. Therefore, $\mathrm{z}_{\mathrm{a}}$-scores using equation I (§3.4), were calculated. With respect to the accuracy one result was questionable (PT481) and two result were unsatisfactory (PT504, PT508).

\subsubsection{Tebuconazole}

Twenty-three participants reported quantitative results for tebuconazole in material B. Six participants reported tebuconazole as not tested and participant PT505 did not report an quantitative result due to the absence of the compound in their scope.

The lowest concentration reported was $0.021 \mathrm{mg} / \mathrm{kg}$ and the highest was $0.23 \mathrm{mg} / \mathrm{kg}$. The consensus value was $0.168 \mathrm{mg} / \mathrm{kg}$ with a robust standard deviation of $0.038 \mathrm{mg} / \mathrm{kg}$ (resulting in an $\mathrm{RSD}_{\mathrm{R}}$ of $22.4 \%$ ) expressing the reproducibility within this proficiency test. The robust standard deviation of $0.038 \mathrm{mg} / \mathrm{kg}$ is comparable to the target standard deviation $\sigma_{\mathrm{P}}$ of $0.042 \mathrm{mg} / \mathrm{kg}$. 
The uncertainty of the consensus value was $0.010 \mathrm{mg} / \mathrm{kg}$. Since this value does not exceed $0.3 \sigma_{\mathrm{p}}$ $(0.013 \mathrm{mg} / \mathrm{kg}, \S 3.2)$, the uncertainty is not taken into account in the evaluation.

No consequential instability was observed for tebuconazole during the storage period of 56 days. Therefore, $z_{\mathrm{a}}$-scores using equation I (§3.4), were calculated. With respect to the accuracy one result was unsatisfactory (PT508).

\subsection{False positive and false negative results}

In this PT, $4 \mathrm{FP}$ and $42 \mathrm{FN}$ results were reported. An overview of the FP and FN results is shown in Annex 8 and Table 7.

In material A (traces of) 2,4D, bromuconazole, cyproconazole, beta-endosulfan, haloxyfop, imazalil, metalaxyl, permethrin, ortho-phenylphenol, tebuconazole, tetraconazole and thiophanate-methyl $(0.011 \mathrm{mg} / \mathrm{kg}$ to $0.82 \mathrm{mg} / \mathrm{kg}$ were detected by several participants. In material B (traces of) $2,4 \mathrm{D}$, acetamiprid, biphenyl, carbendazim, cyfluthrin, p,p-DDD, alpha-endosulfan, fluazifop, haloxyfop, heptachlor, imidacloprid and tricyclazole $(0.005 \mathrm{mg} / \mathrm{kg}$ to $0.13 \mathrm{mg} / \mathrm{kg})$ were detected.

Table 7

False positive and false negative results.

\begin{tabular}{llll} 
Compound & Material A & Compound & Material B \\
biphenyl & $2 \mathrm{FN}$ & cypermethrin & $1 \mathrm{FN}$ \\
\hline cis-chordane & $8 \mathrm{FN}$ & cyproconazole & $1 \mathrm{FN}$ \\
\hline chlorpyrifos & $1 \mathrm{FN}$ & ortho-phenylphenol & $1 \mathrm{FN}$ \\
\hline p, $\mathrm{p}^{\prime}$-DDE & $5 \mathrm{FN}$ & pirimiphos-methyl & $1 \mathrm{FN}$ \\
\hline cis-deltamethrin & $3 \mathrm{FN}$ & & \\
\hline alpha-endosulfan & $6 \mathrm{FN}$ & & \\
\hline endosulfan-sulfate & $9 \mathrm{FN}$ & & \\
\hline pirimiphos-methyl & $4 \mathrm{FN}$ & & $1 \mathrm{FP}$ \\
\hline Imizalil & $2 \mathrm{FP}$ & & $1 \mathrm{FP}$
\end{tabular}

$\mathrm{FN}=$ false negatives; $F P=$ false positives 


\section{$5 \quad$ Discussion and conclusions}

Thirty-one participants subscribed for the proficiency test on pesticides in the feed matrices soy acid oil and soybean and twenty-nine reported results. Twenty-eight participants submitted the results in time, PT485 reported too late but the results were still taken into account and PT482 and PT507 were unable to report results. Each participant was asked to indicate a priori which compounds were included in their scope. This allowed the evaluation of the results which regard to the participants' scope.

Two materials were sent to the participants. The pesticides were homogeneously distributed in the materials. An overview of each participant's performance is shown in Annex 9 and a summary of the results is presented in Table 8 .

Table 8 Summarized performance of participants reporting results.

\begin{tabular}{|c|c|c|c|c|c|c|c|c|c|}
\hline \multicolumn{2}{|c|}{ Compound } & $\begin{array}{l}\text { \# of } \\
\text { articipants. }\end{array}$ & $\begin{array}{l}\text { quant. } \\
\text { result }\end{array}$ & $\begin{array}{l}\text { qual. } \\
\text { result }\end{array}$ & $F N^{1)}$ & $\begin{array}{c}\text { q } \\
\text { z-score }\end{array}$ & $\begin{array}{c}\text { u } \\
\text { z-score }\end{array}$ & $\begin{array}{c}\text { used } \\
\text { z-score }\end{array}$ & $\begin{array}{c}\text { correct } \\
\text { results } \\
(\%)\end{array}$ \\
\hline \multicolumn{2}{|c|}{ anthraquinone } & 8 & 8 & & & & & $\mathrm{z}_{\mathrm{a}}^{\prime}$ & 100 \\
\hline \multicolumn{2}{|c|}{ biphenyl } & 14 & 12 & & 2 & 1 & 1 & $\mathrm{z}_{\mathrm{a}}$ & 71 \\
\hline \multicolumn{2}{|c|}{ chlorpyrifos } & 16 & 15 & & 1 & & 2 & $\mathrm{z}_{\mathrm{a}}$ & 81 \\
\hline \multicolumn{2}{|c|}{$p, p^{\prime}-D D E$} & 18 & 12 & 1 & 5 & & 1 & $\mathrm{z}_{\mathrm{a}}$ & 67 \\
\hline \multicolumn{2}{|c|}{ cis-deltamethrin } & 15 & 12 & & 3 & 1 & 1 & $z_{a}^{\prime}$ & 67 \\
\hline \multicolumn{2}{|c|}{ alpha-endosulfan } & 20 & 13 & 1 & 6 & & \multicolumn{3}{|c|}{ No stat. eval. } \\
\hline \multicolumn{10}{|c|}{ Material B } \\
\hline \multicolumn{2}{|c|}{ Azoxystrobin } & 23 & 23 & & & 1 & 1 & $z_{a}$ & 91 \\
\hline \multicolumn{2}{|c|}{ Boscalid } & 22 & 22 & & & & 1 & $\mathrm{z}_{\mathrm{a}}$ & 95 \\
\hline \multicolumn{2}{|c|}{ Chlorpyrifos } & 23 & 22 & 1 & & 2 & & $z_{a}$ & 91 \\
\hline \multicolumn{2}{|c|}{ Cypermethrin } & 22 & 21 & & 1 & 3 & 3 & $\mathrm{z}_{\mathrm{a}}^{\prime}$ & 68 \\
\hline \multicolumn{2}{|c|}{ Cyproconazole } & 22 & 21 & & 1 & 2 & 1 & $\mathrm{z}_{\mathrm{a}}$ & 82 \\
\hline \multicolumn{2}{|c|}{ Ortho-phenylphenol } & 21 & 20 & & 1 & 1 & 1 & $\mathrm{z}_{\mathrm{a}}^{\prime}$ & 86 \\
\hline \multicolumn{2}{|c|}{ Pirimiphos-methyl } & 24 & 23 & & 1 & 1 & 2 & $z_{a}$ & 83 \\
\hline \multicolumn{2}{|c|}{ Tebuconazole } & 23 & 23 & & & & 1 & $\mathrm{z}_{\mathrm{a}}$ & 96 \\
\hline \multicolumn{10}{|c|}{ quant. quantitative result } \\
\hline
\end{tabular}

Seven participants showed optimal performance by detecting the pesticides with a correct quantification/qualification within the participants' scope, the absence of false positive and false negative results and reporting within the deadline. Twenty-two participants reported FN, FP, questionable or unsatisfactory z-scores. A total of 4 FP and 42 FN results were reported. Ten participants did not analyse the pesticides in material $A$ and five participants did not report quantitative or qualitative results for the pesticides in material $B$ due to the absence of the compounds from their scope. 
Based on the results of this proficiency test it was concluded that:

- The results show that the variation in results for soy acid oil is larger than the variation in the results of soybean meal. The larger variation might be related to the nature of the material. Soy acid oil consists of fat and fatty acids which makes this matrix challenging for pesticide residue analysis.

- There is a need for improvement of quantification of pesticides in soy acid oil especially for cischlordane, alpha-endosulfan and endosulfan sulfate. For cis-chlordane and endosulfan sulfate resp. 50 and $47 \%$ of the results were satisfactory. The results of alpha-endosulfan showed a large variation (high uncertainty, $\mathrm{RSD}_{\mathrm{R}}$. of $54.6 \%$ ), no statistical evaluation could be applied.

- The quantification of cypermethrin in soybean meal needs additional attention, since the variation of the results was large. The relative standard deviation of the reproducibility of cypermethrin was $43 \%$. 


\section{References}

1 Council Directive 93/99/EEC of 29 October 1993 on the subject of additional measures concerning the official control of foodstuffs. Official Journal L 290, 24/11/1993, 0014 - 0017.

2 ISO/IEC 17025:2005(E). 2005. General Requirements for the Competence of Calibration and Testing Laboratories.

3 ISO/IEC 17043:2010. 2010. Conformity assessment - General requirements for proficiency testing.

4 SOPA0989 - De bereiding van referentiematerialen en referentiemonsters - RIKILT.

5 ISO 13528:2015, IDT. 2015. Statistical methods for use in proficiency testing by inter-laboratory comparison, 1st edition.

6 Thompson M. 2000. Recent trends in inter-laboratory precision at $\mu \mathrm{g} / \mathrm{kg}$ and sub- $\mu \mathrm{g} / \mathrm{kg}$ concentrations in relation to fitness for purpose criteria in proficiency testing. Analyst. 125: 385-386.

7 Thompson M, Ellison SL, Wood R. 2006. The International Harmonized Protocol for the Proficiency Testing of Analytical Chemistry Laboratories. Pure Appl. Chem. 78(1):145-196.

8 Analytical Methods Committee. 1989. Robust statistics - How not to reject outliers Part 1. Basic concepts. Analyst 114:1693-1697.

9 Analytical Methods Committee. 1989. Robust statistics - How not to reject outliers Part 2. Interlaboratory trials. Analyst. 114:1699-1702.

10 Regulation (EC) No 396/2005 of 23 February 2005 on maximum residue levels of pesticides in or on food and feed of plant and animal origin and amending Council 91/414/EEC. 


\section{Annex 1 Codification of the samples}

\begin{tabular}{|c|c|c|}
\hline Participants code & Material A* & Material B* \\
\hline PT479 & 130 & 359 \\
\hline PT480 & 843 & 165 \\
\hline PT481 & 622 & 518 \\
\hline PT483 & 110 & 636 \\
\hline PT484 & 303 & 169 \\
\hline PT485 & 337 & 344 \\
\hline PT486 & 690 & 515 \\
\hline PT487 & 929 & 224 \\
\hline PT488 & 561 & 313 \\
\hline PT489 & 205 & 177 \\
\hline PT490 & 733 & 916 \\
\hline PT491 & 641 & 973 \\
\hline PT492 & 137 & 352 \\
\hline PT493 & 962 & 713 \\
\hline PT494 & 708 & 479 \\
\hline PT497 & 892 & 426 \\
\hline PT498 & & 468 \\
\hline PT499 & 552 & 959 \\
\hline PT500 & 837 & 902 \\
\hline PT501 & 269 & 724 \\
\hline PT502 & 939 & 104 \\
\hline PT503 & 745 & 148 \\
\hline PT504 & 583 & 987 \\
\hline PT505 & 703 & 321 \\
\hline PT506 & 906 & 716 \\
\hline PT508 & 281 & 514 \\
\hline PT509 & 192 & 761 \\
\hline PT510 & 143 & 431 \\
\hline PT511 & 739 & 271 \\
\hline
\end{tabular}

* All sample codes start with Pesticides/2017/feed/ 


\section{Annex 2 Instruction letter}

WAGENINGEN

UNIVERSITY \& RESEARCH

January 12,2017

Invitation profidency test

pesticldes in acld oll and

soysbean meal

Oue kifmetsci

1701719/RuK

Dear participant,

Thank you very much for your interest in the proficiency study for the analysis of pesticides in the feed matrices acid oil and soyabean meal. Hereby I send you a parcel containing two randomly coded samples. Each sample consists of approximately $\mathbf{2 5}$ grams of test material. The samples may contain one or more of the analytes indicated below (in alphabetical order):

\begin{tabular}{|c|c|c|c|c|}
\hline \multicolumn{4}{|c|}{ pesticldes included in the scope of the laboratory (*) } & \multirow[b]{2}{*}{ 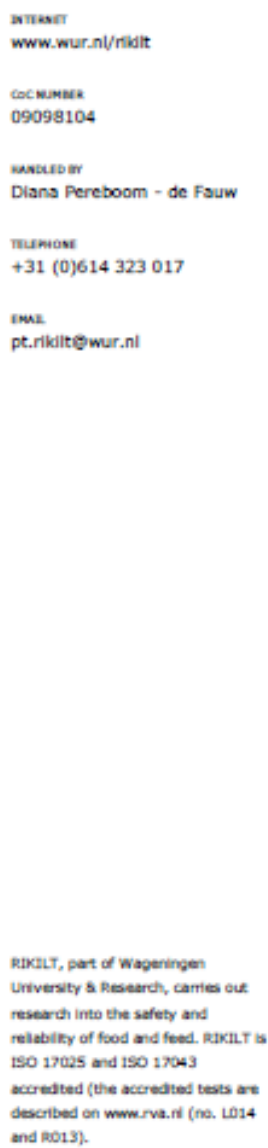 } \\
\hline 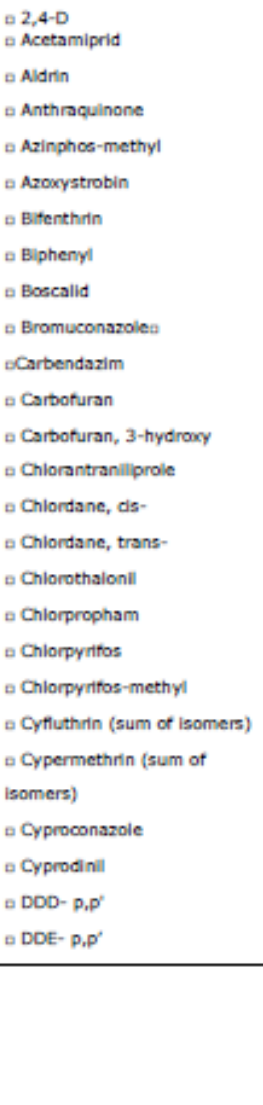 & 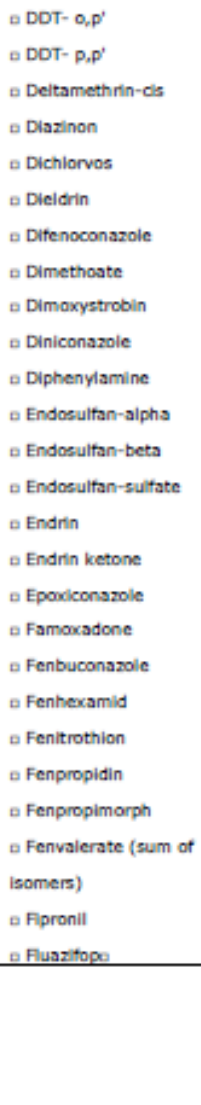 & 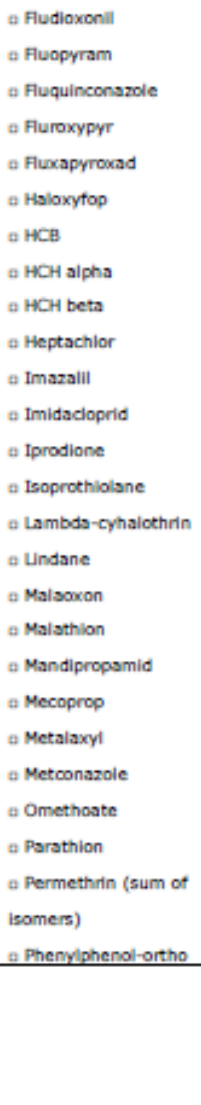 & 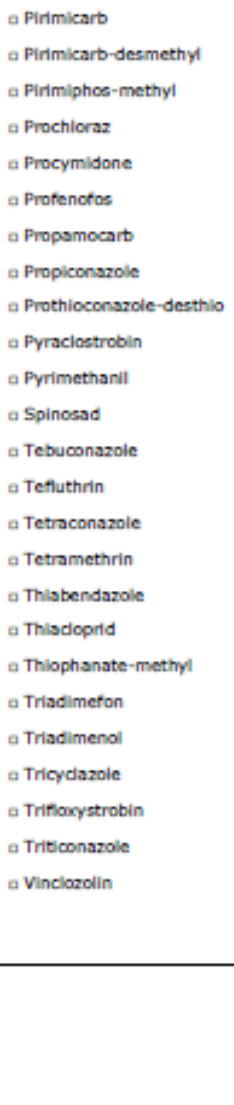 & \\
\hline
\end{tabular}


BNI

January 12, 2017

ouskimass

$1701719 /$ RIK

mose 2 of 2

Instructions:

- $\quad$ After arrival the samples should be stored at $+4^{\circ} \mathrm{C}$.

- Before analysis, homogenize the samples according to your laboratory procedure.

Carry out a single analysis for each sample and treat the test material as if it was a sample for routine analysis and make use of your own reference standards

- Please upload your results via the web application

(https://crlwebshop.wur.n//apex/f?p=307:LOGIN) before March $10^{\text {th }} 2017$.

- Report all the results in $\mathrm{mg} / \mathrm{kg}$ sample as received. For the analytes found and reported, please provide the recovery $(\%)$ if available. Mention under the button "Method" in the column "Remark", whether or not the result has been corrected for recovery.

- Your usemame is:

- Your password is:

- Your lab code to enter this proficiency test is:

- $\quad$ Please inform us about your applied method and detection technique (preferably via the web application).

Please contact me if you have any questions or need any assistance.

With kind regards,

\section{Pereloom}

Diana Pereboom

pt.rikilt@wur.nl 


\section{Annex 3 Statistical evaluation of homogeneity data}

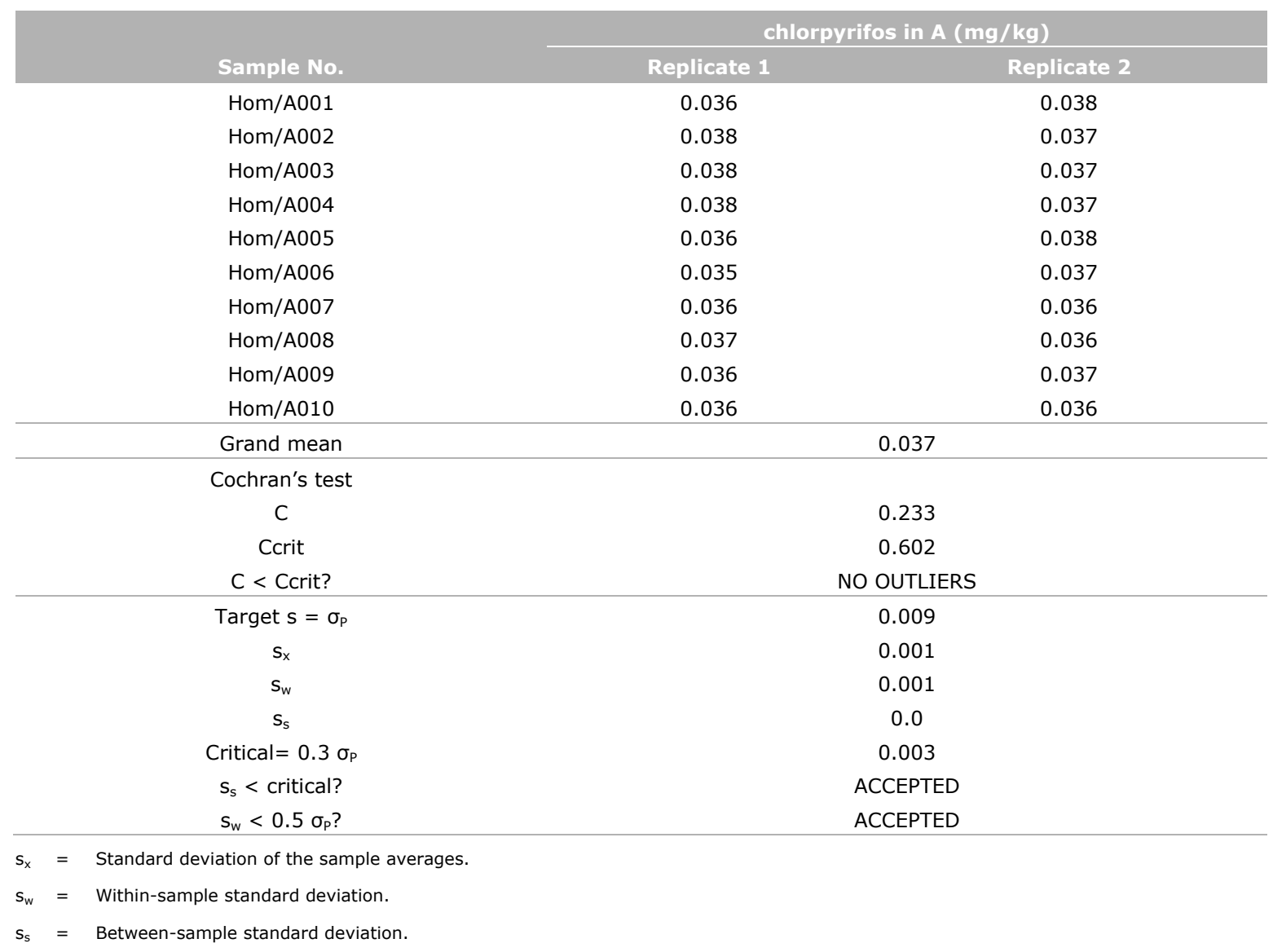




\begin{tabular}{|c|c|c|}
\hline \multirow[b]{2}{*}{ Sample No. } & \multicolumn{2}{|c|}{ cis-deltamethrin in A ( $\mathrm{mg} / \mathbf{k g})$} \\
\hline & Replicate 1 & Replicate 2 \\
\hline Hom/A001 & 0.020 & 0.020 \\
\hline Hom/A002 & 0.019 & 0.019 \\
\hline Hom/A003 & 0.018 & 0.018 \\
\hline Hom/A004 & 0.019 & 0.018 \\
\hline Hom/A005 & 0.020 & 0.020 \\
\hline Hom/A006 & 0.021 & 0.021 \\
\hline Hom/A007 & 0.020 & 0.020 \\
\hline Hom/A008 & 0.019 & 0.020 \\
\hline Hom/A009 & 0.019 & 0.018 \\
\hline Hom/A010 & 0.020 & 0.019 \\
\hline Grand mean & \multicolumn{2}{|c|}{0.019} \\
\hline \multicolumn{3}{|l|}{ Cochran's test } \\
\hline $\mathrm{C}$ & \multicolumn{2}{|c|}{0.393} \\
\hline Ccrit & \multicolumn{2}{|c|}{0.602} \\
\hline$C<$ Ccrit? & \multicolumn{2}{|c|}{ NO OUTLIERS } \\
\hline Target $\mathrm{s}=\sigma_{\mathrm{P}}$ & \multicolumn{2}{|c|}{0.005} \\
\hline$s_{x}$ & \multicolumn{2}{|c|}{0.001} \\
\hline $\mathrm{S}_{\mathrm{w}}$ & \multicolumn{2}{|c|}{0.001} \\
\hline $\mathrm{s}_{\mathrm{s}}$ & \multicolumn{2}{|c|}{0.001} \\
\hline Critical $=0.3 \sigma_{p}$ & \multicolumn{2}{|c|}{0.001} \\
\hline $\mathrm{S}_{\mathrm{s}}<$ critical? & \multicolumn{2}{|c|}{ ACCEPTED } \\
\hline$s_{w}<0.5 \sigma_{p} ?$ & \multicolumn{2}{|c|}{ ACCEPTED } \\
\hline
\end{tabular}

$\mathrm{s}_{\mathrm{x}}=$ Standard deviation of the sample averages.

$\mathrm{S}_{\mathrm{w}}=$ Within-sample standard deviation.

$\mathrm{s}_{\mathrm{s}}=$ Between-sample standard deviation.

\begin{tabular}{|c|c|c|}
\hline Sample No. & \multicolumn{2}{|c|}{ pirimiphos-methyl in A ( $\mathrm{mg} / \mathrm{kg}$ ) } \\
\hline Hom/A001 & 0.101 & 0.102 \\
\hline Hom/A003 & 0.105 & 0.099 \\
\hline Hom/A004 & 0.098 & 0.101 \\
\hline Hom/A006 & 0.100 & 0.101 \\
\hline Hom/A007 & 0.100 & 0.099 \\
\hline Hom/A008 & 0.102 & 0.099 \\
\hline Hom/A009 & 0.100 & 0.100 \\
\hline Hom/A010 & 0.100 & 0.101 \\
\hline $\mathrm{C}$ & \multicolumn{2}{|c|}{0.352} \\
\hline Ccrit & \multicolumn{2}{|c|}{0.602} \\
\hline C < Ccrit? & \multicolumn{2}{|c|}{ NO OUTLIERS } \\
\hline Target $\mathrm{s}=\sigma_{\mathrm{p}}$ & \multicolumn{2}{|c|}{0.025} \\
\hline $\mathrm{s}_{\mathrm{x}}$ & \multicolumn{2}{|c|}{0.001} \\
\hline $\mathrm{s}_{\mathrm{w}}$ & \multicolumn{2}{|c|}{0.002} \\
\hline $\mathrm{S}_{\mathrm{s}}$ & \multicolumn{2}{|c|}{0.0} \\
\hline Critical $=0.3 \sigma_{p}$ & \multicolumn{2}{|c|}{0.008} \\
\hline $\mathrm{s}_{\mathrm{s}}<$ critical? & \multicolumn{2}{|c|}{ ACCEPTED } \\
\hline
\end{tabular}

$\mathrm{s}_{\mathrm{x}}=$ Standard deviation of the sample averages.

$\mathrm{s}_{\mathrm{w}}=$ Within-sample standard deviation.

$\mathrm{s}_{\mathrm{s}}=$ Between-sample standard deviation. 


\begin{tabular}{|c|c|c|}
\hline \multirow[b]{2}{*}{ Sample No. } & \multicolumn{2}{|c|}{ azoxystrobin in B $(\mathrm{mg} / \mathrm{kg})$} \\
\hline & Replicate 1 & Replicate 2 \\
\hline Hom/A001 & 0.435 & 0.378 \\
\hline Hom/A002 & 0.410 & 0.371 \\
\hline Hom/A003 & 0.397 & 0.392 \\
\hline Hom/A004 & 0.401 & 0.395 \\
\hline Hom/A005 & 0.383 & 0.371 \\
\hline Hom/A006 & 0.383 & 0.326 \\
\hline Hom/A007 & 0.341 & 0.347 \\
\hline Hom/A008 & 0.392 & 0.358 \\
\hline Hom/A009 & 0.345 & 0.369 \\
\hline Hom/A010 & 0.382 & 0.362 \\
\hline Grand mean & \multicolumn{2}{|c|}{0.377} \\
\hline \multicolumn{3}{|l|}{ Cochran's test } \\
\hline $\mathrm{C}$ & \multicolumn{2}{|c|}{0.313} \\
\hline Ccrit & \multicolumn{2}{|c|}{0.602} \\
\hline$C<$ Ccrit? & \multicolumn{2}{|c|}{ NO OUTLIERS } \\
\hline Target $\mathrm{s}=\sigma_{\mathrm{P}}$ & \multicolumn{2}{|c|}{0.094} \\
\hline$s_{x}$ & \multicolumn{2}{|c|}{0.021} \\
\hline $\mathrm{s}_{\mathrm{w}}$ & \multicolumn{2}{|c|}{0.023} \\
\hline $\mathrm{S}_{\mathrm{s}}$ & \multicolumn{2}{|c|}{0.013} \\
\hline Critical $=0.3 \sigma_{p}$ & \multicolumn{2}{|c|}{0.028} \\
\hline $\mathrm{S}_{\mathrm{s}}<$ critical? & \multicolumn{2}{|c|}{ ACCEPTED } \\
\hline $\mathrm{s}_{\mathrm{w}}<0.5 \sigma_{\mathrm{p}} ?$ & \multicolumn{2}{|c|}{ ACCEPTED } \\
\hline
\end{tabular}

$\mathrm{s}_{\mathrm{x}}=$ Standard deviation of the sample averages.

$\mathrm{S}_{\mathrm{w}}=$ Within-sample standard deviation.

$\mathrm{s}_{\mathrm{s}}=$ Between-sample standard deviation.

\begin{tabular}{|c|c|c|}
\hline Sample No. & \multicolumn{2}{|c|}{ boscalid in B ( $\mathrm{mg} / \mathrm{kg})$} \\
\hline Hom/A001 & 1.027 & 0.962 \\
\hline Hom/A003 & 1.003 & 1.028 \\
\hline Hom/A004 & 1.076 & 1.006 \\
\hline Hom/A006 & 0.957 & 0.878 \\
\hline Hom/A007 & 0.927 & 0.921 \\
\hline Hom/A008 & 1.009 & 1.010 \\
\hline Hom/A009 & 0.904 & 0.951 \\
\hline Hom/A010 & 0.970 & 0.914 \\
\hline $\mathrm{C}$ & \multicolumn{2}{|c|}{0.291} \\
\hline Ccrit & \multicolumn{2}{|c|}{0.602} \\
\hline$C<$ Ccrit? & \multicolumn{2}{|c|}{ NO OUTLIERS } \\
\hline Target $\mathrm{s}=\sigma_{\mathrm{p}}$ & \multicolumn{2}{|c|}{0.242} \\
\hline $\mathrm{s}_{\mathrm{x}}$ & \multicolumn{2}{|c|}{0.044} \\
\hline $\mathrm{s}_{\mathrm{w}}$ & \multicolumn{2}{|c|}{0.033} \\
\hline $\mathrm{S}_{\mathrm{s}}$ & \multicolumn{2}{|c|}{0.038} \\
\hline Critical $=0.3 \sigma_{p}$ & \multicolumn{2}{|c|}{0.073} \\
\hline $\mathrm{s}_{\mathrm{s}}<$ critical? & \multicolumn{2}{|c|}{ ACCEPTED } \\
\hline
\end{tabular}

$\mathrm{s}_{\mathrm{x}}=$ Standard deviation of the sample averages.

$\mathrm{S}_{\mathrm{w}}=$ Within-sample standard deviation.

$\mathrm{s}_{\mathrm{s}}=$ Between-sample standard deviation. 


\begin{tabular}{|c|c|c|}
\hline \multirow[b]{2}{*}{ Sample No. } & \multicolumn{2}{|c|}{ chorpyrifos in B ( $\mathrm{mg} / \mathrm{kg})$} \\
\hline & Replicate 1 & Replicate 2 \\
\hline Hom/A001 & 0.044 & 0.043 \\
\hline Hom/A002 & 0.041 & 0.038 \\
\hline Hom/A003 & 0.041 & 0.039 \\
\hline Hom/A004 & 0.045 & 0.043 \\
\hline Hom/A005 & 0.042 & 0.043 \\
\hline Hom/A006 & 0.041 & 0.044 \\
\hline Hom/A007 & 0.041 & 0.044 \\
\hline Hom/A008 & 0.044 & 0.042 \\
\hline Hom/A009 & 0.038 & 0.042 \\
\hline Hom/A010 & 0.039 & 0.042 \\
\hline Grand mean & \multicolumn{2}{|c|}{0.042} \\
\hline \multicolumn{3}{|l|}{ Cochran's test } \\
\hline $\mathrm{C}$ & \multicolumn{2}{|c|}{0.292} \\
\hline Ccrit & \multicolumn{2}{|c|}{0.602} \\
\hline$C<$ Ccrit? & \multicolumn{2}{|c|}{ NO OUTLIERS } \\
\hline Target $\mathrm{s}=\sigma_{\mathrm{P}}$ & \multicolumn{2}{|c|}{0.010} \\
\hline$s_{x}$ & \multicolumn{2}{|c|}{0.002} \\
\hline $\mathrm{s}_{\mathrm{w}}$ & \multicolumn{2}{|c|}{0.002} \\
\hline $\mathrm{S}_{\mathrm{s}}$ & \multicolumn{2}{|c|}{0.001} \\
\hline Critical $=0.3 \sigma_{p}$ & \multicolumn{2}{|c|}{0.003} \\
\hline $\mathrm{S}_{\mathrm{s}}<$ critical? & \multicolumn{2}{|c|}{ ACCEPTED } \\
\hline $\mathrm{s}_{\mathrm{w}}<0.5 \sigma_{\mathrm{p}} ?$ & \multicolumn{2}{|c|}{ ACCEPTED } \\
\hline
\end{tabular}

$\mathrm{s}_{\mathrm{x}}=$ Standard deviation of the sample averages.

$\mathrm{S}_{\mathrm{w}}=$ Within-sample standard deviation.

$\mathrm{s}_{\mathrm{s}}=$ Between-sample standard deviation.

\begin{tabular}{|c|c|c|}
\hline Sample No. & \multicolumn{2}{|c|}{ cypermethrin in B ( $\mathrm{mg} / \mathrm{kg})$} \\
\hline Hom/A001 & 0.050 & 0.028 \\
\hline Hom/A003 & 0.033 & 0.050 \\
\hline Hom/A004 & 0.037 & 0.043 \\
\hline Hom/A006 & 0.031 & 0.029 \\
\hline Hom/A007 & 0.023 & 0.027 \\
\hline Hom/A008 & 0.047 & 0.053 \\
\hline Hom/A009 & 0.022 & 0.035 \\
\hline Hom/A010 & 0.027 & 0.032 \\
\hline $\mathrm{C}$ & \multicolumn{2}{|c|}{0.441} \\
\hline Ccrit & \multicolumn{2}{|c|}{0.602} \\
\hline$C<$ Ccrit? & \multicolumn{2}{|c|}{ NO OUTLIERS } \\
\hline Target $\mathrm{s}=\sigma_{\mathrm{p}}$ & \multicolumn{2}{|c|}{0.008} \\
\hline$s_{x}$ & \multicolumn{2}{|c|}{0.008} \\
\hline $\mathrm{S}_{\mathrm{w}}$ & \multicolumn{2}{|c|}{0.007} \\
\hline $\mathrm{S}_{\mathrm{s}}$ & \multicolumn{2}{|c|}{0.007} \\
\hline Critical $=0.3 \sigma_{p}$ & \multicolumn{2}{|c|}{0.003} \\
\hline $\mathrm{S}_{\mathrm{s}}<$ critical? & \multicolumn{2}{|c|}{ NOT ACCEPTED } \\
\hline
\end{tabular}

$\mathrm{s}_{\mathrm{x}}=$ Standard deviation of the sample averages.

$\mathrm{s}_{\mathrm{w}}=$ Within-sample standard deviation.

$\mathrm{s}_{\mathrm{s}}=$ Between-sample standard deviation. 


\begin{tabular}{|c|c|c|}
\hline \multirow[b]{2}{*}{ Sample No. } & \multicolumn{2}{|c|}{ cyproconazole in B ( $\mathrm{mg} / \mathrm{kg})$} \\
\hline & Replicate 1 & Replicate 2 \\
\hline Hom/A001 & 0.067 & 0.073 \\
\hline Hom/A002 & 0.071 & 0.068 \\
\hline Hom/A003 & 0.069 & 0.069 \\
\hline Hom/A004 & 0.070 & 0.069 \\
\hline Hom/A005 & 0.068 & 0.069 \\
\hline Hom/A006 & 0.068 & 0.064 \\
\hline Hom/A007 & 0.066 & 0.070 \\
\hline Hom/A008 & 0.069 & 0.069 \\
\hline Hom/A009 & 0.065 & 0.067 \\
\hline Hom/A010 & 0.070 & 0.066 \\
\hline Grand mean & \multicolumn{2}{|c|}{0.068} \\
\hline \multicolumn{3}{|l|}{ Cochran's test } \\
\hline $\mathrm{C}$ & \multicolumn{2}{|c|}{0.363} \\
\hline Ccrit & \multicolumn{2}{|c|}{0.602} \\
\hline$C<$ Ccrit? & \multicolumn{2}{|c|}{ NO OUTLIERS } \\
\hline Target $\mathrm{s}=\sigma_{\mathrm{P}}$ & \multicolumn{2}{|c|}{0.017} \\
\hline$s_{x}$ & \multicolumn{2}{|c|}{0.001} \\
\hline $\mathrm{s}_{\mathrm{w}}$ & \multicolumn{2}{|c|}{0.002} \\
\hline $\mathrm{S}_{\mathrm{s}}$ & \multicolumn{2}{|c|}{0.0} \\
\hline Critical $=0.3 \sigma_{p}$ & \multicolumn{2}{|c|}{0.005} \\
\hline $\mathrm{S}_{\mathrm{s}}<$ critical? & \multicolumn{2}{|c|}{ ACCEPTED } \\
\hline $\mathrm{s}_{\mathrm{w}}<0.5 \sigma_{\mathrm{p}} ?$ & \multicolumn{2}{|c|}{ ACCEPTED } \\
\hline
\end{tabular}

$\mathrm{s}_{\mathrm{x}}=$ Standard deviation of the sample averages.

$\mathrm{S}_{\mathrm{w}}=$ Within-sample standard deviation.

$\mathrm{s}_{\mathrm{s}}=$ Between-sample standard deviation.

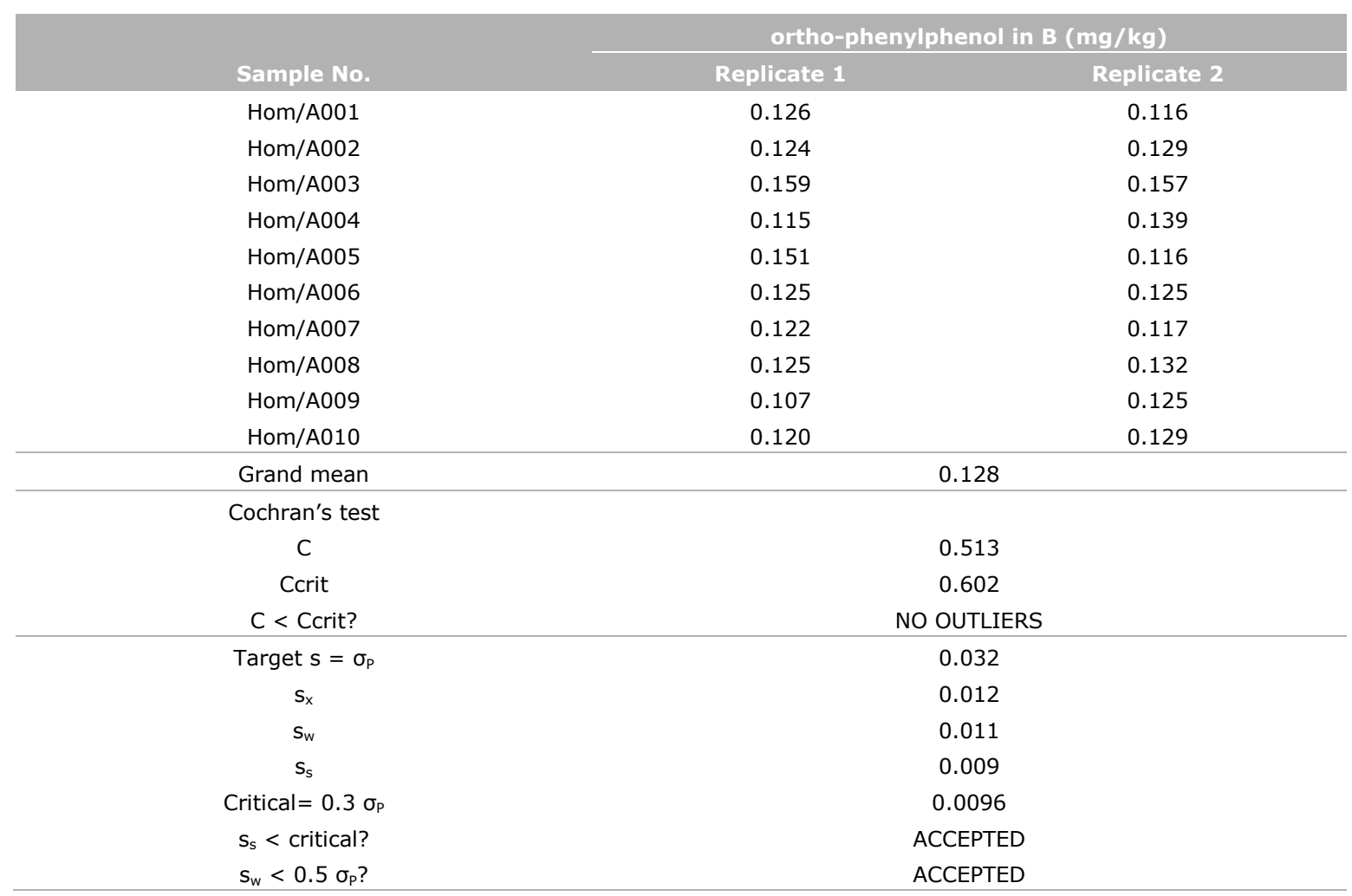

$\mathrm{s}_{\mathrm{x}}=$ Standard deviation of the sample averages.

$\mathrm{s}_{\mathrm{w}}=$ Within-sample standard deviation.

$\mathrm{s}_{\mathrm{s}}=$ Between-sample standard deviation. 


\begin{tabular}{|c|c|c|}
\hline \multirow[b]{2}{*}{ Sample No. } & \multicolumn{2}{|c|}{ pirimiphos-methyl in B $(\mathrm{mg} / \mathrm{kg})$} \\
\hline & Replicate 1 & Replicate 2 \\
\hline Hom/A001 & 0.254 & 0.228 \\
\hline Hom/A002 & 0.248 & 0.215 \\
\hline Hom/A003 & 0.239 & 0.229 \\
\hline Hom/A004 & 0.238 & 0.243 \\
\hline Hom/A005 & 0.234 & 0.238 \\
\hline Hom/A006 & 0.223 & 0.240 \\
\hline Hom/A007 & 0.229 & 0.237 \\
\hline Hom/A008 & 0.245 & 0.234 \\
\hline Hom/A009 & 0.209 & 0.228 \\
\hline $\mathrm{Hom} / \mathrm{A010}$ & 0.234 & 0.255 \\
\hline Grand mean & \multicolumn{2}{|c|}{0.235} \\
\hline \multicolumn{3}{|l|}{ Cochran's test } \\
\hline $\mathrm{C}$ & \multicolumn{2}{|c|}{0.341} \\
\hline Ccrit & \multicolumn{2}{|c|}{0.602} \\
\hline$C<$ Ccrit? & \multicolumn{2}{|c|}{ NO OUTLIERS } \\
\hline Target $\mathrm{s}=\sigma_{\mathrm{P}}$ & \multicolumn{2}{|c|}{0.059} \\
\hline$s_{x}$ & \multicolumn{2}{|c|}{0.007} \\
\hline $\mathrm{s}_{\mathrm{w}}$ & \multicolumn{2}{|c|}{0.013} \\
\hline $\mathrm{S}_{\mathrm{s}}$ & \multicolumn{2}{|c|}{0.0} \\
\hline Critical $=0.3 \sigma_{p}$ & \multicolumn{2}{|c|}{0.018} \\
\hline $\mathrm{S}_{\mathrm{s}}<$ critical? & \multicolumn{2}{|c|}{ ACCEPTED } \\
\hline $\mathrm{s}_{\mathrm{w}}<0.5 \sigma_{\mathrm{p}} ?$ & \multicolumn{2}{|c|}{ ACCEPTED } \\
\hline
\end{tabular}

$\mathrm{s}_{\mathrm{x}}=$ Standard deviation of the sample averages.

$\mathrm{S}_{\mathrm{w}}=$ Within-sample standard deviation.

$\mathrm{s}_{\mathrm{s}}=$ Between-sample standard deviation.

\begin{tabular}{|c|c|c|}
\hline Sample No. & \multicolumn{2}{|c|}{ tebuconazole in B ( $\mathrm{mg} / \mathrm{kg})$} \\
\hline Hom/A001 & 0.155 & 0.162 \\
\hline Hom/A003 & 0.160 & 0.161 \\
\hline Hom/A004 & 0.165 & 0.151 \\
\hline Hom/A006 & 0.157 & 0.150 \\
\hline Hom/A007 & 0.160 & 0.158 \\
\hline Hom/A008 & 0.158 & 0.165 \\
\hline Hom/A009 & 0.152 & 0.157 \\
\hline Hom/A010 & 0.159 & 0.147 \\
\hline \multicolumn{3}{|l|}{ Cochran's test } \\
\hline $\mathrm{C}$ & \multicolumn{2}{|c|}{0.374} \\
\hline Ccrit & \multicolumn{2}{|c|}{0.602} \\
\hline $\mathrm{C}<$ Ccrit? & \multicolumn{2}{|c|}{ NO OUTLIERS } \\
\hline Target $\mathrm{s}=\sigma_{\mathrm{p}}$ & \multicolumn{2}{|c|}{0.039} \\
\hline$s_{x}$ & \multicolumn{2}{|c|}{0.003} \\
\hline $\mathrm{S}_{\mathrm{w}}$ & \multicolumn{2}{|c|}{0.005} \\
\hline $\mathrm{s}_{\mathrm{s}}$ & \multicolumn{2}{|c|}{0.0} \\
\hline Critical $=0.3 \sigma_{p}$ & \multicolumn{2}{|c|}{0.012} \\
\hline $\mathrm{s}_{\mathrm{s}}<$ critical? & \multicolumn{2}{|c|}{ ACCEPTED } \\
\hline
\end{tabular}

$\mathrm{s}_{\mathrm{x}}=$ Standard deviation of the sample averages.

$\mathrm{s}_{\mathrm{w}}=$ Within-sample standard deviation.

$\mathrm{s}_{\mathrm{s}}=$ Between-sample standard deviation. 


\section{Annex 4 Statistical evaluation of stability data}

Statistical evaluation for antraquinone in material A.

\begin{tabular}{ccc} 
Storage temperature & $-18{ }^{\circ} \mathrm{C}$ & $4{ }^{\circ} \mathrm{C}$ \\
Time (days) & 0 & 56 \\
\hline Calculated amounts $(\mathrm{mg} / \mathrm{kg})$ & 0.081 & 0.097 \\
& 0.086 & 0.108 \\
\hline Average amount $(\mathrm{mg} / \mathrm{kg})$ & 0.098 & 0.115 \\
$\mathrm{n}$ & 0.089 & 0.106 \\
st. dev $(\mathrm{mg} / \mathrm{kg})$ & 3 & 3 \\
Difference & 0.009 & 0.009 \\
$0.3^{*} \sigma_{p}$ & & -0.018 \\
Consequential difference? Diff $<0.3^{*} \sigma_{\mathrm{p}}$ & & 0.007 \\
\hline
\end{tabular}

Statistical evaluation for biphenyl in material A.

\begin{tabular}{ccc} 
Storage temperature & $-18{ }^{\circ} \mathrm{C}$ & $4{ }^{\circ} \mathrm{C}$ \\
Time (days) & 0 & 56 \\
\hline Calculated amounts $(\mathrm{mg} / \mathrm{kg})$ & 0.110 & 0.171 \\
& 0.120 & 0.191 \\
\hline Average amount $(\mathrm{mg} / \mathrm{kg})$ & $*$ & 0.168 \\
$\mathrm{n}$ & 0.115 & 0.177 \\
st. dev $(\mathrm{mg} / \mathrm{kg})$ & 2 & 3 \\
\hline Difference & 0.007 & 0.012 \\
$0.3 * \sigma_{\mathrm{p}}$ & & -0.061 \\
\hline Consequential difference? Diff $<0.3 * \sigma_{\mathrm{p}}$ & 0.009 \\
\hline
\end{tabular}

*outlier according to grubbs"test

Statistical evaluation for cis-chlordane in material A.

\begin{tabular}{ccc} 
Storage temperature & $-18{ }^{\circ} \mathrm{C}$ & $4{ }^{\circ} \mathrm{C}$ \\
Time (days) & 0 & 56 \\
\hline Calculated amounts $(\mathrm{mg} / \mathrm{kg})$ & 0.043 & 0.031 \\
& 0.056 & 0.049 \\
Average amount $(\mathrm{mg} / \mathrm{kg})$ & 0.056 & 0.052 \\
$\mathrm{n}$ & 0.052 & 0.044 \\
st. dev $(\mathrm{mg} / \mathrm{kg})$ & 3 & 3 \\
\hline Difference & 0.008 & 0.011 \\
$0.3^{*} \sigma_{\mathrm{P}}$ & & 0.007 \\
Consequential difference? Diff $<0.3 * \sigma_{\mathrm{p}}$ & & 0.004 \\
\hline
\end{tabular}


Statistical evaluation for chlorpyrifos in material A.

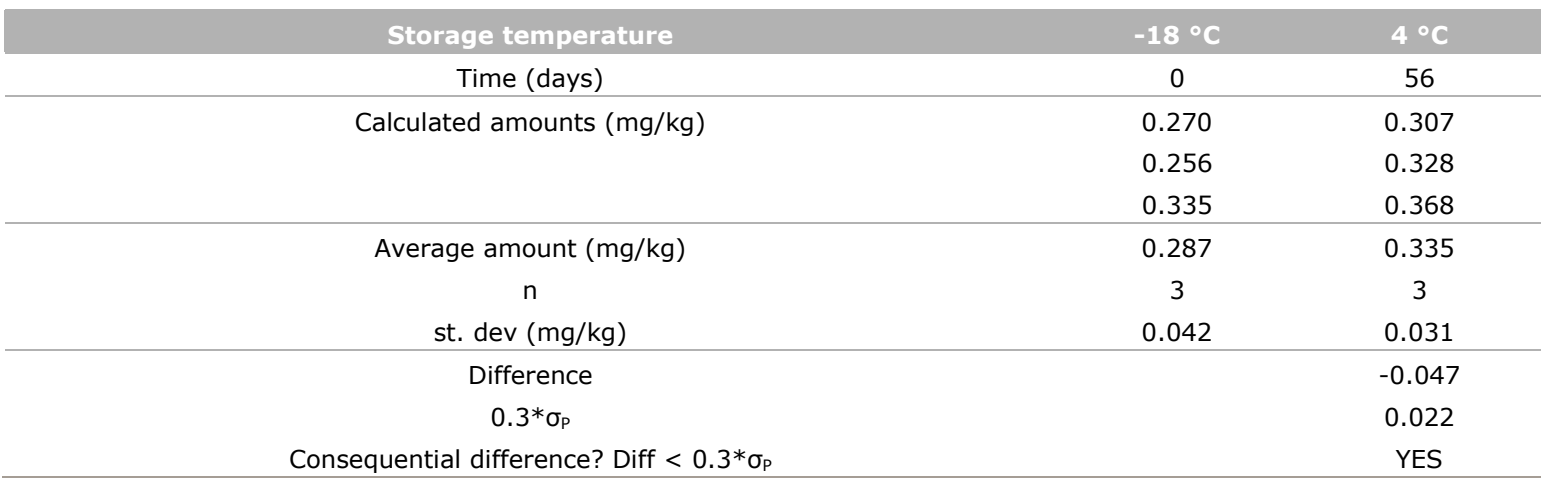

Statistical evaluation for $\boldsymbol{p}, \boldsymbol{p}^{\prime}-\mathbf{D D E}$ in material $\boldsymbol{A}$.

\begin{tabular}{|c|c|c|}
\hline Storage temperature & $-18^{\circ} \mathrm{C}$ & $4^{\circ} \mathrm{C}$ \\
\hline Time (days) & 0 & 56 \\
\hline \multirow[t]{2}{*}{ Calculated amounts (mg/kg) } & 0.041 & 0.044 \\
\hline & 0.041 & 0.053 \\
\hline Average amount (mg/kg) & 0.042 & 0.050 \\
\hline st. dev (mg/kg) & 0.001 & 0.005 \\
\hline Difference & & -0.008 \\
\hline $0.3^{*} \sigma_{\mathrm{p}}$ & & 0.003 \\
\hline Consequential difference? Diff $<0.3^{*} \sigma_{p}$ & & YES \\
\hline
\end{tabular}

Statistical evaluation for cis-deltamethrin in material A.

\begin{tabular}{|c|c|c|}
\hline Storage temperature & $-18^{\circ} \mathrm{C}$ & $4^{\circ} \mathrm{C}$ \\
\hline Time (days) & 0 & 56 \\
\hline \multirow[t]{2}{*}{ Calculated amounts (mg/kg) } & 0.086 & 0.109 \\
\hline & 0.083 & 0.148 \\
\hline Average amount $(\mathrm{mg} / \mathrm{kg})$ & 0.096 & 0.143 \\
\hline st. dev (mg/kg) & 0.020 & 0.032 \\
\hline Difference & & -0.047 \\
\hline $0.3^{*} \sigma_{\mathrm{P}}$ & & 0.007 \\
\hline Consequential difference? Diff $<0.3^{*} \sigma_{p}$ & & YES \\
\hline
\end{tabular}

Statistical evaluation for alpha-endosulfan in material A.

\begin{tabular}{|c|c|c|}
\hline Storage temperature & $-18^{\circ} \mathrm{C}$ & $4^{\circ} \mathrm{C}$ \\
\hline \multirow[t]{2}{*}{ Calculated amounts (mg/kg) } & 0.108 & 0.094 \\
\hline & 0.111 & 0.141 \\
\hline Average amount $(\mathrm{mg} / \mathrm{kg})$ & 0.110 & 0.120 \\
\hline st. dev (mg/kg) & 0.002 & 0.024 \\
\hline Difference & & -0.010 \\
\hline $0.3^{*} \sigma_{\mathrm{p}}$ & & 0.008 \\
\hline Consequential difference? Diff $<0.3^{*} \sigma_{p}$ & & YES \\
\hline
\end{tabular}


Statistical evaluation for endosulfan sulfate in material A.

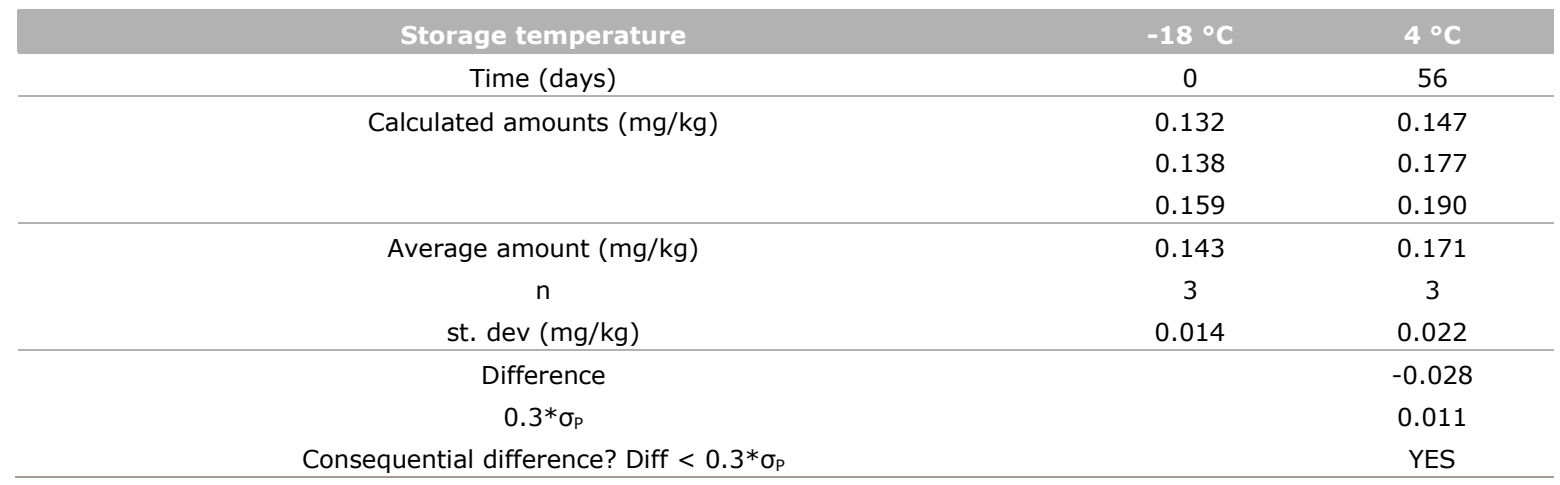

Statistical evaluation for pirimiphos-methyl in material A.

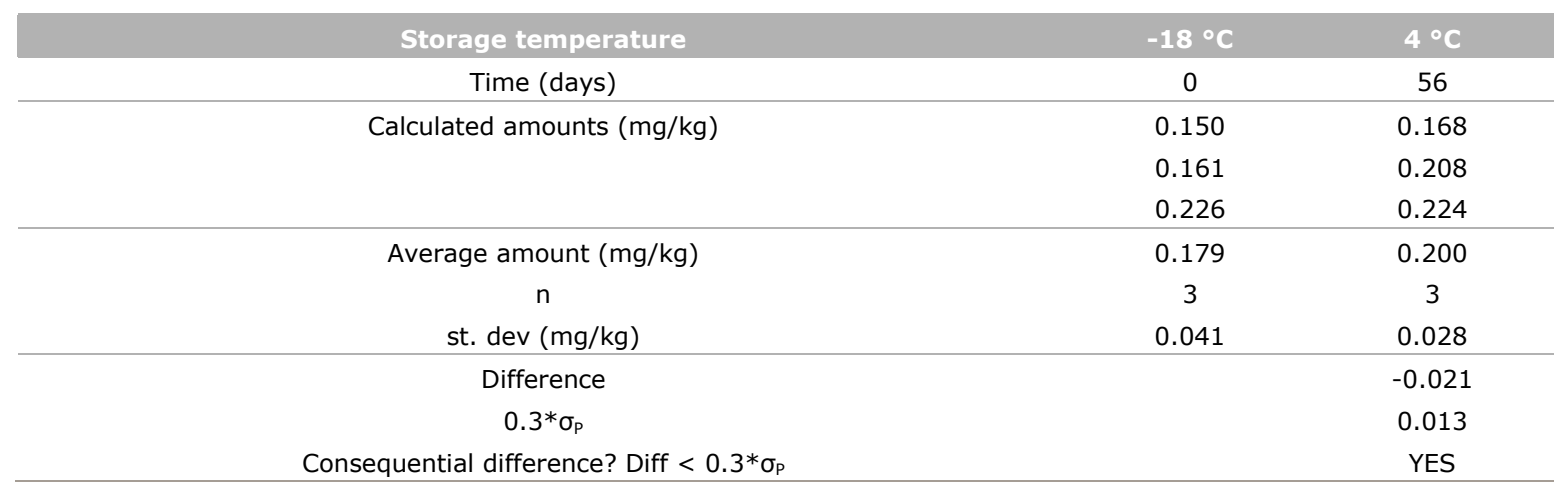

Statistical evaluation for azostrobin in material B.

\begin{tabular}{|c|c|c|}
\hline Storage temperature & $-18^{\circ} \mathrm{C}$ & $4^{\circ} \mathrm{C}$ \\
\hline \multirow[t]{4}{*}{ Calculated amounts (mg/kg) } & 0.446 & 0.439 \\
\hline & 0.413 & 0.411 \\
\hline & 0.355 & 0.437 \\
\hline & 0.463 & 0.439 \\
\hline Average amount (mg/kg) & 0.423 & 0.434 \\
\hline $\mathrm{n}$ & 6 & 6 \\
\hline st. dev (mg/kg) & 0.039 & 0.026 \\
\hline Difference & & -0.011 \\
\hline
\end{tabular}




\section{Statistical evaluation for boscalid in material B.}

\begin{tabular}{|c|c|c|}
\hline Storage temperature & $-18^{\circ} \mathrm{C}$ & $4^{\circ} \mathrm{C}$ \\
\hline \multirow[t]{4}{*}{ Calculated amounts (mg/kg) } & 1.16 & 1.16 \\
\hline & 1.15 & 1.13 \\
\hline & $*$ & 1.16 \\
\hline & 1.13 & 1.15 \\
\hline Average amount (mg/kg) & 1.16 & 1.15 \\
\hline $\mathrm{n}$ & 5 & 6 \\
\hline st. dev (mg/kg) & 0.020 & 0.020 \\
\hline Difference & & 0.010 \\
\hline
\end{tabular}

*outlier according to Grubbs test

Statistical evaluation for chlorpyrifos in material B.

\begin{tabular}{|c|c|c|}
\hline Storage temperature & $-18^{\circ} \mathrm{C}$ & $4^{\circ} \mathrm{C}$ \\
\hline Time (days) & 0 & 56 \\
\hline \multirow[t]{4}{*}{ Calculated amounts (mg/kg) } & 0.047 & 0.045 \\
\hline & 0.044 & 0.043 \\
\hline & 0.048 & 0.043 \\
\hline & 0.043 & 0.043 \\
\hline Average amount (mg/kg) & 0.045 & 0.043 \\
\hline $\mathrm{n}$ & 6 & 6 \\
\hline st. dev (mg/kg) & 0.002 & 0.001 \\
\hline Difference & & 0.002 \\
\hline
\end{tabular}

Statistical evaluation for cypermethrin in material B.

\begin{tabular}{|c|c|c|}
\hline Storage temperature & $-18^{\circ} \mathrm{C}$ & $4^{\circ} \mathrm{C}$ \\
\hline Time (days) & 0 & 56 \\
\hline \multirow[t]{4}{*}{ Calculated amounts (mg/kg) } & 0.070 & 0.058 \\
\hline & 0.067 & 0.066 \\
\hline & $*$ & 0.066 \\
\hline & 0.067 & 0.065 \\
\hline Average amount $(\mathrm{mg} / \mathrm{kg})$ & 0.067 & 0.064 \\
\hline $\mathrm{n}$ & 5 & 6 \\
\hline st. dev (mg/kg) & 0.006 & 0.003 \\
\hline Difference & & 0.003 \\
\hline
\end{tabular}

\footnotetext{
* Outlier according to Grubbs test
} 
Statistical evaluation for cyproconazole in material B.

\begin{tabular}{|c|c|c|}
\hline Storage temperature & $-18^{\circ} \mathrm{C}$ & $4^{\circ} \mathrm{C}$ \\
\hline Time (days) & 0 & 56 \\
\hline \multirow[t]{4}{*}{ Calculated amounts $(\mathrm{mg} / \mathrm{kg})$} & 0.074 & 0.069 \\
\hline & 0.073 & 0.072 \\
\hline & 0.078 & 0.071 \\
\hline & 0.068 & 0.071 \\
\hline Average amount $(\mathrm{mg} / \mathrm{kg})$ & 0.073 & 0.071 \\
\hline $\mathrm{n}$ & 6 & 6 \\
\hline st. dev (mg/kg) & 0.003 & 0.001 \\
\hline Difference & & 0.003 \\
\hline
\end{tabular}

Statistical evaluation for ortho-phenylphenol in material B.

\begin{tabular}{|c|c|c|}
\hline Storage temperature & $-18^{\circ} \mathrm{C}$ & $4^{\circ} \mathrm{C}$ \\
\hline Time (days) & 0 & 56 \\
\hline \multirow[t]{4}{*}{ Calculated amounts $(\mathrm{mg} / \mathrm{kg})$} & 0.139 & 0.138 \\
\hline & 0.138 & 0.146 \\
\hline & & 0.137 \\
\hline & 0.133 & 0.134 \\
\hline Average amount $(\mathrm{mg} / \mathrm{kg})$ & 0.139 & 0.137 \\
\hline $\mathrm{n}$ & 5 & 6 \\
\hline st. $\operatorname{dev}(\mathrm{mg} / \mathrm{kg})$ & 0.004 & 0.006 \\
\hline Difference & & 0.002 \\
\hline
\end{tabular}

Statistical evaluation for pirimiphos-methyl in material B.

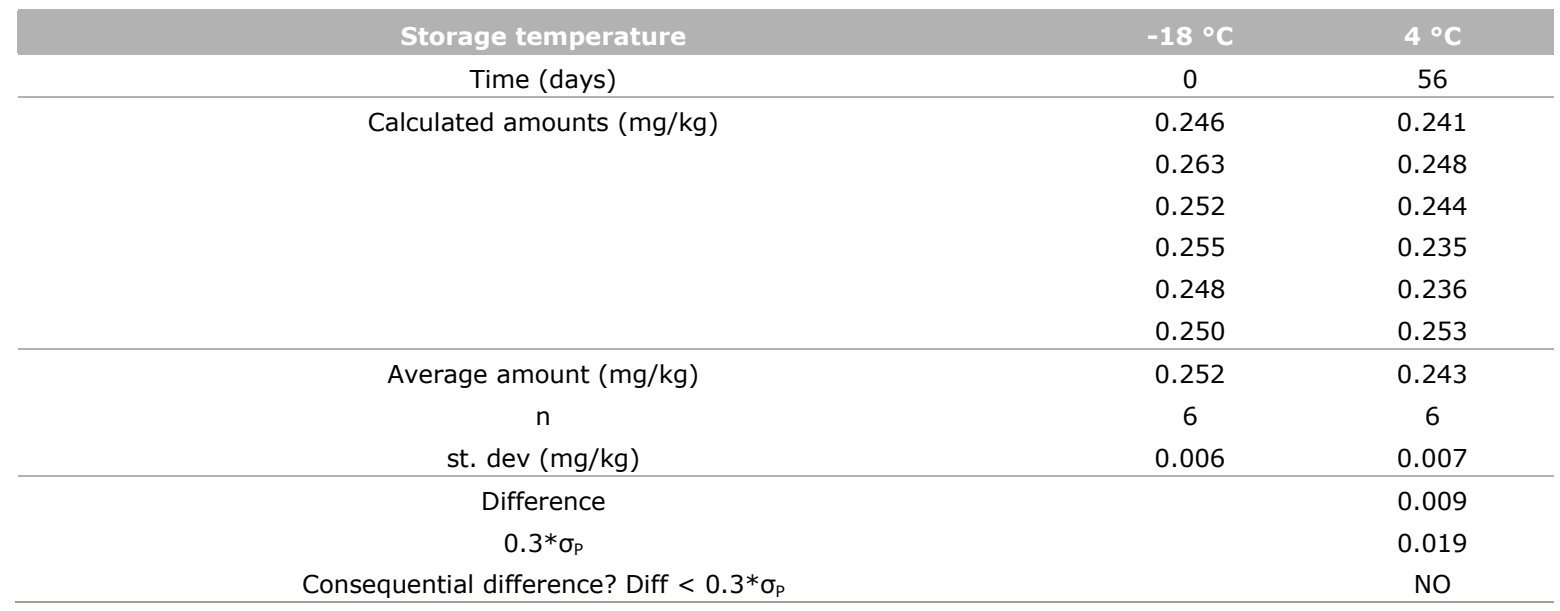




\section{Statistical evaluation for tebuconazole in material B.}

\begin{tabular}{|c|c|c|}
\hline Storage temperature & $-18^{\circ} \mathrm{C}$ & $4^{\circ} \mathrm{C}$ \\
\hline Time (days) & 0 & 56 \\
\hline \multirow[t]{6}{*}{ Calculated amounts (mg/kg) } & 0.156 & 0.161 \\
\hline & 0.168 & 0.161 \\
\hline & 0.154 & 0.169 \\
\hline & 0.176 & 0.166 \\
\hline & 0.171 & 0.162 \\
\hline & 0.161 & 0.163 \\
\hline Average amount (mg/kg) & 0.164 & 0.164 \\
\hline $\mathrm{n}$ & 6 & 6 \\
\hline st. dev (mg/kg) & 0.009 & 0.003 \\
\hline Difference & & 0.001 \\
\hline $0.3 * \sigma_{\mathrm{p}}$ & & 0.012 \\
\hline Consequential difference? Diff $<0.3^{*} \sigma_{p}$ & & NO \\
\hline
\end{tabular}




\section{Annex 5 Overview of the applied methods}

\begin{tabular}{|c|c|c|c|}
\hline \multicolumn{4}{|c|}{ Material A } \\
\hline Lab & Sample purification & Internal standard & Detection technique \\
\hline PT479 & Yes, Quechers & yes & MS/MS \\
\hline PT480 & None & Sulfotep, PCB 31 & "LC-MS/MS ，GC-MS/MS" \\
\hline PT484 & Quechers & & \\
\hline PT486 & Quechers & No & GC-MS \\
\hline PT488 & Thermal, Florisil, Solvent exchange, PSA, Thermal. In between centrifugation and in the end Filtration with RC. & LC $=$ Triphenylphosphate,$G C=$ PCD-153 & LC-TQ and GC-TQ \\
\hline PT491 & Extraction with CalfloE and Celite, GPC & $\begin{array}{l}\text { Triphenyl Phosphate and } \\
\text { Chloropyriphosethyl_D10 }\end{array}$ & GC-MS/MS and LC-MS/MS \\
\hline PT492 & Gel Permeation Chromatography & No & $\begin{array}{l}\text { HRGC-ECD - double column/double } \\
\text { detector system }\end{array}$ \\
\hline PT493 & dispersive PSA & no & LC-MS/MS and GC-MS/MS \\
\hline PT494 & $\begin{array}{l}2 \mathrm{~g} \text { of soy acid oil were mixed with } 10 \mathrm{~mL} \text { of } \mathrm{ACN} \text {, shacked for } 10 \mathrm{~min} \text { and centrifuged. } 8 \mathrm{~mL} \text { of the supernatant was } \\
\text { placed at }-18^{\circ} \mathrm{C} \text { for } 2 \text { hours and filtered into a tube containing } 150 \mathrm{mg} \mathrm{PSA} / 900 \mathrm{mg} \mathrm{MgSO} \text {. Shacked for } 10 \mathrm{~min} \\
\text { and centrifuged. }\end{array}$ & Tris-(1,3-dicloroisopropyl)-phosphat & $\begin{array}{l}\text { GC-MS/MS triple quadrupole and for } \\
\text { chlorpyrifos, cis-deltamethrin and } \\
\text { pirimiphos-methyl LC-MS/Ms triple } \\
\text { quadrupole was used }\end{array}$ \\
\hline PT497 & GPC, SPE Florisil & PCB 207 & $\begin{array}{l}\text { GC-ECD, two columns with different } \\
\text { phases }\end{array}$ \\
\hline PT500 & d-SPE with Agilent EMR Lipid removal followed by a polish step with $\mathrm{NaCl}$ and $\mathrm{MgSO} 4$ & Triphenylphosphate & GC-MS/MS, HPLC-MS/MS \\
\hline PT501 & Only Freeze & No Internal standard & $\begin{array}{l}\text { GC-ECD, GC-NP, for chlorpyrifos and } \\
\text { pirimiphos-methyl LC-MS/MS was used }\end{array}$ \\
\hline PT502 & dispersive SPE (PSA + C18) & Triphenylphosphate & $\begin{array}{l}\text { GC-MS/MS and LC-MS/MS (MRM } \\
\text { mode) }\end{array}$ \\
\hline \multicolumn{4}{|l|}{ PT503 } \\
\hline PT504 & GPC & Triphenylphosphate, Hexabroombenzeen & GC-MS/MS \\
\hline PT505 & extraction with hexane, clean up with $\mathrm{Al} 2 \mathrm{O} 3$ & Mirex & GC with ECD \\
\hline PT508 & liquid liquid extraction & yes & MS/MS \\
\hline PT510 & Thermal, Florisil, Solvent exchange, PSA, Thermal. In between centrifugation and in the end Filtration with RC & $\mathrm{LC}=$ Triphenylphosphate, $\mathrm{GC}=\mathrm{PCD}-153$ & LC-TQ and GC-TQ \\
\hline
\end{tabular}




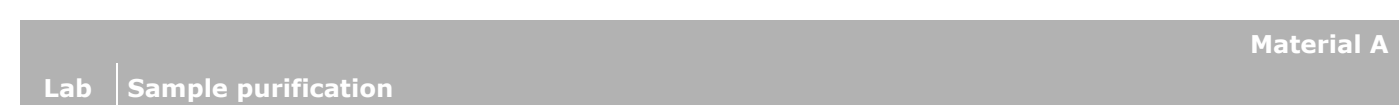

PT511 Dispersive SPE and chemical filtration PSA
Internal standard

tetrabromobenzene, Dichlorvos D6,

Terbutryn D5, Atrazine D5, Dimethoate

D6, Cypermethrin C13, Chlordane C13,

Alachlor D6, HCB C13, Antracene D12 and

Chlorpyryfos-methyl D6

\begin{tabular}{|c|c|c|c|}
\hline \multicolumn{4}{|c|}{ Material B } \\
\hline Lab & Sample purification & Internal standard & Detection technique \\
\hline PT479 & Quechers & yes & MS/MS \\
\hline PT480 & None & Sulfotep, PCB 31 & "LC-MS/MS ，GC-MS/MS" \\
\hline PT481 & Quechers extraction - Citrate buffered (EN 151662. Dispersive-SPE (Z-Sep) & $\begin{array}{l}\text { Triphenylphosphate and no internal } \\
\text { standard was used for azoxystrobin, } \\
\text { cypermethrin, cyproconazole and } \\
\text { tebuconazole. }\end{array}$ & $\begin{array}{l}\text { LC-MS/MS, ESI in positive mode and } \\
\text { for boscalid, chlorpirifos, ortho- } \\
\text { phenylphenol and pirimiphos-methyl } \\
\text { GC-MS/MS, Electron impact, positive } \\
\text { was used }\end{array}$ \\
\hline PT483 & $\begin{array}{l}5 \mathrm{~g} \text { soyabean meal, } 10 \mathrm{ml} \text { water, } 10 \mathrm{ml} \text { acetonitrile, extraction } 15 \mathrm{~min} \text {, freeze for } 30 \mathrm{~min} \text {, addition salts, mix, } \\
\text { centrifuge, remove } 8 \mathrm{ml} \mathrm{ACN} \mathrm{layer,} \mathrm{freeze} \mathrm{out} \mathrm{fat} \mathrm{over} \mathrm{night,} \mathrm{centrifuge,} \mathrm{clean} \mathrm{up} \mathrm{with} \mathrm{PSA/} \mathrm{C18} \mathrm{and} \mathrm{EMR;} \mathrm{another} \\
\text { sample purification for the pesticides chlorpyrifos, cypermetrhin and pirimiphos-methyl ( } 10 \mathrm{~g}, 100 \mathrm{ml} \text { water, } 25 \mathrm{~g} \\
\mathrm{NaCl}, 200 \mathrm{ml} \text { acetone, } 150 \mathrm{ml} \text { petrol ether, shake } 90 \mathrm{~min} \text {, wait for phase separation (overnight), filter, dry over } \\
\text { sodium sulfate, evaporate, GPC, small silica gel column with different elution solvents) }\end{array}$ & D6 chlorpyriphosmethyl & $\begin{array}{l}\text { LC-MS/MS and for chlorpyrifos, } \\
\text { cypermethrin and pirimiphos-methyl } \\
\text { GC-MS/MS was used }\end{array}$ \\
\hline \multicolumn{4}{|c|}{ PT484 } \\
\hline \multicolumn{4}{|l|}{ PT485 } \\
\hline PT486 & Quechers & NO & LC-MS/MS \\
\hline PT487 & dispersive SPE & & GC-MS/MS \\
\hline PT488 & thermal, Florisil, Thermal. In between centrifugation and at the end Filtration over RC. & $\begin{array}{l}\text { LC }=\text { TPP (Triphenylphosphate) GC = } \\
\text { PCB-153 }\end{array}$ & LC-TQ and GC-TQ \\
\hline PT489 & DSPE, freezing out & $\begin{array}{l}\text { Pirimicarb D6, Chlorpyrifos D10, } \\
\text { Nicarbazin }\end{array}$ & $\begin{array}{l}\text { "LC-MS/MS ，GC-MS/MS ，GC- } \\
\text { MS(NCI)" }\end{array}$ \\
\hline PT490 & d-SPE & PCB 209 & GC-MS/MS \\
\hline PT491 & dispersive SPE & $\begin{array}{l}\text { Triphenyl Phosphate and } \\
\text { Chloropyriphosetyhl_D10 }\end{array}$ & GC-MS/MS and LC-MS/MS \\
\hline PT492 & Quechers & No & GC/MSMS \\
\hline
\end{tabular}




\begin{tabular}{|c|c|c|c|}
\hline \multicolumn{4}{|c|}{ Material B } \\
\hline Lab & Sample purification & Internal standard & Detection technique \\
\hline PT493 & dispersive SPE PSA/C18 & No & LC-MS/MS and GC-MS/MS \\
\hline PT494 & $\begin{array}{l}5 \mathrm{~g} \text { of soyabean meal were procedured according to the method QuEChERS - Citrate buffered (EN 151662). Clean } \\
\text { up was done by freezing out, not by using C18-sorbent. }\end{array}$ & Tris-(1,3-dicloroisopropyl)-phosphat & $\begin{array}{l}\text { "LC-MS/MS triple quadrupole and for } \\
\text { ortho-phenylphenol GC-MS/MS triple } \\
\text { quadrupole was used }\end{array}$ \\
\hline PT497 & SPE Silica & PCB 207 & $\begin{array}{l}\text { GC-ECD, two columns with different } \\
\text { polar phases }\end{array}$ \\
\hline PT498 & QUECHERS & TTP & QQQ \\
\hline PT499 & QUECHERS PSA+C18+GCB & $\begin{array}{l}\text { dimethoate D6 used for all pesticides } \\
\text { except for chlorpyrifos, cypermethrin, } \\
\text { pirimiphos-methyl the internal standard } \\
\text { triphenylphosphate was used. }\end{array}$ & LC-QQQ \\
\hline PT500 & No clean-up is needed. Only extraction with acidified ethyl acetate. & TPP (Triphenylphosphate) & GC-MS/MS, HPLC-MS/MS \\
\hline PT501 & Only freeze & No Internal Standard & LC-MS/MS, \\
\hline PT502 & dispersive SPE (PSA + C18) & Triphenylphosphate & $\begin{array}{l}\text { GC-MS/MS and LC-MS/MS (MRM } \\
\text { mode) }\end{array}$ \\
\hline \multicolumn{4}{|l|}{ PT503 } \\
\hline PT504 & $\begin{array}{l}\text { Quechers and Gel Permeation Chromatography as sample purification for chlorpyrifos, cypermethrin, ortho- } \\
\text { phenylphenol and pirimiphos-methyl }\end{array}$ & $\begin{array}{l}\text { Triphenylphosphate, hexabroombenzeen } \\
\text { was used for the pesticides chlorpyrifos, } \\
\text { cypermethrin, ortho-phenylphenol and } \\
\text { pirimiphos-methyl and none internal } \\
\text { standard was used for the other pesticides. }\end{array}$ & $\begin{array}{l}\text { LC-MS/MS and for chlorpyrifos, } \\
\text { cypermethrin, ortho-phenylphenol and } \\
\text { pirimiphos-methyl GC-MS/MS was used }\end{array}$ \\
\hline PT505 & extraction with hexane, clean up with $\mathrm{Al} 2 \mathrm{O} 3$ & Mirex & GC with ECD \\
\hline PT506 & Sample was clean-up with freezing and with dispersive solid phase extraction - PSA,MgSO4,C18 & $\begin{array}{l}\text { TRIS(2-chloro-1- } \\
\text { (chloromethyl)ethyl)phosphate }\end{array}$ & $\begin{array}{l}\text { GC-MS single quadrupole, with SIM } \\
\text { mode from Agilent }\end{array}$ \\
\hline PT508 & liquid liquid extraction & yes & MS/MS \\
\hline \multicolumn{4}{|l|}{ PT509 } \\
\hline PT510 & Thermal, Florisil, Thermal. In between centrifugation and at the end Filtration over RC. & $\begin{array}{l}\text { LC }=\text { TPP (Triphenylphosphate), GC = } \\
\text { PCB-153 }\end{array}$ & LC-TQ and GC-TQ \\
\hline PT511 & Dispersive SPE and chemical filtration PSA & $\begin{array}{l}\text { tetrabromobenzene, Dichlorvos D6, } \\
\text { Terbutryn D5, Atrazine D5, Dimethoate } \\
\text { D6, Cypermethrin C13, Chlordane C13, } \\
\text { Alachlor D6, HCB C13, Antracene D12 and } \\
\text { Chlorpyryfos-methyl D6 }\end{array}$ & GC MS/MS and LC-MS/S \\
\hline
\end{tabular}




\section{Annex 6 Results material A}

\begin{tabular}{|c|c|c|c|c|c|c|}
\hline \multirow[b]{2}{*}{$\begin{array}{l}\text { Lab } \\
\text { code }\end{array}$} & \multicolumn{2}{|c|}{$\begin{array}{c}\text { anthraquinone } \\
\mathrm{CV}: 0.072 \mathrm{mg} / \mathrm{kg} \\
\text { u: } 0.008 \mathrm{mg} / \mathrm{kg} \\
\sigma_{\mathrm{p}}: 0.018 \mathrm{mg} / \mathrm{kg} \\
\text { robust } 0: 0.017 \mathrm{mg} / \mathrm{kg}\end{array}$} & \multicolumn{2}{|c|}{$\begin{array}{c}\text { biphenyl } \\
\text { CV: } 0.144 \mathrm{mg} / \mathrm{kg} \\
\text { u: } 0.007 \mathrm{mg} / \mathrm{kg} \\
\sigma_{\mathrm{p}}: 0.036 \mathrm{mg} / \mathrm{kg} \\
\text { robust } 0: 0.019 \mathrm{mg} / \mathrm{kg}\end{array}$} & \multicolumn{2}{|c|}{$\begin{array}{c}\text { cis-chlordane } \\
\text { CV: } 0.030 \mathrm{mg} / \mathrm{kg} \\
\text { u: } 0.001 \mathrm{mg} / \mathrm{kg} \\
\sigma_{\mathrm{p}}: 0.007 \mathrm{mg} / \mathrm{kg} \\
\text { robust } \sigma: 0.003 \mathrm{mg} / \mathrm{kg}\end{array}$} \\
\hline & $\begin{array}{c}\text { Result } \\
\text { (mg/kg) }\end{array}$ & $z_{a}^{\prime}$-score & $\begin{array}{c}\text { Result } \\
\text { (mg/kg) }\end{array}$ & $\mathrm{z}_{\mathrm{a}}$-score & $\begin{array}{c}\text { Result } \\
\text { (mg/kg) }\end{array}$ & $\mathrm{z}_{\mathrm{ai}}$-score \\
\hline PT479 & 0.08 & 0.40 & 0.154 & 0.29 & 0.025 & -0.66 \\
\hline PT480 & 0.076 & 0.20 & 0.147 & 0.09 & 0.024 & -0.80 \\
\hline PT481 & nt & & nt & & nt & \\
\hline PT483 & nt & & $\mathrm{nt}$ & & $\mathrm{nt}$ & \\
\hline \multicolumn{7}{|l|}{ PT484 } \\
\hline \multicolumn{7}{|l|}{ PT485 } \\
\hline PT486 & $\mathrm{nt}$ & & 0.074 & -1.94 & nt & \\
\hline PT487 & $\mathrm{nt}$ & & $\mathrm{nt}$ & & $\mathrm{nt}$ & \\
\hline PT488 & 0.04 & -1.64 & 0.15 & 0.17 & 0.03 & 0.00 \\
\hline \multicolumn{7}{|l|}{ PT489 } \\
\hline PT490 & nt & & nt & & nt & \\
\hline PT491 & nt & & 0.325 & 5.04 & nd & \\
\hline PT492 & nt & & nt & & 0.033 & 0.40 \\
\hline PT493 & nt & & nt & & 0.053 & 3.07 \\
\hline PT494 & nt & & 0.14 & -0.10 & nd & \\
\hline PT497 & nt & & nt & & 0.028 & -0.26 \\
\hline \multicolumn{7}{|l|}{ PT498 } \\
\hline PT499 & nt & & nt & & nt & \\
\hline PT500 & nt & & 0.2 & 1.57 & 0.031 & 0.14 \\
\hline PT501 & nt & & nt & & nd & \\
\hline PT502 & 0.085 & 0.66 & 0.131 & -0.35 & 0.032 & 0.27 \\
\hline PT503 & nt & & nt & & nd & \\
\hline PT504 & 0.071 & -0.06 & 0.144 & 0.01 & nd & \\
\hline PT505 & & & & & $<0.05$ & \\
\hline PT506 & nt & & $\mathrm{nt}$ & & nt & \\
\hline PT508 & 0.065 & -0.36 & 0.06 & -2.33 & nd & \\
\hline PT509 & $\mathrm{nt}$ & & $\mathrm{nt}$ & & $\mathrm{nt}$ & \\
\hline PT510 & 0.042 & -1.54 & 0.151 & 0.20 & 0.03 & 0.00 \\
\hline PT511 & 0.104 & 1.63 & 0.126 & -0.49 & nd & \\
\hline $\mathrm{CV}$ & \multicolumn{6}{|c|}{$=$ consensus value } \\
\hline$=$ & \multicolumn{6}{|c|}{$=$ uncertainty of consensus value. } \\
\hline$=$ & \multicolumn{6}{|c|}{$=$ not tested. } \\
\hline nd $=$ & \multicolumn{6}{|c|}{$=$ not detected } \\
\hline
\end{tabular}




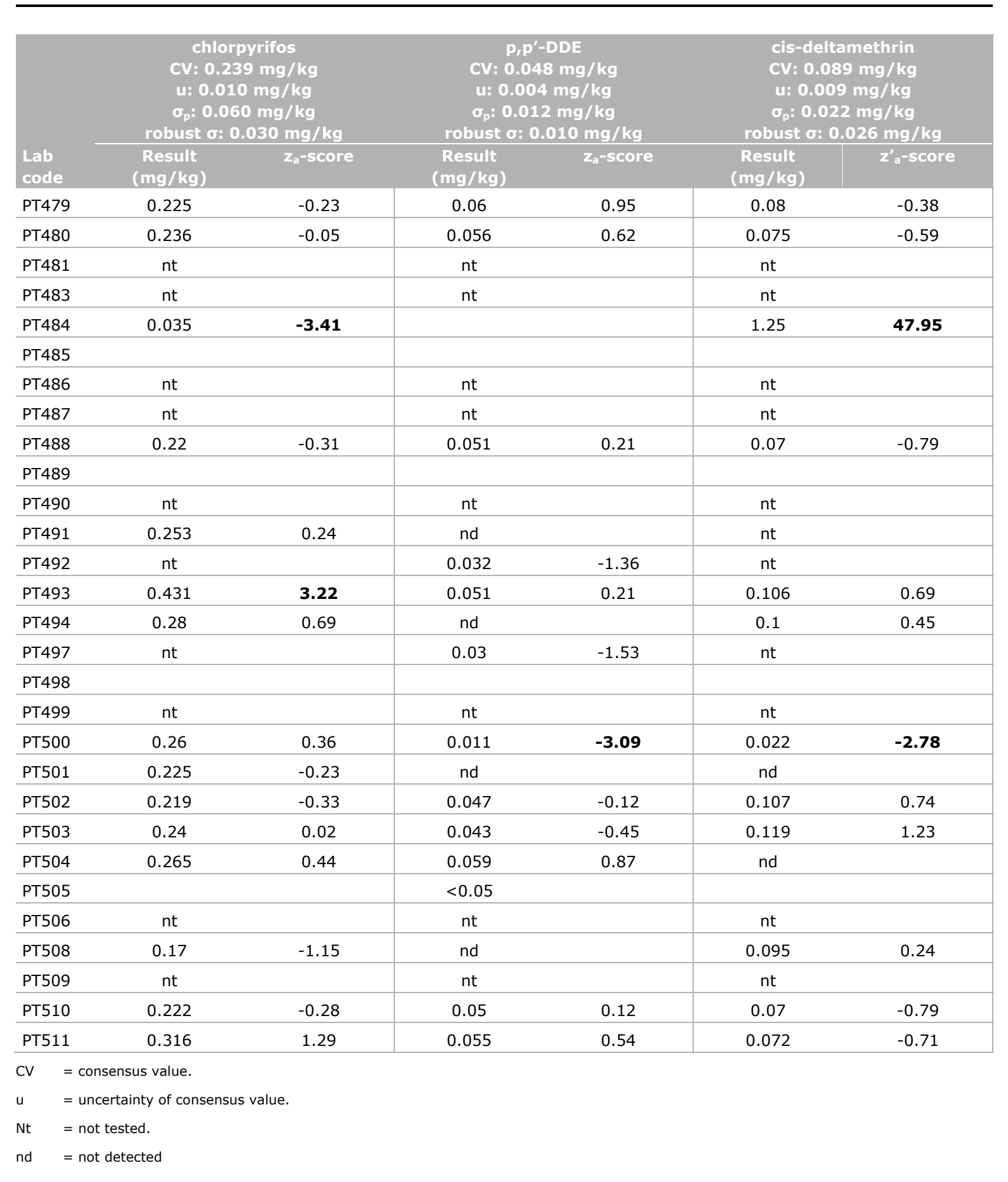




\begin{tabular}{|c|c|c|c|c|}
\hline \multirow[b]{2}{*}{$\begin{array}{l}\text { Lab } \\
\text { code }\end{array}$} & \multirow{2}{*}{$\begin{array}{l}\text { alpha-endosulfan } \\
\text { CV: } 0.077 \mathrm{mg} / \mathrm{kg} \\
\text { u: } 0.014 \mathrm{mg} / \mathrm{kg} \\
\sigma_{\mathrm{p}}: 0.019 \mathrm{mg} / \mathrm{kg} \\
\text { robust o: } 0.041 \mathrm{mg} / \mathrm{kg} \\
\text { Result } \\
\text { (mg/kg) }\end{array}$} & $\begin{array}{c}\text { endosulfan-sulfate } \\
\text { CV: } 0.134 \mathrm{mg} / \mathrm{kg} \\
\text { u: } 0.011 \mathrm{mg} / \mathrm{kg} \\
\sigma_{\mathrm{p}}: 0.034 \mathrm{mg} / \mathrm{kg} \\
\text { robust } \sigma: 0.028 \mathrm{mg} / \mathrm{kg}\end{array}$ & \multicolumn{2}{|c|}{$\begin{array}{c}\text { pirimiphos-methyl } \\
\text { CV: } 0.178 \mathrm{mg} / \mathrm{kg} \\
\text { u: } 0.013 \mathrm{mg} / \mathrm{kg} \\
\sigma_{\mathrm{p}}: 0.045 \mathrm{mg} / \mathrm{kg} \\
\text { robust o: } 0.038 \mathrm{mg} / \mathrm{kg}\end{array}$} \\
\hline & & $\begin{array}{l}\text { Result } \quad z_{a}^{\prime} \text {-score } \\
(\mathrm{mg} / \mathrm{kg})\end{array}$ & $\begin{array}{l}\text { Result } \\
(\mathrm{mg} / \mathrm{kg})\end{array}$ & $z_{a}$-score \\
\hline PT479 & $0.02 \quad$ No statistical & nd & nd & \\
\hline PT480 & evaluation & nd & 0.13 & -1.08 \\
\hline PT481 & nt & nt & nt & \\
\hline PT483 & nt & nt & nt & \\
\hline \multicolumn{5}{|l|}{ PT484 } \\
\hline \multicolumn{5}{|l|}{ PT485 } \\
\hline PT486 & nd & nd & nd & \\
\hline PT487 & nt & nt & nt & \\
\hline PT488 & 0.075 & nd & 0.162 & -0.36 \\
\hline \multicolumn{5}{|l|}{ PT489 } \\
\hline PT490 & nt & nt & nt & \\
\hline PT491 & nt & nd & 0.161 & -0.39 \\
\hline PT492 & 0.061 & 0.101 & nt & \\
\hline PT493 & 0.104 & 0.45 & 0.186 & 0.17 \\
\hline PT494 & nd & 0.15 & 0.19 & 0.26 \\
\hline PT497 & 0.063 & 0.144 & nt & \\
\hline \multicolumn{5}{|l|}{ PT498 } \\
\hline PT499 & nt & nt & nt & \\
\hline PT500 & 0.11 & -0.68 & 0.25 & 1.61 \\
\hline PT501 & nd & nd & 0.108 & -1.58 \\
\hline PT502 & 0.102 & 0.109 & 0.207 & 0.65 \\
\hline PT503 & 0.093 & 0.124 & 0.193 & 0.33 \\
\hline PT504 & nd & 0.121 & 0.188 & 0.22 \\
\hline PT505 & 0.114 & & & \\
\hline PT506 & nt & nt & nt & \\
\hline PT508 & 0.02 & 0.158 & 0.138 & -0.90 \\
\hline PT509 & nt & nt & nt & \\
\hline PT510 & 0.07 & & 0.164 & -0.32 \\
\hline PT511 & 0.123 & 0.264 & 0.226 & 1.07 \\
\hline$=$ & \multicolumn{4}{|l|}{$=$ consensus value. } \\
\hline$=$ & \multicolumn{4}{|l|}{$=$ uncertainty of consensus value. } \\
\hline nt $\quad=$ & \multicolumn{4}{|l|}{$=$ not tested. } \\
\hline nd $=$ & \multicolumn{4}{|l|}{$=$ not detected } \\
\hline
\end{tabular}




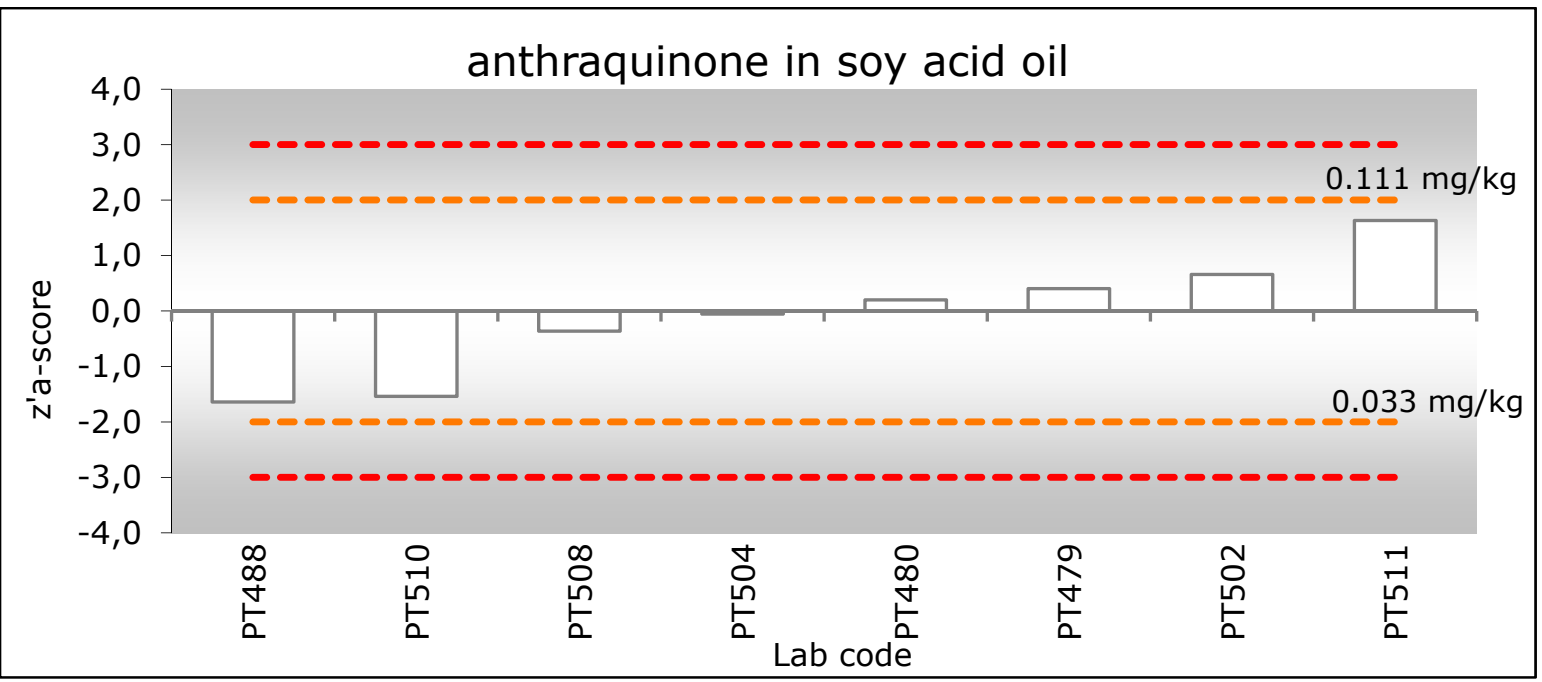

Figure a Graphical representation of the $z_{a}^{\prime}$-scores for anthraquinone. The $X \pm 2 \sigma_{P}$ lines (dotted) are calculated according to equation II in $\S 3.4$.

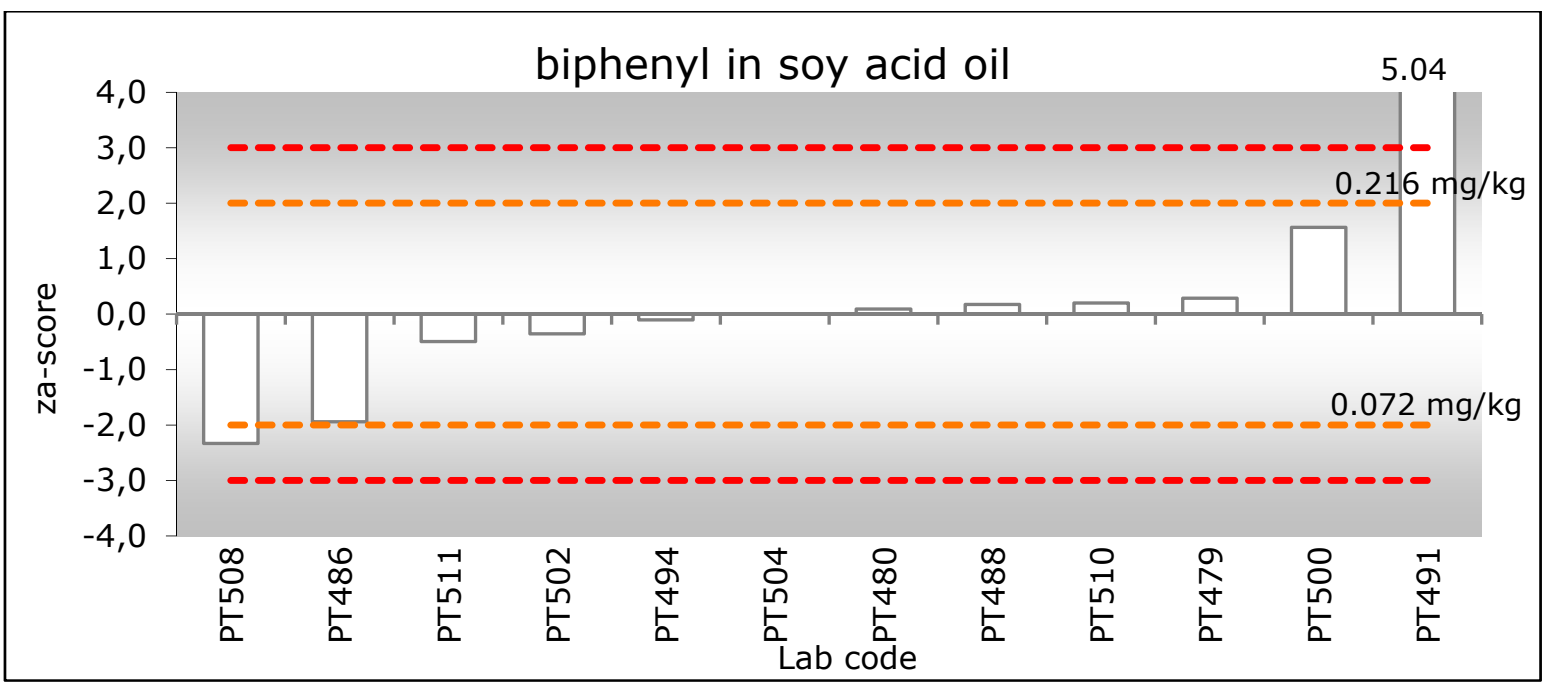

Figure $\boldsymbol{b} \quad$ Graphical representation of the $z_{a}$-scores for biphenyl. The $X \pm 2 \sigma_{p}$ lines (dotted) are calculated according to equation I in $\$ 3.4$.

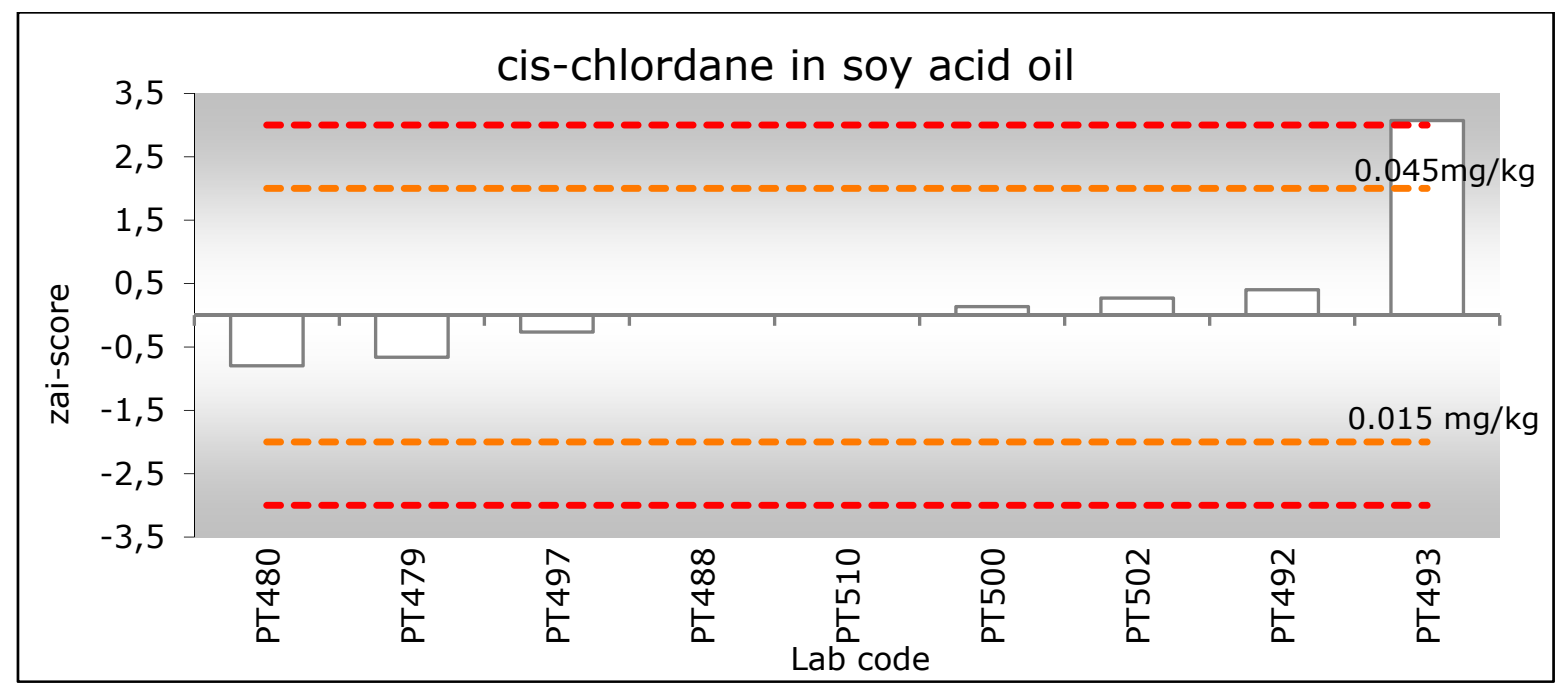

Figure $\boldsymbol{c}$ Graphical representation of the $z_{a i}$-scores for cis-chlordane. The $X \pm 2 \sigma_{p}$ lines (dotted) are calculated according to equation III in §3.4. 


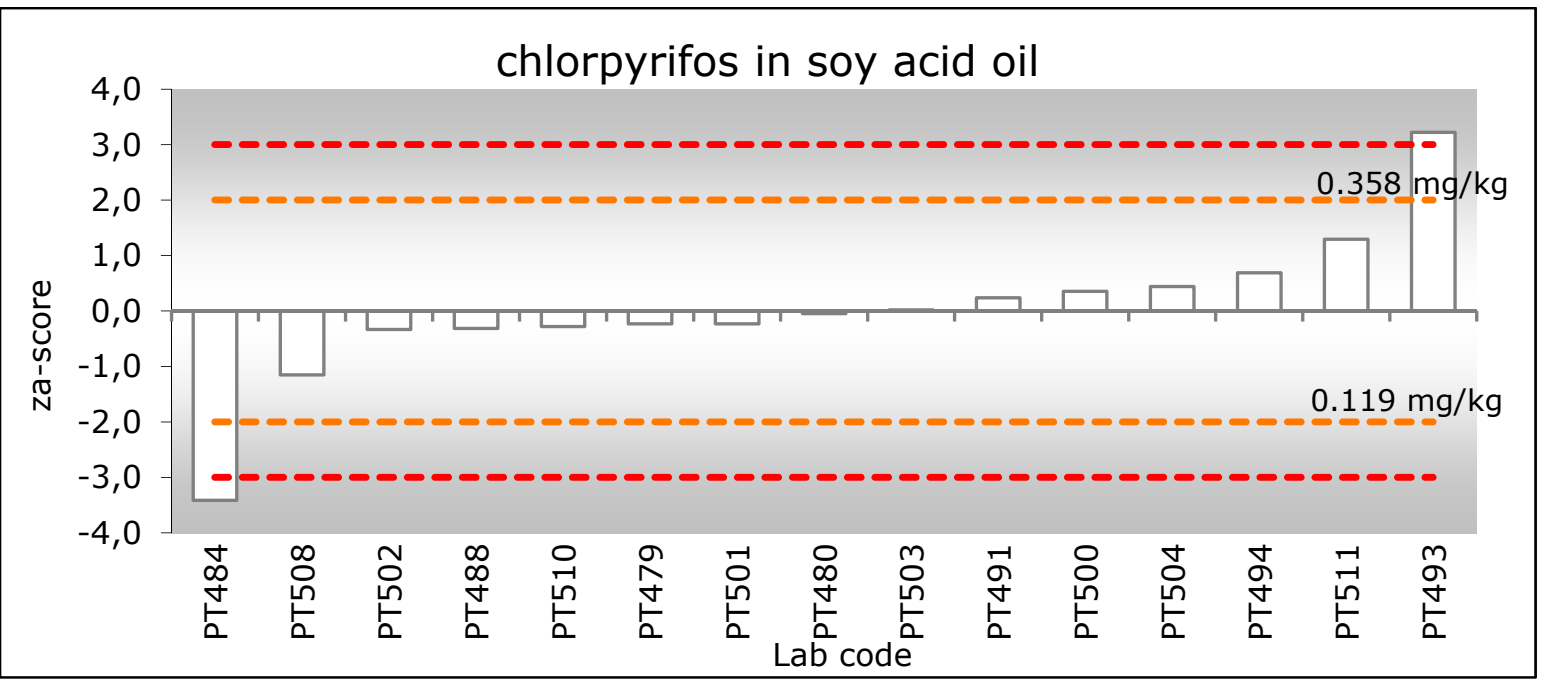

Figure d Graphical representation of the $z_{a}$-scores for chlorpyrifos. The $X \pm 2 \sigma_{P}$ lines (dotted) are calculated according to equation I in $\$ 3.4$

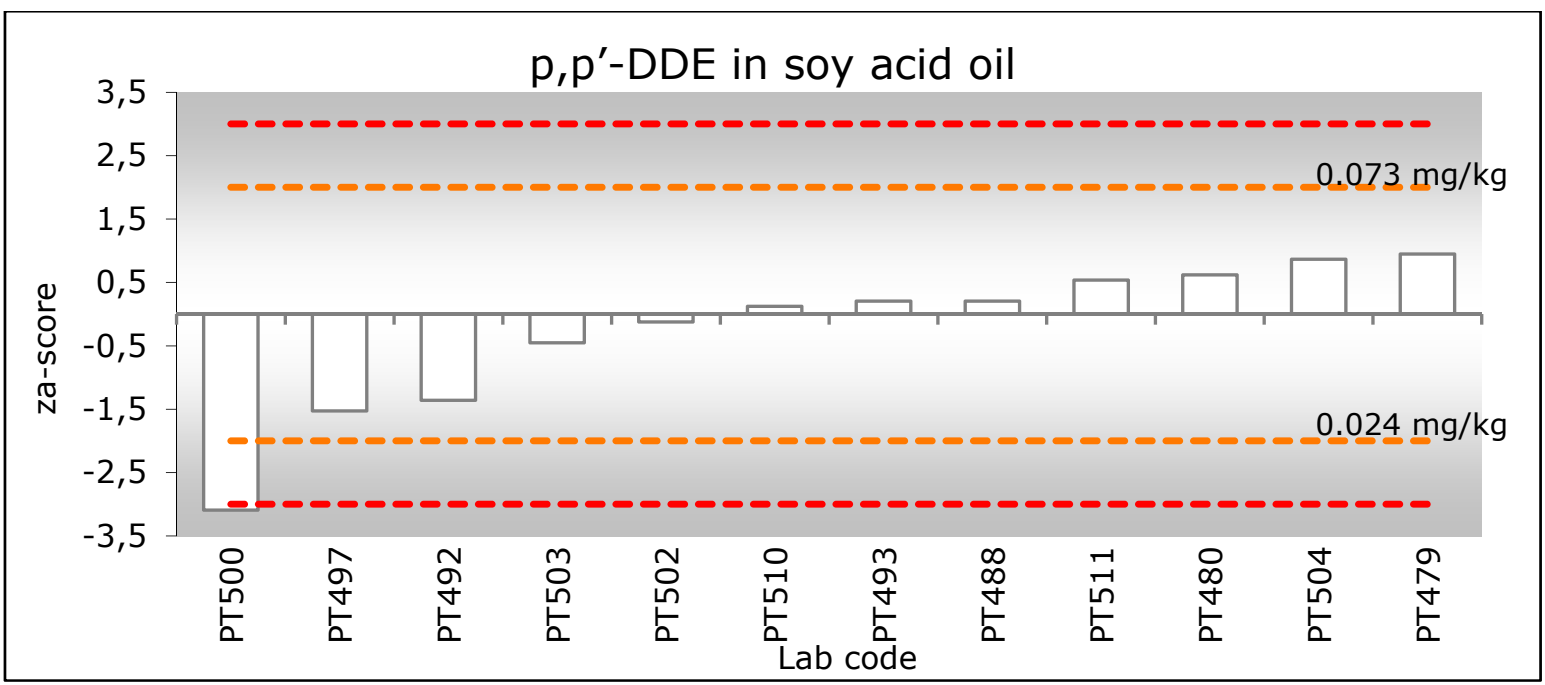

Figure e Graphical representation of the $z_{a}$-scores for $p, p^{\prime}-D D E$. The $X \pm 2 \sigma_{p}$ lines (dotted) are calculated according to equation I in §3.4.

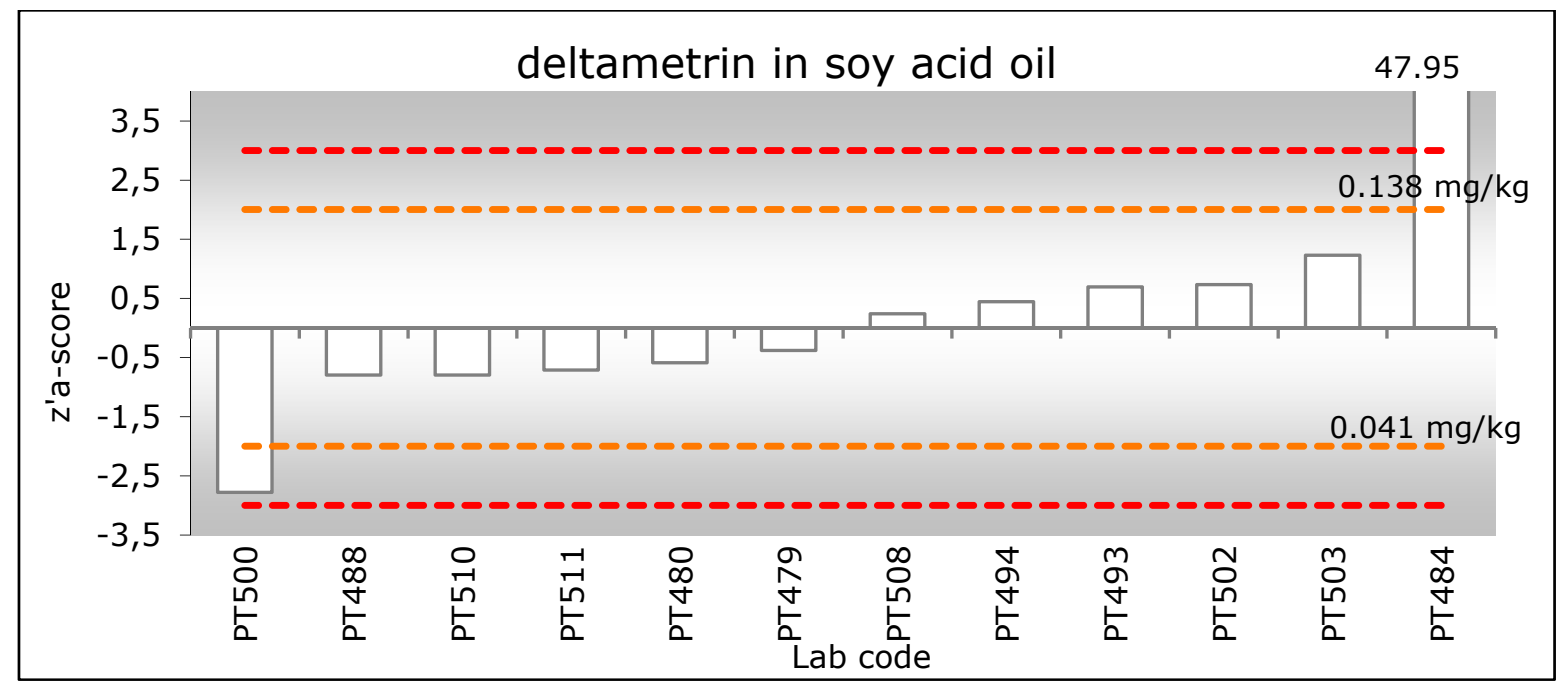

Figure $\boldsymbol{f} \quad$ Graphical representation of the $z_{a}^{\prime}$-scores for cis-deltamethrin. The $X \pm 2 \sigma_{p}$ lines (dotted) are calculated according to equation II in $\$ 3.4$. 


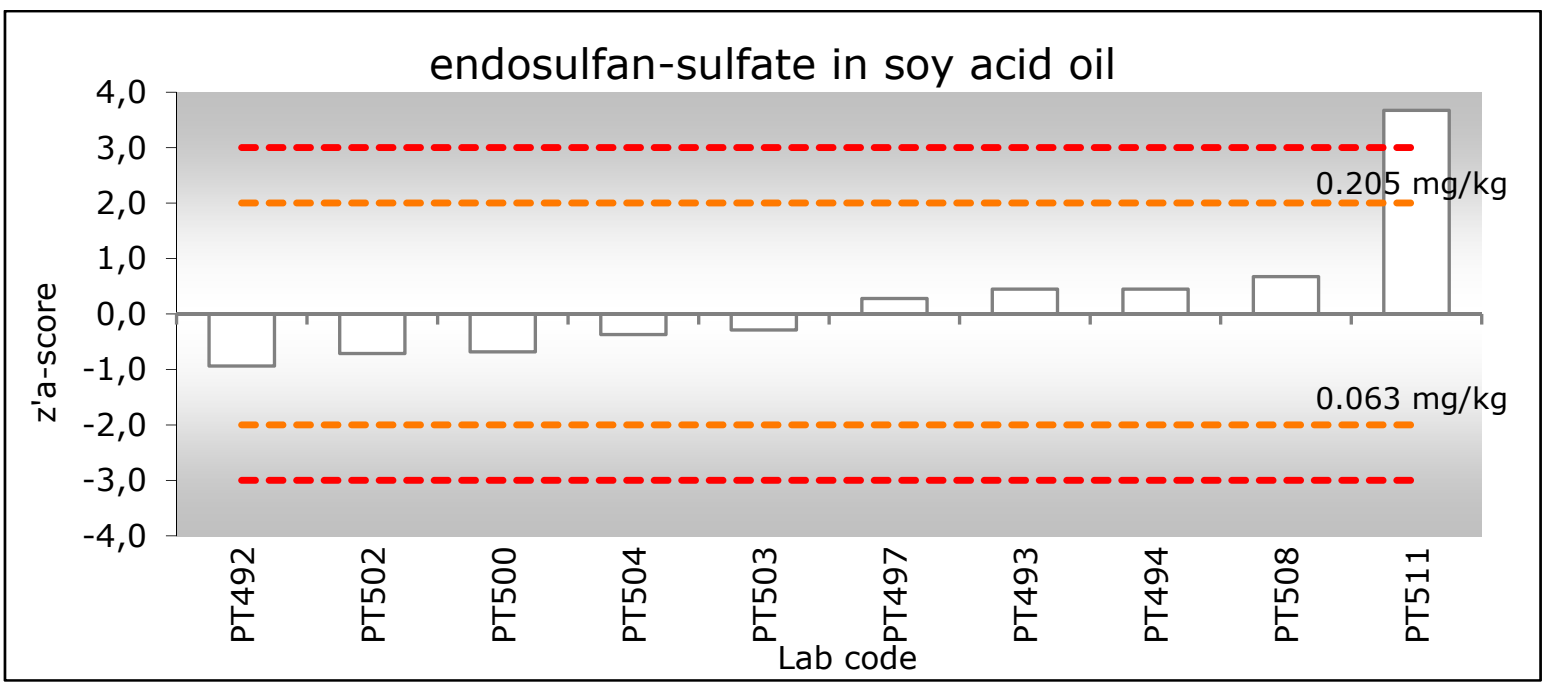

Figure $\boldsymbol{g}$ Graphical representation of the $z_{a}^{\prime}$-scores for endosulfan-sulfate. The $X \pm 2 \sigma_{P}$ lines (dotted) are calculated according to equation II in $\$ 3.4$.

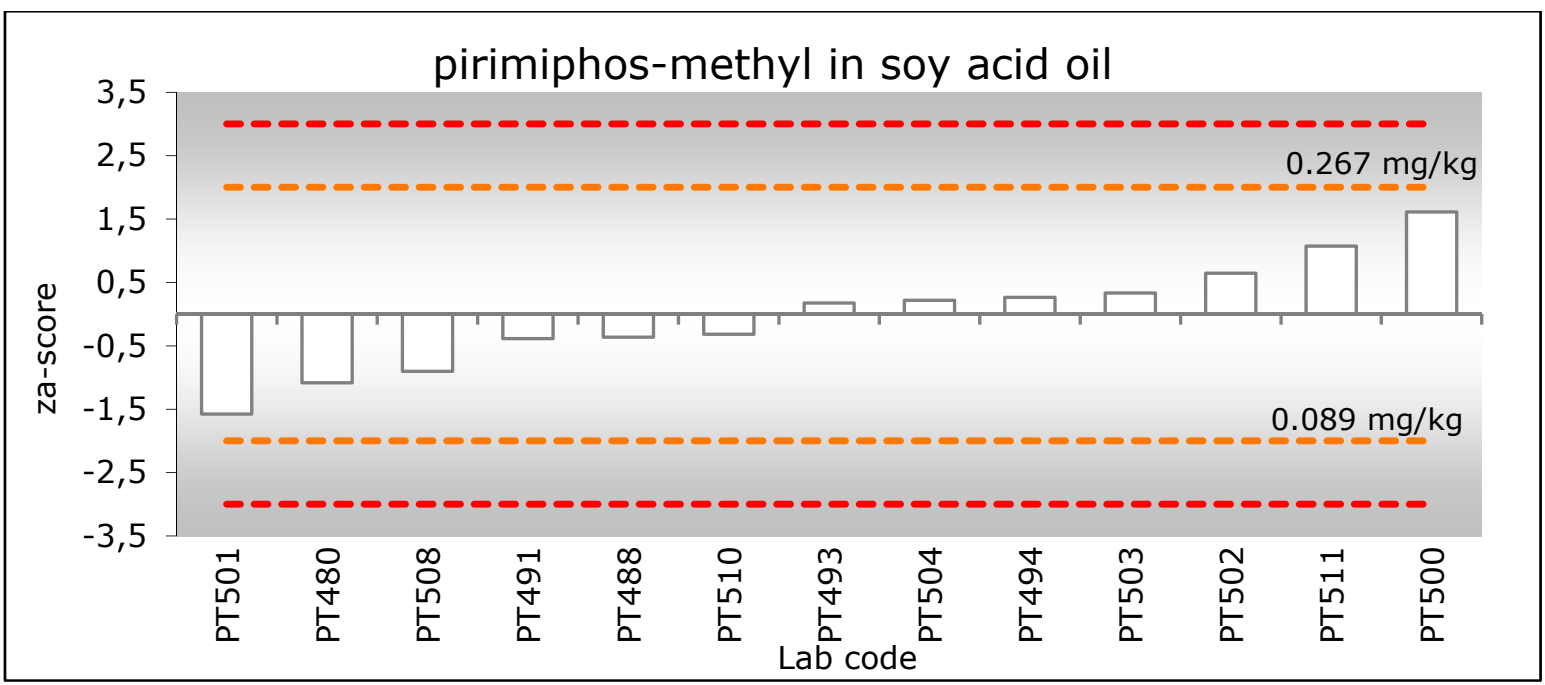

Figure $\boldsymbol{h} \quad$ Graphical representation of the $z_{a}$-scores for pirimiphos-methyl. The $X \pm 2 \sigma_{P}$ lines (dotted) are calculated according to equation I in \$3.4. 


\section{Annex 7 Results material B}

\begin{tabular}{|c|c|c|c|c|c|c|}
\hline \multirow[b]{2}{*}{$\begin{array}{l}\text { Lab } \\
\text { code }\end{array}$} & \multicolumn{2}{|c|}{$\begin{array}{c}\text { azoxystrobin } \\
\text { CV: } 0.379 \mathrm{mg} / \mathrm{kg} \\
\text { u: } 0.017 \mathrm{mg} / \mathrm{kg} \\
\sigma_{\mathrm{p}}: 0.095 \mathrm{mg} / \mathrm{kg} \\
\text { robust } 0: 0.065 \mathrm{mg} / \mathrm{kg}\end{array}$} & \multicolumn{2}{|c|}{$\begin{array}{c}\text { boscalid } \\
\text { CV: } 0.999 \mathrm{mg} / \mathrm{kg} \\
\text { u: } 0.070 \mathrm{mg} / \mathrm{kg} \\
\sigma_{\mathrm{p}}: 0.250 \mathrm{mg} / \mathrm{kg} \\
\text { robust } 0: 0.262 \mathrm{mg} / \mathrm{kg}\end{array}$} & \multicolumn{2}{|c|}{$\begin{array}{c}\text { chlorpyrifos } \\
\text { CV: } 0.039 \mathrm{mg} / \mathrm{kg} \\
\text { u: } 0.003 \mathrm{mg} / \mathrm{kg} \\
\sigma_{p}: 0.010 \mathrm{mg} / \mathrm{kg} \\
\text { robust } \sigma: 0.010 \mathrm{mg} / \mathrm{kg} \\
\end{array}$} \\
\hline & $\begin{array}{c}\text { Result } \\
\text { (mg/kg) }\end{array}$ & $z_{a}$-score & $\begin{array}{c}\text { Result } \\
\text { (mg/kg) }\end{array}$ & $\mathrm{z}_{\mathrm{a}}$-score & $\begin{array}{c}\text { Result } \\
\text { (mg/kg) }\end{array}$ & $\mathrm{z}_{\mathrm{a}}$-score \\
\hline PT479 & 0.28 & -1.05 & 0.8 & -0.80 & 0.038 & -0.11 \\
\hline PT480 & 0.289 & -0.95 & 0.855 & -0.58 & 0.042 & 0.30 \\
\hline PT481 & 0.427 & 0.50 & 0.841 & -0.63 & 0.0526 & 1.38 \\
\hline PT483 & 0.404 & 0.26 & 1.006 & 0.03 & 0.036 & -0.32 \\
\hline PT484 & 0.407 & 0.29 & 1.09 & 0.36 & 0.032 & -0.73 \\
\hline PT485 & nt & & nt & & nt & \\
\hline PT486 & $\mathrm{nt}$ & & $\mathrm{nt}$ & & nt & \\
\hline PT487 & 0.127 & -2.66 & 0.818 & -0.72 & 0.03 & -0.93 \\
\hline PT488 & 0.258 & -1.28 & 0.75 & -1.00 & 0.032 & -0.73 \\
\hline PT489 & 0.358 & -0.22 & 1.179 & 0.72 & 0.05 & 1.12 \\
\hline PT490 & nt & & nt & & nt & \\
\hline PT491 & 0.424 & 0.47 & 1.282 & 1.13 & 0.054 & 1.52 \\
\hline PT492 & nt & & nt & & nt & \\
\hline PT493 & 0.447 & 0.71 & 1.186 & 0.75 & 0.049 & 1.01 \\
\hline PT494 & 0.41 & 0.32 & 1.3 & 1.20 & 0.048 & 0.91 \\
\hline PT497 & nt & & nt & & nt & \\
\hline PT498 & 0.408 & 0.30 & 0.798 & -0.80 & 0.035 & -0.42 \\
\hline PT499 & 0.45 & 0.75 & 1.1 & 0.40 & 0.044 & 0.50 \\
\hline PT500 & 0.3 & -0.84 & 0.99 & -0.04 & 0.047 & 0.81 \\
\hline PT501 & 0.426 & 0.49 & 1.38 & 1.53 & 0.0275 & -1.19 \\
\hline PT502 & 0.369 & -0.11 & 1.232 & 0.93 & 0.043 & 0.40 \\
\hline PT503 & 0.397 & 0.19 & 1.07 & 0.28 & 0.038 & -0.11 \\
\hline PT504 & 0.41 & 0.32 & 1.35 & 1.41 & 0.012 & -2.77 \\
\hline \multicolumn{7}{|l|}{ PT505 } \\
\hline PT506 & 0.429 & 0.52 & 0.813 & -0.74 & nd & \\
\hline PT508 & 0.026 & -3.73 & 0.136 & -3.46 & 0.012 & -2.77 \\
\hline PT509 & 0.489 & 1.16 & nt & & 0.047 & 0.81 \\
\hline PT510 & 0.255 & -1.31 & 0.749 & -1.00 & 0.035 & -0.42 \\
\hline PT511 & 0.21 & -1.79 & 0.775 & -0.90 & 0.033 & -0.62 \\
\hline CV & \multicolumn{6}{|c|}{$=$ consensus value. } \\
\hline$=$ & \multicolumn{6}{|c|}{ = uncertainty of consensus value. } \\
\hline$=$ & \multicolumn{6}{|c|}{$=$ not tested. } \\
\hline$=$ & \multicolumn{6}{|c|}{$=$ not detected } \\
\hline
\end{tabular}




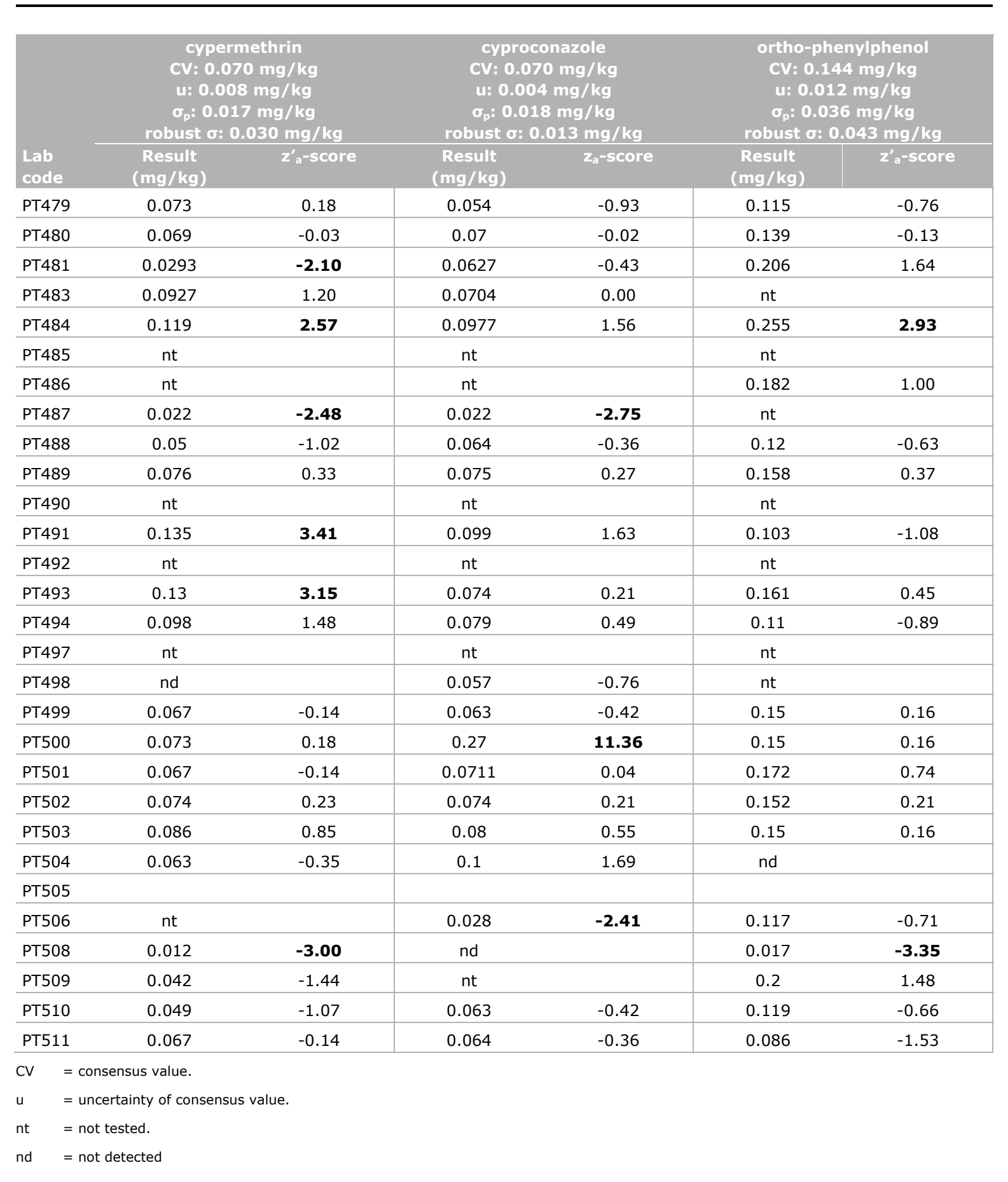




\begin{tabular}{|c|c|c|c|c|}
\hline \multirow[b]{6}{*}{$\begin{array}{l}\text { Lab } \\
\text { code }\end{array}$} & \multirow{5}{*}{\multicolumn{2}{|c|}{$\begin{array}{c}\text { pirimiphos-methyl } \\
\text { CV: } 0.224 \mathrm{mg} / \mathrm{kg} \\
\text { u: } 0.016 \mathrm{mg} / \mathrm{kg} \\
\sigma_{\mathrm{p}}: 0.056 \mathrm{mg} / \mathrm{kg} \\
\text { robust o: } 0.061 \mathrm{mg} / \mathrm{kg} \\
\end{array}$}} & \multirow{5}{*}{\multicolumn{2}{|c|}{$\begin{array}{c}\text { tebuconazole } \\
\text { CV: } 0.168 \mathrm{mg} / \mathrm{kg} \\
\text { u: } 0.010 \mathrm{mg} / \mathrm{kg} \\
\sigma_{\mathrm{p}}: 0.042 \mathrm{mg} / \mathrm{kg} \\
\text { robust o: } 0.038 \mathrm{mg} / \mathrm{kg}\end{array}$}} \\
\hline & & & & \\
\hline & & & & \\
\hline & & & & \\
\hline & & & & \\
\hline & $\begin{array}{l}\text { Result } \\
\text { (mg/kg) }\end{array}$ & $\mathrm{z}_{\mathrm{a}}$-score & $\begin{array}{l}\text { Result } \\
\text { (mg/kg) }\end{array}$ & $\mathbf{z}_{\mathrm{a}}$-score \\
\hline PT479 & 0.21 & -0.25 & 0.15 & -0.42 \\
\hline PT480 & 0.214 & -0.18 & 0.153 & -0.35 \\
\hline PT481 & 0.349 & 2.23 & 0.177 & 0.22 \\
\hline PT483 & 0.209 & -0.27 & 0.197 & 0.70 \\
\hline РT484 & & & 0.186 & 0.44 \\
\hline PT485 & nt & & nt & \\
\hline PT486 & 0.326 & 1.82 & nt & \\
\hline PT487 & 0.156 & -1.22 & 0.145 & -0.54 \\
\hline PT488 & 0.16 & -1.15 & 0.129 & -0.92 \\
\hline PT489 & 0.241 & 0.30 & 0.192 & 0.58 \\
\hline PT490 & nt & & $\mathrm{nt}$ & \\
\hline PT491 & 0.273 & 0.87 & 0.203 & 0.84 \\
\hline PT492 & $\mathrm{Nt}$ & & nt & \\
\hline PT493 & 0.258 & 0.60 & 0.198 & 0.72 \\
\hline PT494 & 0.26 & 0.64 & 0.19 & 0.53 \\
\hline PT497 & nt & & nt & \\
\hline PT498 & 0.218 & -0.11 & 0.159 & -0.21 \\
\hline PT499 & 0.28 & 1.00 & 0.12 & -1.14 \\
\hline PT500 & 0.21 & -0.25 & 0.23 & 1.49 \\
\hline PT501 & 0.215 & -0.16 & 0.137 & -0.73 \\
\hline PT502 & 0.262 & 0.67 & 0.162 & -0.14 \\
\hline PT503 & 0.247 & 0.41 & 0.192 & 0.58 \\
\hline PT504 & 0.047 & -3.16 & 0.21 & 1.01 \\
\hline PT505 & & & & \\
\hline PT506 & 0.251 & 0.48 & 0.167 & -0.02 \\
\hline PT508 & 0.051 & -3.09 & 0.021 & -3.50 \\
\hline PT509 & 0.269 & 0.80 & 0.204 & 0.87 \\
\hline PT510 & 0.157 & -1.20 & 0.129 & -0.92 \\
\hline PT511 & 0.17 & -0.97 & 0.122 & -1.09 \\
\hline$=c$ & alue. & & & \\
\hline$=\iota$ & of consensus value. & & & \\
\hline $\mathrm{nt}: \quad=\mathrm{r}$ & & & & \\
\hline nd $=$ & & & & \\
\hline
\end{tabular}




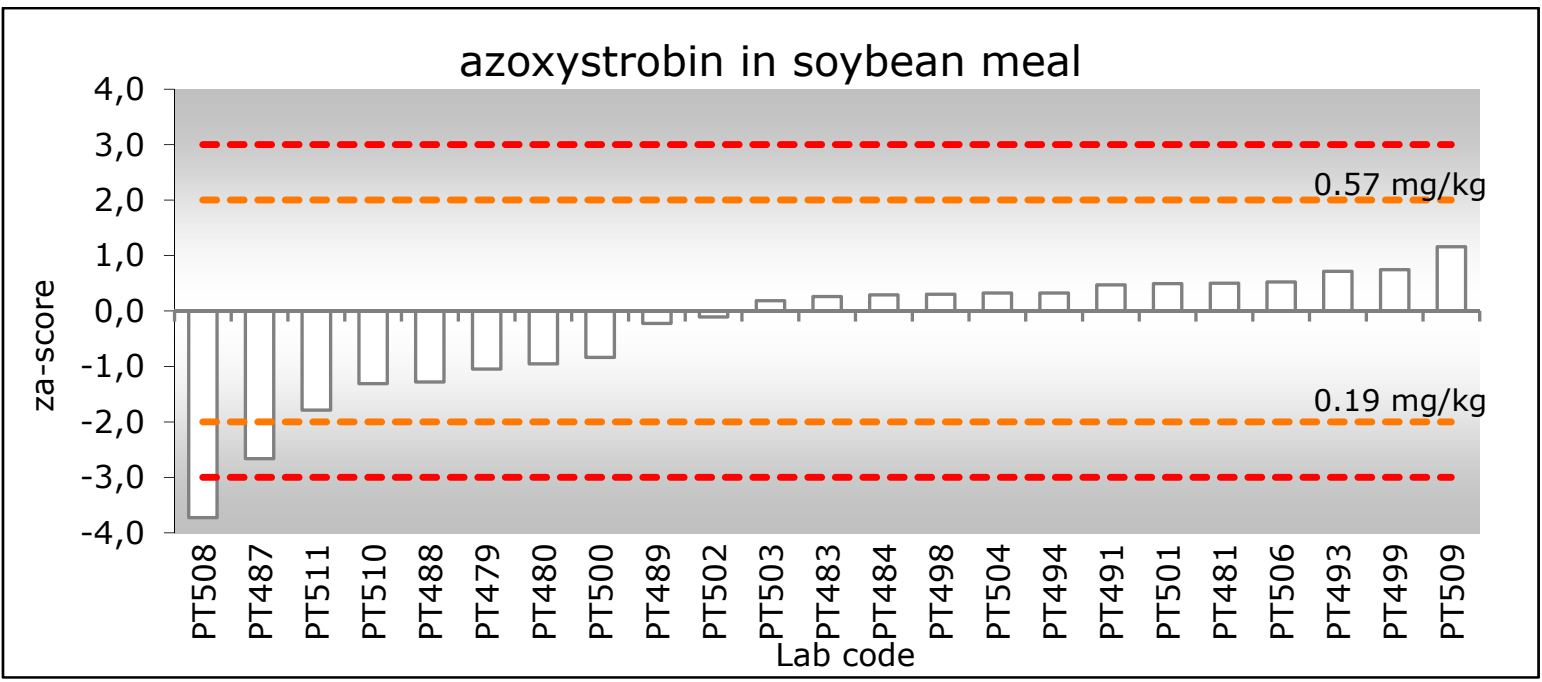

Figure $\boldsymbol{i} \quad$ Graphical representation of the $z_{a}$-scores for azoxystrobin. The $X \pm 2 \sigma_{P}$ lines (dotted) are calculated according to equation I in §3.4.

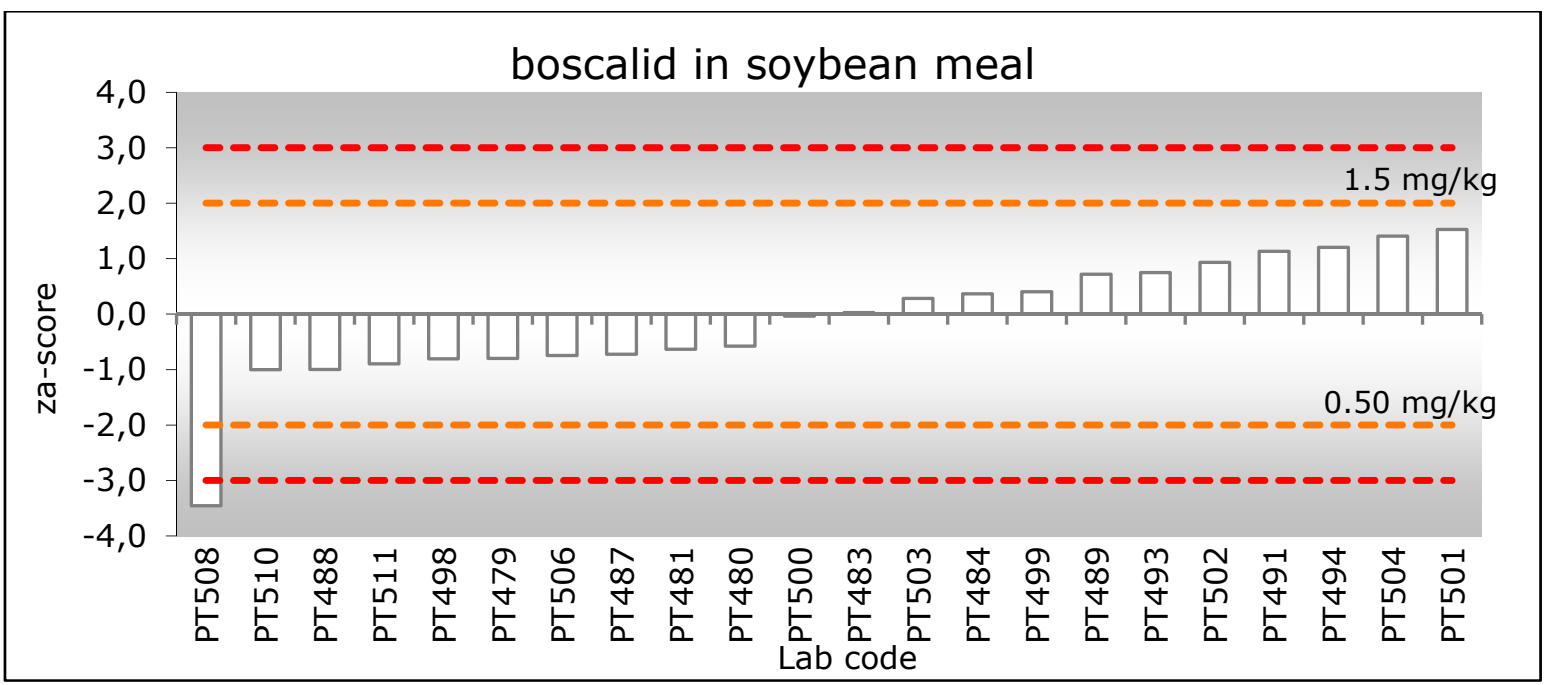

Figure $\boldsymbol{j} \quad$ Graphical representation of the $z_{a}$-scores for boscalid. The $X \pm 2 \sigma_{p}$ lines (dotted) are calculated according to equation I in $\$ 3.4$.

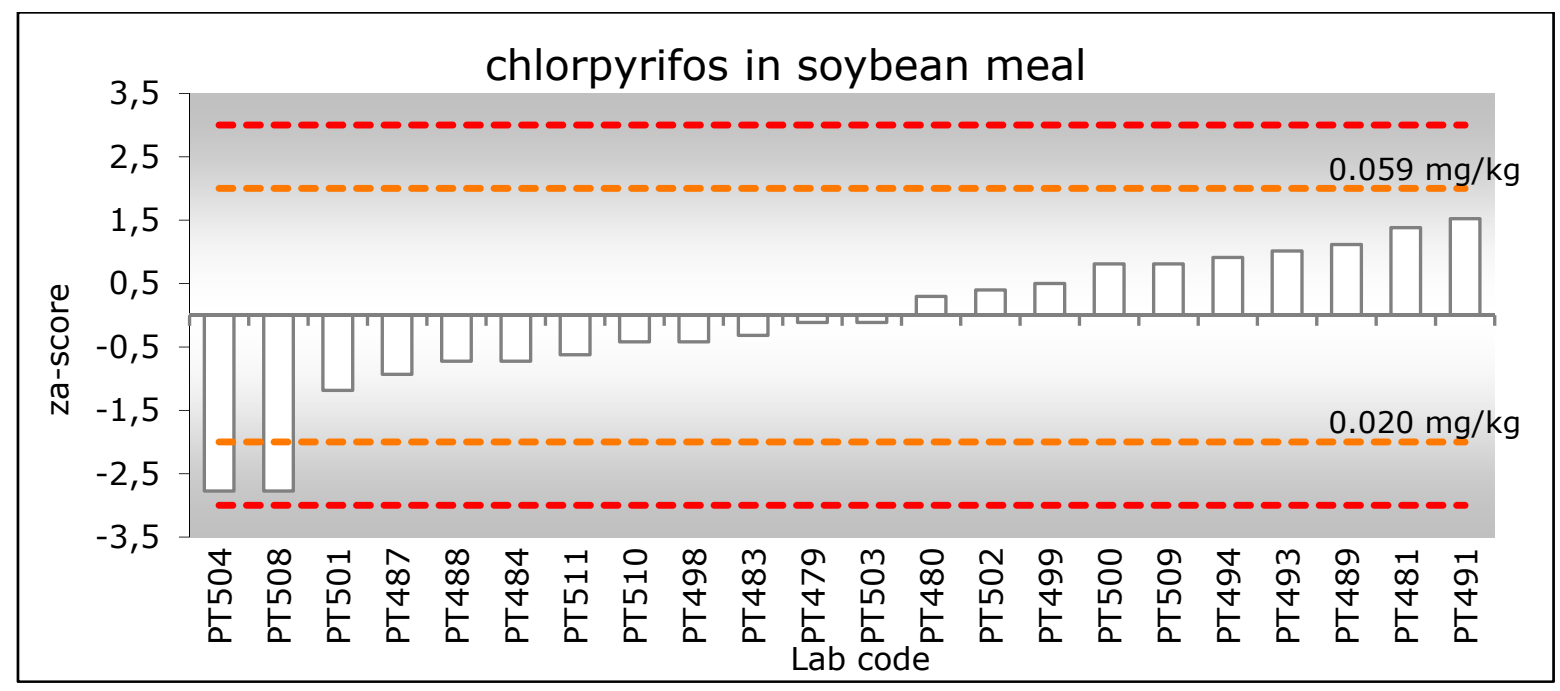

Figure $\boldsymbol{k} \quad$ Graphical representation of the $z_{a}$-scores for chlorpyrifos. The $X \pm 2 \sigma_{P}$ lines (dotted) are calculated according to equation I in \$3.4. 


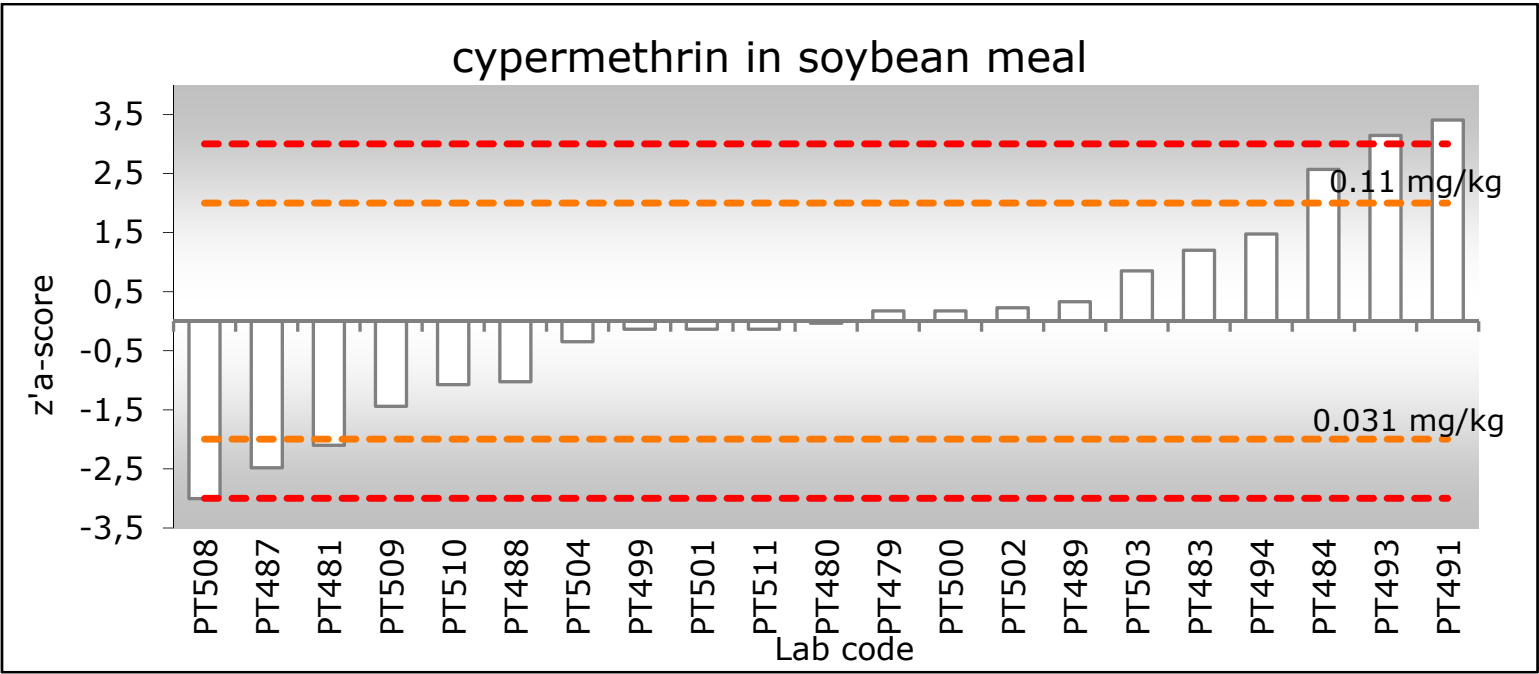

Figure I Graphical representation of the $z_{a}^{\prime}$-scores for cypermethrin. The $X \pm 2 \sigma_{P}$ lines (dotted) are calculated according to equation II in $\S 3.4$.

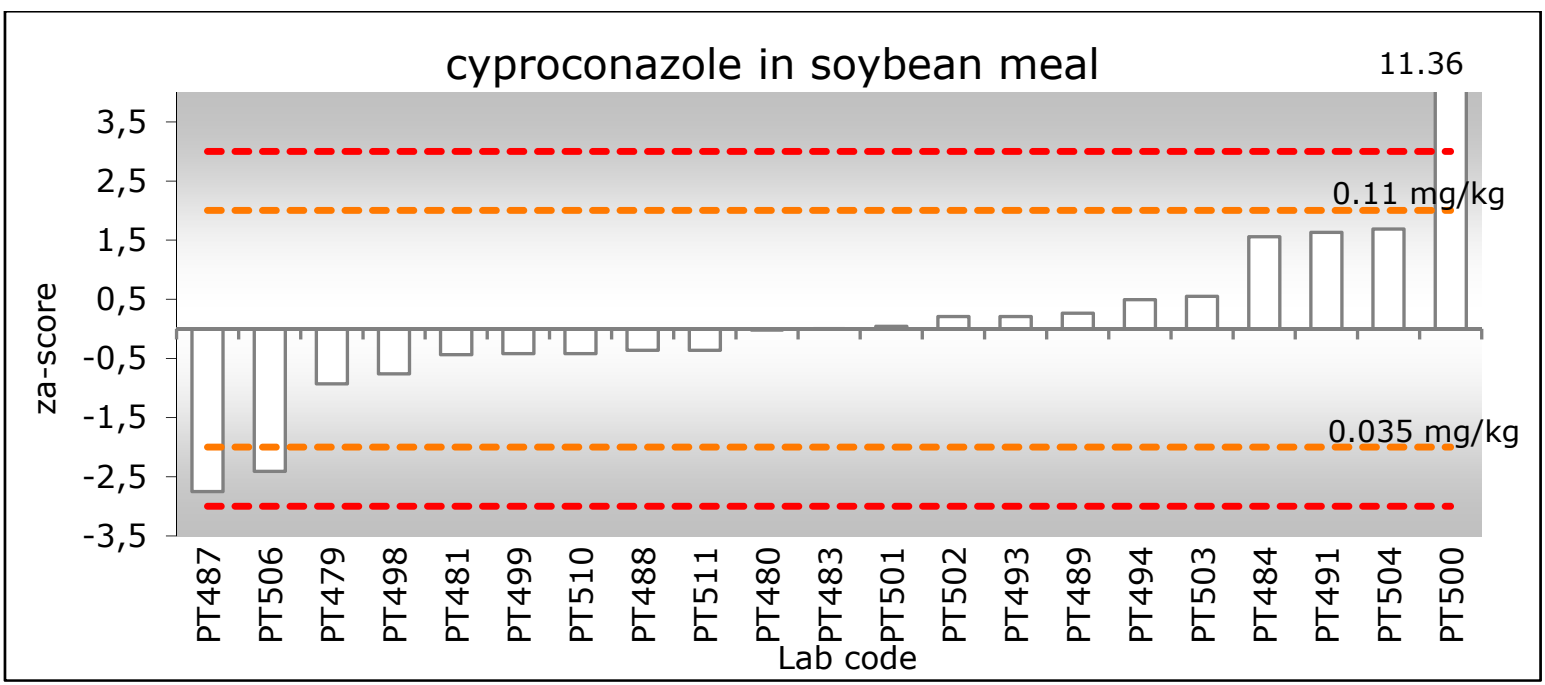

Figure $\boldsymbol{m} \quad$ Graphical representation of the $z_{a}$-scores for cyproconazole. The $X \pm 2 \sigma_{p}$ lines (dotted) are calculated according to equation $I$ in $\$ 3.4$.

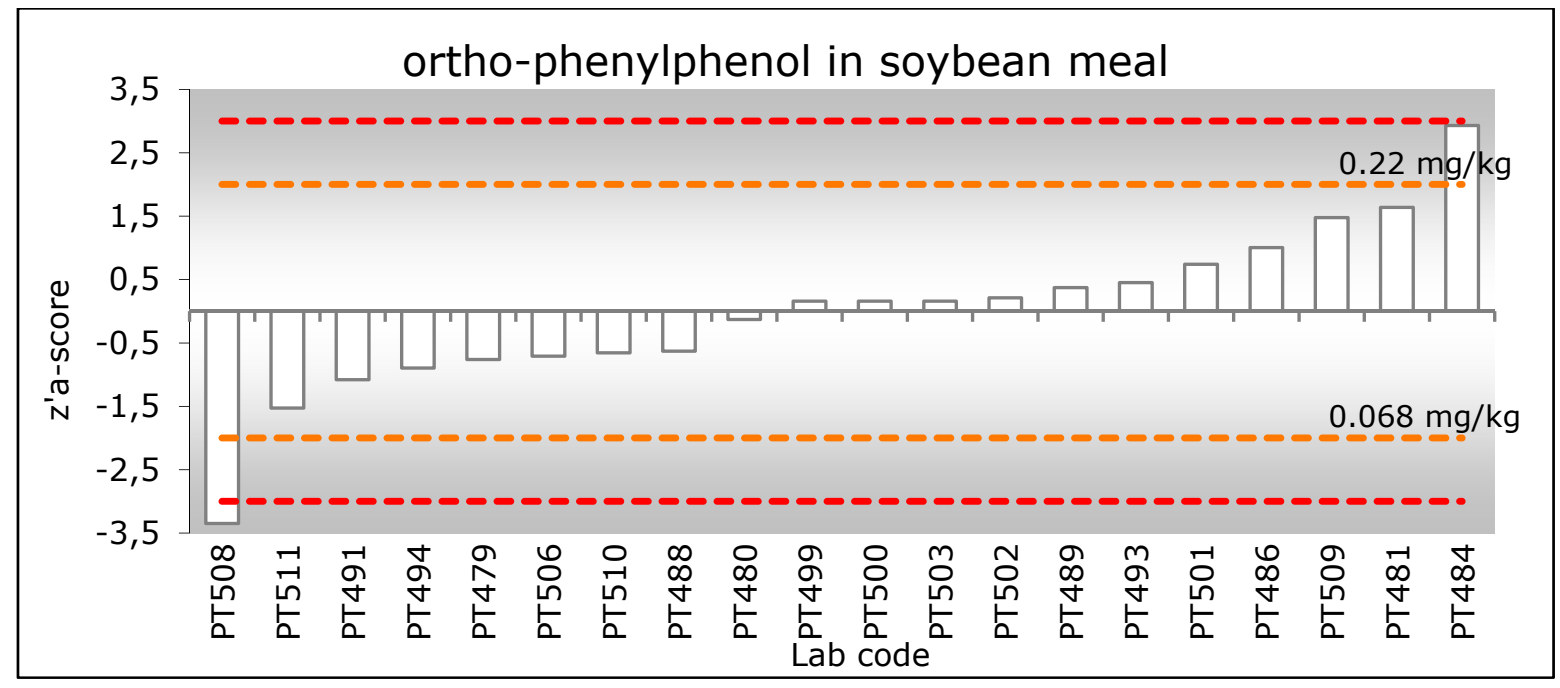

Figure $n \quad G r a p h i c a l$ representation of the $z^{\prime}{ }_{a}$-scores for ortho-phenylphenol. The $X \pm 2 \sigma_{p}$ lines (dotted) are calculated according to equation II in $\$ 3.4$. 


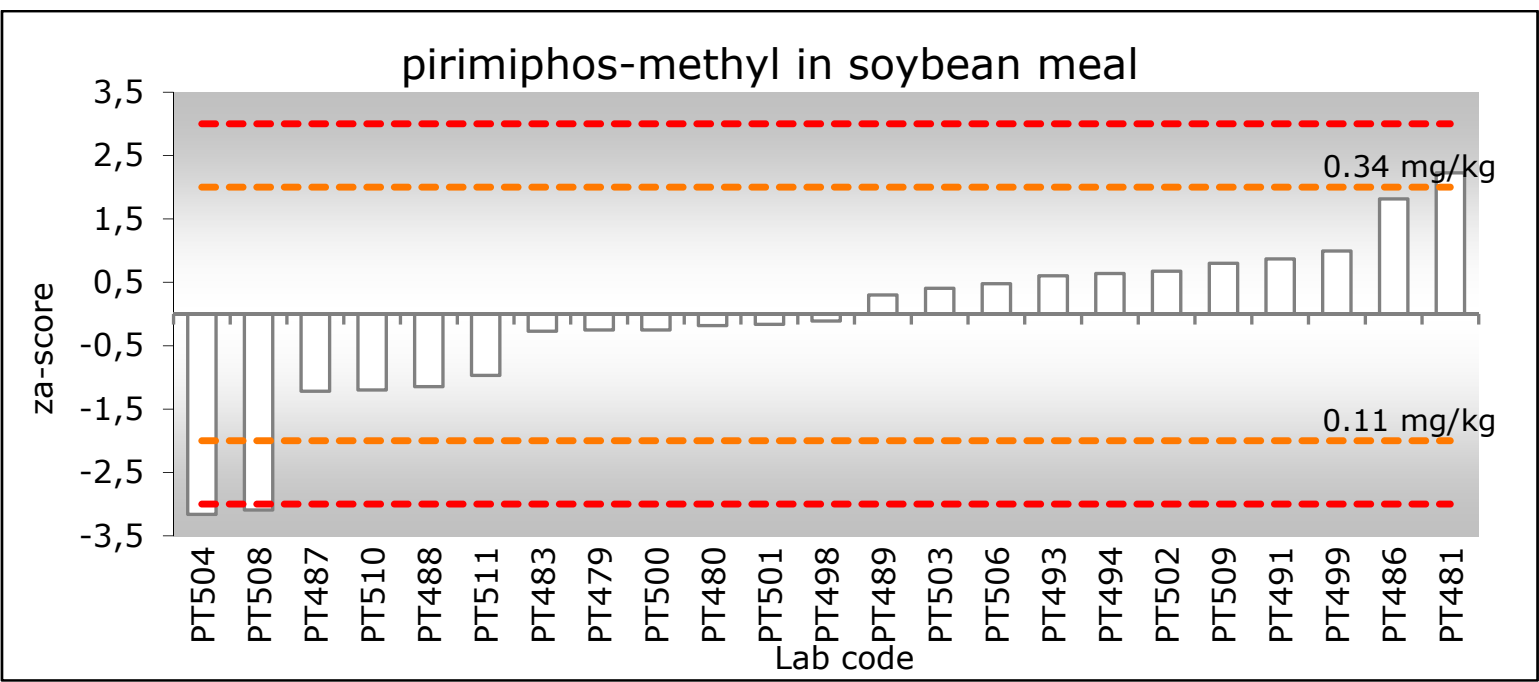

Figure $0 \quad$ Graphical representation of the $z_{a}$-scores for pirimiphos-methyl. The $X \pm 2 \sigma_{P}$ lines (dotted) are calculated according to equation I in $\$ 3.4$.

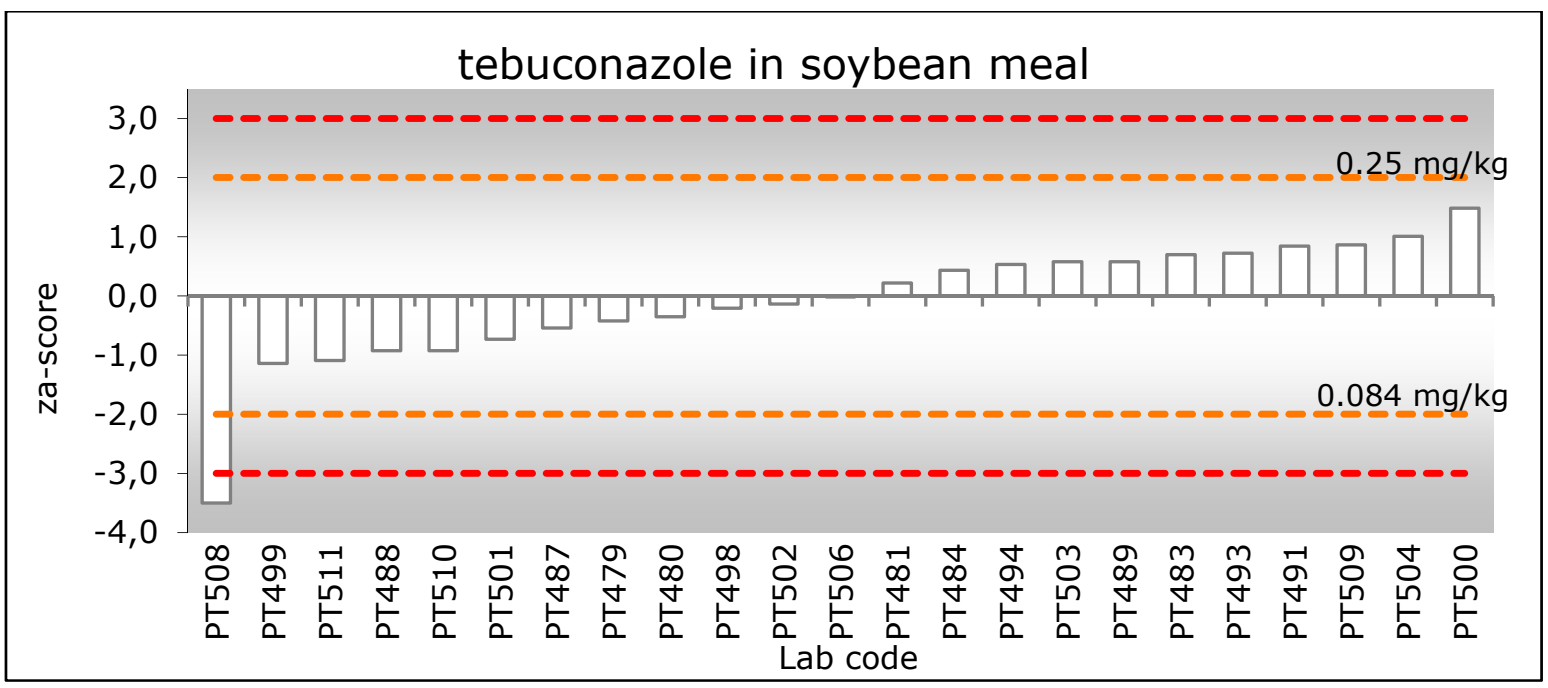

Figure $\boldsymbol{p} \quad$ Graphical representation of the $z_{a}$-scores for tebuconazole. The $X \pm 2 \sigma_{p}$ lines (dotted) are calculated according to equation $I$ in $\$ 3.4$. 


\section{Annex 8 False positive and false negative results}

False positive results

\begin{tabular}{cccc} 
Lab code & Material & Compound reported & Concentration mg/kg \\
PT481 & B & cyfluthrin & 0.0839 \\
PT484 & A & imazalil & 0.149 \\
\hline PT500 & B & carbendazim & 0.087 \\
\hline PT501 & A & imazalil & 0.184 \\
\hline
\end{tabular}

False negative results

\begin{tabular}{|c|c|c|c|c|c|}
\hline Lab code & Material & Compound missed & Lab code & Material & Compound missed \\
\hline PT479 & A & endosulfan-sulfate & PT489 & A & endosulfan-sulfate \\
\hline PT479 & A & pirimiphos-methyl & PT489 & $A$ & pirimiphos-methyl \\
\hline PT484 & A & biphenyl & PT494 & A & $p, p^{\prime}-D D E$ \\
\hline PT484 & A & alpha-endosulfan & PT494 & A & alpha-endosulfan \\
\hline PT484 & A & pirimiphos-methyl & PT501 & A & cis-chlordane \\
\hline PT484 & $\mathrm{B}$ & pirimiphos-methyl & PT501 & A & $p, p^{\prime}-D D E$ \\
\hline PT485 & A & cis-chlordane & PT501 & A & cis-deltamethrin \\
\hline PT485 & A & $p, p^{\prime}-D D E$ & PT501 & A & alpha-endosulfan \\
\hline PT486 & A & pirimiphos-methyl & PT504 & A & cis-deltamethrin \\
\hline PT488 & A & endosulfan-sulfate & PT504 & A & alpha-endosulfan \\
\hline PT489 & A & biphenyl & PT504 & $\mathrm{B}$ & ortho-phenylphenol \\
\hline PT489 & A & cis-chlordane & PT508 & A & cis-chlordane \\
\hline PT489 & A & chlorpyrifos & PT508 & A & $p, p^{\prime}-D D E$ \\
\hline PT489 & A & $p, p^{\prime}-D D E$ & PT508 & B & cyproconazole \\
\hline PT489 & A & cis-deltamethrin & PT510 & A & endosulfan-sulfate \\
\hline PT489 & $A$ & alpha-endosulfan & PT511 & $A$ & cis-chlordane \\
\hline
\end{tabular}




\section{Annex 9 Overview performance per laboratory}

\begin{tabular}{|c|c|}
\hline Laboratory code & Performance \\
\hline PT479 & $2 \mathrm{FN}$ \\
\hline PT480 & $1 \mathrm{FN}$ \\
\hline PT481 & Material A not analysed, 2 questionable $z$-scores for material B, 1 FP \\
\hline PT483 & Optimal performance for material B, material A not analysed \\
\hline PT484 & $1 \mathrm{FP}, 5 \mathrm{FN}, 2$ questionable z-scores, 2 unsatisfactory z-scores \\
\hline PT485 & $4 \mathrm{FN}$, material A not analysed, pesticides in material B not in scope, reported too late \\
\hline PT486 & $2 \mathrm{FN}$ \\
\hline PT487 & Material A not analysed, 3 questionable z-scores for material B \\
\hline PT488 & $1 \mathrm{FN}$ \\
\hline PT489 & $8 \mathrm{FN}$, material A not analysed \\
\hline PT490 & Material A not analysed, pesticides in material B not in scope, \\
\hline PT491 & 2 unsatisfactory z-scores \\
\hline PT492 & Optimal performance for material A, pesticides in material B not in scope \\
\hline PT493 & 3 unsatisfactory z-scores \\
\hline PT494 & $3 \mathrm{FN}$ \\
\hline PT497 & Optimal performance for material A, pesticides in material B not in scope \\
\hline PT498 & Material A not analysed, $1 \mathrm{FN}$ for material B \\
\hline PT499 & Optimal performance for material B, material A not analysed \\
\hline PT500 & $1 \mathrm{FP}, 1$ questionable $\mathrm{z}$-scores, 2 unsatisfactory $\mathrm{z}$-scores \\
\hline PT501 & $1 \mathrm{FP}, 5 \mathrm{FN}$ \\
\hline PT502 & Optimal performance \\
\hline PT503 & $1 \mathrm{FN}$ \\
\hline PT504 & $4 \mathrm{FN}, 1$ questionable $z$-score, 1 unsatisfactory $z$-score \\
\hline PT505 & Optimal performance for material A, pesticides in material B not in scope \\
\hline PT506 & Material A not analysed, 1 questionable z-score for material B \\
\hline PT508 & 3 FN, 2 questionable z-scores, 6 unsatisfactory z-scores \\
\hline PT509 & Optimal performance for material B, material A not analysed \\
\hline PT510 & $1 \mathrm{FN}$ \\
\hline PT511 & $1 \mathrm{FN}, 1$ unsatisfactory $z$-score \\
\hline
\end{tabular}


RIKILT Wageningen University \& Research P.O. Box 230

6700 AE Wageningen

The Netherlands

$\mathrm{T}+31(0) 317480256$

www.wur.eu/rikilt

RIKILT report 2017.008
The mission of Wageningen University and Research is "To explore the potential of nature to improve the quality of life". Under the banner Wageningen University \& Research, Wageningen University and the specialised research institutes of the Wageningen Research Foundation have joined forces in contributing to finding solutions to important questions in the domain of healthy food and living environment. With its roughly 30 branches, 5,000 employees and 10,000 students, Wageningen University \& Research is one of the leading organisations in its domain. The unique Wageningen approach lies in its integrated approach to issues and the collaboration between different disciplines.

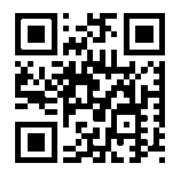





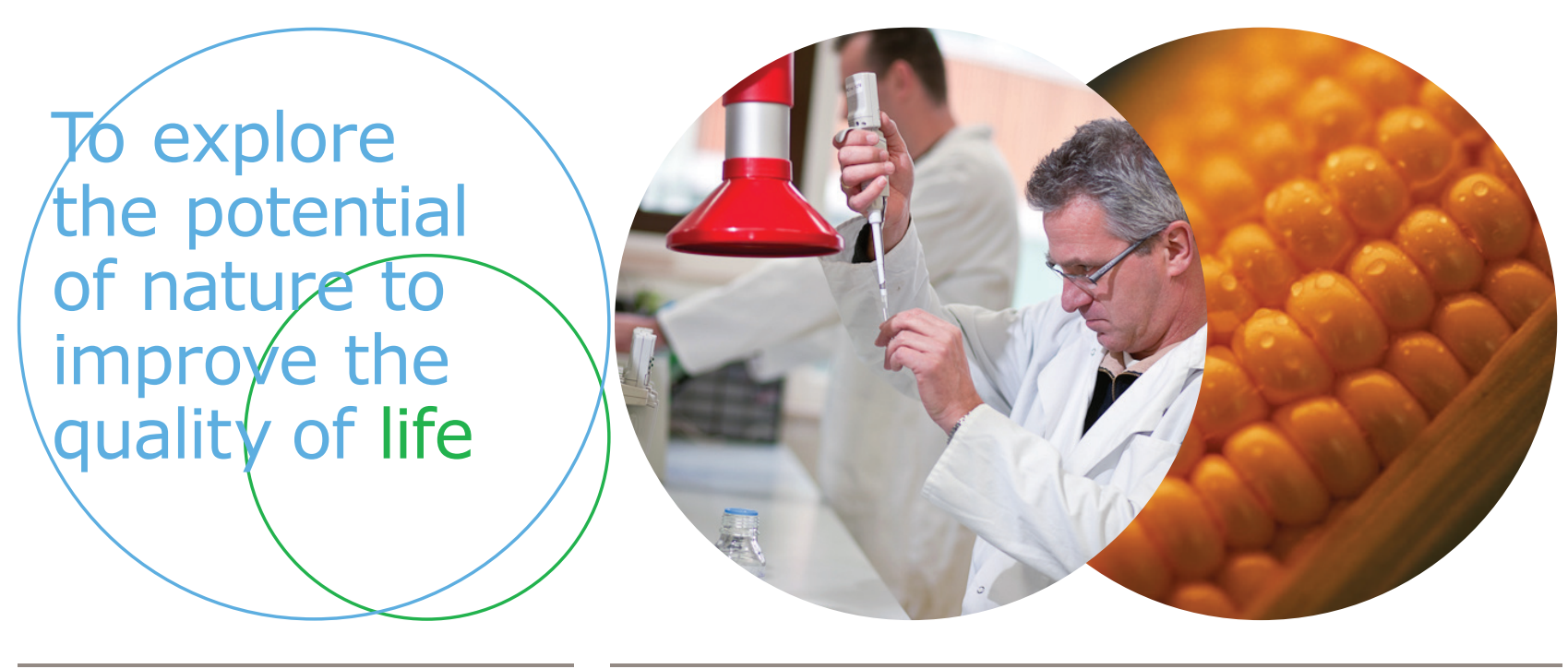

RIKILT Wageningen University \& Research P.O. Box 230

6700 AE Wageningen

The Netherlands

T +31 (0)317480256

www.wur.eu/rikilt

Report 2017.008
The mission of Wageningen University and Research is "To explore the potential of nature to improve the quality of life". Under the banner Wageningen University \& Research, Wageningen University and the specialised research institutes of the Wageningen Research Foundation have joined forces in contributing to inding solutions to important questions in the domain of healthy food and living environment. With its roughly 30 branches, 5,000 employees and 10,000 students, Wageningen University \& Research is one of the leading organisations in its domain. The unique Wageningen approach lies in its integrated approach to issues and the collaboration between different disciplines. 